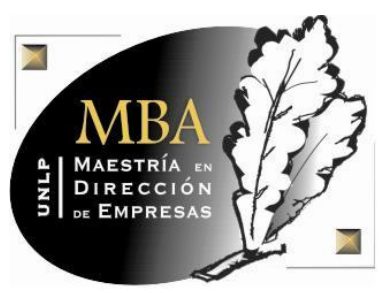

Universidad Nacional de La Plata

Facultad de Ciencias Económicas

MBA - Maestría en Dirección de Empresas

\title{
Calidad Educativa del Nivel Secundario de Berisso
}

Autor: Ing. Gambino, Lucas Francisco

Director: Dr. Alonso, Aldo Hernán

La Plata

Julio de 2014 


\section{Contenido}

1. Planteo del Problema

2. Objetivos de la investigación __ 5

3. Evaluación del problema___ 5

4. Alcances de la investigación ___ 8

5. Marco teórico __ 8

5.1 Antecedentes de la Investigación

5.2. Bases Teóricas — 32

5.3. Definición de términos Básicos___ 41

5.4. Definición de las variables___ 46

6. Metodología de la investigación___ 48

6.1. Población y muestra ___ 48

6.2. Tipo de investigación __ 49

6.3. Técnica de recolección de datos___ 49

6.4. Técnicas de análisis _ 56

7. Resultados de la Investigación ___ 59

7.1 Datos de Fuente Secundaria___ 59

7.2 Datos de Fuente Primaria

8. Conclusiones___ 114

9. Bibliografía ___ 1177

10. Anexos _ 1200 


\section{Planteo del Problema}

En la región de La Plata, Berisso y Ensenada no existe información pública que permita conocer el estado o nivel real de la educación en el nivel secundario. Es por ello que esta problemática está siendo objeto de estudio por el MBA, contribuyendo a la necesidad de saber cuál es en realidad la situación de la educación secundaria. Este trabajo se encuentra limitado en recoger datos y analizar los resultados en los años 2010 y 2011.

En nuestro país la escuela media ha sido escenario de profundas transformaciones y redefiniciones en su estructura, a pesar que su sentido y formas de organización son objeto de cuestionamiento y debate.

En los últimos años ha continuado la incorporación al sistema educativo de la Provincia de Buenos Aires de adolescentes provenientes de sectores sociales entre los que concluir la escuela secundaria era impensable en generaciones anteriores. $Y$ esa incorporación ha conllevado el aumento de la complejidad del sistema educativo, especialmente en el nivel secundario.

En un contexto de crecimiento continuo de la pobreza y de la exclusión, las transformaciones han adquirido un matiz particular en las escuelas que trabajan con población en situación de vulnerabilidad.

En 2006 la sanción de la Ley 26206 de Educación Nacional, que establece la obligatoriedad del nivel secundario para toda la población en edad escolar, atribuye al Estado metas de ampliación de la cobertura del nivel, y de resolución de los problemas de repitencia y desgranamiento. El artículo 11 de dicha ley establece en el inciso a) Asegurar una educación de calidad con igualdad de oportunidades y posibilidades, sin desequilibrios regionales ni inequidades sociales.

Los ciudadanos tienen derecho a conocer el funcionamiento de un servicio público como es el de la educación en una sociedad democrática y participativa. Sin embargo, el principal problema en Argentina radica en la falta de información acerca del nivel de calidad de la educación, tanto a nivel provincial y nacional. 
En el ámbito regional, uno de los puntos más resonantes de los últimos años tiene que ver con el ingreso a primer año en las carreras de la Universidad Nacional de La Plata. Si bien concurren estudiantes del interior del país sirve como una gran muestra del nivel que posee el alumno al concluir la escuela secundaria. En muchos casos no logran responder sobre cuestionarios preparados para alumnos de séptimo grado de la primaria, a preguntas sobre matemática, química y física, y solo aprueban el examen de ingreso entre el 10\% y el $30 \%$ de los alumnos (véase Anexo Artículos Periodísticos).

$\mathrm{Si}$ bien son cada vez más los jóvenes que pueden acceder al sistema educativo, al mismo tiempo disminuye la cantidad de los que logran permanecer y cumplir su ciclo. Al mismo tiempo, las competencias adquiridas en la escuela secundaria son menos reconocidas por los empleadores.

Además, se observa que la transición de la escuela al trabajo para los jóvenes de hoy es más difícil que para sus pares de hace apenas unas décadas. Mariana Bassi y otros (2012)

En países con mayor desarrollo en educación, los resultados de las evaluaciones son comunicados inmediatamente a las escuelas y están a disposición de la comunidad en un modo transparente. En Argentina, los resultados de las evaluaciones no son devueltos a las escuelas en tiempo y forma, son comunicados en forma discontinua, de modo poco claro y todo eso deteriora su credibilidad.

Según Terigi (2010) expresa: "hay chicos que realizan las trayectorias educativas continuas pero no completan su escolaridad y hay chicos que realizan trayectorias educativas discontinuas. Estas últimas impactan tan negativamente como el abandono. Esta autora sugiere que debemos desarrollar trayectorias continuas y completas para preparar a los jóvenes para vivir en sociedades más complejas y plurales que aquellas en las cuales se creó la escuela. La estructura de la escuela tradicional no se encuentra acorde a las nuevas realidades que atraviesan las instituciones, tiene que ser pensada de manera diferentes, es decir reinvertarse para incluir a los que no pueden hacerlo, escenarios escolares que 
deben ser recreados para transformar a esos sujetos en alumnos ¿que se le enseña? ¿Cómo se le enseña?, es decir se debe revisar lo pedagógico y didáctico porque el formato escolar de la escuela media tiende a excluir al alumno"1.

Un estudio del Banco Interamericano de Desarrollo indica que la formación académica no es suficiente, ya que las empresas necesitan de gente que asuma compromisos; la impuntualidad y la falta de responsabilidad es habitual en los jóvenes. A estos, el mundo del trabajo se les presenta como algo lejano y hasta, a veces, extraño la calidad y cantidad de educación recibida inciden en su accionar, aunque un mejor promedio no los convertirá necesariamente en un buen trabajador....

EI BID indagó sobre las condiciones en que los jóvenes argentinos ingresan al mercado laboral y concluyó lo siguiente: "Se requieren políticas educativas urgentes no sólo para abordar el problema de la calidad de la educación, sino de la pertinencia de la misma cuando se trata de facilitar las transiciones de los jóvenes al mundo del trabajo".

En este sentido los conocimientos académicos no son suficientes para el desarrollo de los jóvenes en su vida adulta, por la tanto la escuela secundaria debe cambiar su formato escolar para preparar a los jóvenes a desempeñarse en un mercado de trabajo más competitivo y exigente.

Según lo expresado por Terigi, "una serie de cambios en las culturas juveniles y en las expectativas de inclusión educativa desafían desde hace tiempo las funciones y la organización tradicional de la escuela secundaria. En su origen selectiva y con una currícula comprehensivo y academicista, diferenciada tempranamente en modalidades profesionales y propedéuticas, la escuela secundaria debe enfrentar hoy nuevos tiempos y nuevos públicos. La llegada de nuevos sectores sociales ha contribuido a desestabilizar los acuerdos previos sobre este nivel educativo, y enfrenta a los gobiernos y a las escuelas con los límites de las tradiciones pedagógicas y de la organización institucional.

1 Terigi Flavia (2010) "Las cronologías de aprendizaje: un concepto para pensar las trayectorias escolares"

Autor: Ing. Lucas F. Gambino 
En definitiva el nivel secundario sigue buscando soluciones para sus problemas de antigua data, al tiempo que deben asumir los nuevos desafíos de la obligatoriedad. Alcanzar el cumplimiento pleno de la obligatoriedad escolar supone la activación conjunta de tres factores: el incremento de la oferta educativa a cargo del Estado, la constitución de la llamada "obligatoriedad subjetiva", y la remoción de las dificultades que producen trayectorias escolares signadas por el fracaso. Los tres factores dependen de políticas de promoción y sostenimiento de la escolaridad, para establecer las cuales se hace necesaria una mejor comprensión de los itinerarios que los adolescentes y jóvenes van delineando a lo largo de su vida. No se trata de "normalizar las trayectorias", sino de ofrecer una amplia gama de trayectorias educativas diversas y flexibles" ${ }^{2}$.

Un estudio reciente de la CEPAL $^{3}$ (Comisión Económica para América Latina y el Caribe) señala que existen fuertes distorsiones en la distribución interna de la inversión educativa en perjuicio de los escalones primarios del sistema. Esta forma de distribución afecta, en primer lugar, a los grupos de menores ingresos, que dependen del sistema público para su educación básica. En segundo lugar perjudica a los escalones superiores del sistema, que reciben aspirantes con formación inadecuada. Este déficit obliga a las universidades a establecer sistemas de selección o de nivelación. Si estos sistemas son estrictos impiden el ingreso de muchos aspirantes, pero si no lo son obligan a las universidades a costear la permanencia de un enorme grupo de estudiantes que abandonarán las aulas. Además de aumentar los recursos destinados a la educación, es necesario prestar atención a otros aspectos clave como la forma más adecuada de distribuir los fondos, la mejora en la calidad y la búsqueda de una mejor articulación entre sus diferentes niveles. De este modo se logrará una mejor utilización de los recursos sociales.

\footnotetext{
2 Terigi Fravia, (2007), "Los desafíos que plantea las trayectorias escolares"

3 CEPAL (2001) - "Perspectivas Económicas de América Latina 2012: Transformación del Estado para el Desarrollo"
} 


\section{Objetivos de la investigación}

Los objetivos planteados en esta investigación son:

- Identificar parámetros de eficiencia del nivel secundario de la educación de Berisso

- Comparar los parámetros de educación de Berisso con la región.

- Generar información acerca de la calidad educativa en el nivel secundario de la educación de Berisso

\section{Evaluación del problema}

La educación se ha convertido en uno de los principales caminos para el desarrollo económico de un País. De allí que los países avanzados hagan fuertes inversiones para aumentar el volumen y la calidad de la educación. En el mundo industrializado, la adecuación de los estándares educativos a lo que cada país o grupo de interés considera estratégico es motivo de análisis y discusión permanente.

En la actualidad se percibe un sistema educativo en el cual la calidad está sumamente deteriorada y cuestionada.

“...Hoy más que ayer este sistema debe soportar el peso de las expectativas, los fantasmas, las exigencias de toda una sociedad para quien la educación es la última reserva de sueños a la que desearíamos poder exigirle todo..." (Chevallard, 1997)4.

La escuela secundaria está hoy en el centro de la definición de políticas que deben avanzar en varias direcciones, particularmente en el aumento de la

\footnotetext{
4 "La educación secundaria en la ciudad de Buenos Aires". Pág. 1.
} 
cobertura y en el mejoramiento de la calidad de la propuesta en términos de producir aprendizajes relevantes para todos los estudiantes que a ellas concurren.

Según Tenti Fanfani ${ }^{5}$ "la enseñanza media tiene un significado distinto al de antes. Hoy se trata de la última etapa de la escolaridad obligatoria, es una enseñanza "final" (un techo) para la mayoría de la población y un proceso de formación para la minoría, que tiende a prolongarse a lo largo de su vida. Dicha extensión está produciendo contradicciones entre los viejos mecanismos pedagógicos y disciplinarios, las expectativas de docentes y alumnos y las nuevas disposiciones legales y normativas. Hoy se habla que todos los adolescentes y jóvenes deben estar incluidos en el sistema para eso el Estado debe ampliar la oferta educativa y garantizar las condiciones sociales y pedagógicas para que aprendan a través de becas, subsidios y apoyo a jóvenes y familias".

El mismo autor "La escuela media hoy: masificación con exclusión social y cultural": propone tres ejes problemáticos para discutir los nuevos desafíos de la escolarización: la identidad y cultura de los adolescentes, el déficit de interés y motivación para aprender y la crisis de la autoridad pedagógica tradicional.

Según el autor las viejas escuelas primarias fueron pensadas y diseñadas para los niños y la escuela media, tiende a reproducir los mecanismos y estilos de la educación infantil. Factor que también contribuye al fracaso escolar y malestar en la enseñanza media.

La escuela no puede satisfacer demandas sociales nuevas y complejas relacionadas con la formación de las subjetividades, de ciudadanos, etc. Este tipo de instituciones son llamadas débiles. Instituciones que están sobredemandada y subdotada. En cuanto a la demanda del conocimiento: existen dos realidades, los que más capital cultural tienen son los que más demandan, lo más desfavorecidos son quienes están en peores de condiciones de demandar. Una política efectiva, entre otras cosas, requiere de la movilización de saberes y voluntades por parte de los docentes.

${ }^{5}$ Tenti Fanfani, (2009) "La enseñanza media hoy: masificación con exclusión social y cultural"

Autor: Ing. Lucas F. Gambino 
Hasta el momento, las reformas y los cambios producidos en el sistema educativo, no han favorecido una mayor escolarización de los jóvenes. Si bien los años de escolaridad han aumentado, sigue existiendo abandono escolar. Hablar de una escuela inclusiva significa hablar de sueños, desafíos, propuestas, ideas, compromiso, de nuevas miradas al interior de la institución escolar. Se debe tomar conciencia que en las escuelas se construyen subjetividades, significados acerca del mundo, de los otros, en contextos socio-históricos específicos. Por lo tanto mejorar los procesos educativos implica mejorar los procesos sociales, "se trata de aprender a vivir con la diversidad y, de hecho, aprender de las diferencias".

Los jóvenes de hoy, desde su propia perspectiva, ven una escasez de expectativas en su futuro inmediato, tanto en su formación y estudios como en su calidad de vida y futuro profesional aun cuando éste no sea tan inmediato. Por eso, todos los esfuerzos que el conjunto de la sociedad pueda realizar en educación, y en particular en este nivel de la escuela pública, pueden parecer insuficientes para atender una demanda creciente que hoy por hoy, no ha logrado el nivel de cobertura y calidad que se requieren para dar certidumbre a los futuros alumnos de educación secundaria, que el país demanda.

El nivel educativo de la sociedad siempre fue importante para el desempeño de las instituciones públicas o privadas, pero esa importancia aumenta con la complejidad de los procesos administrativos o productivos. También, con la velocidad con la que cambia la información educativa y la necesidad de actualizarla. Las exigencias de la actualidad, de la globalización y las demandas del mercado, son las nuevas reglas de juego para emprender nuevos desafíos.

Cabe destacar, que la escuela secundaria es el último contacto con el sistema educativo y la plataforma desde la cual los adolescentes ingresan al mercado laboral. Es por ello que el sistema educativo de la región tiene el enorme desafío de retener a los jóvenes hasta culminar su formación y de proporcionarles 
las destrezas que el trabajo y la sociedad les exigirán después. Falta estudio de base de políticas educativas.

\section{Alcances de la investigación}

Existen limitaciones de información debido a la falta de datos estadísticos sobre los alumnos que no terminan el secundario, y los alumnos que finalizan pero luego no realizan carrera terciaria o universitaria alguna, ni se insertan al mundo laboral; es por ello que no es factible tener el seguimiento correspondiente de estos casos.

Los resultados que se presentan son el producto de un proyecto de investigación del MBA cuyo título es "La competitividad empresarial y su impacto regional", acreditado en el marco del Programa de Incentivos de la Secretaría de Ciencia y Técnica de la UNLP, con un tronco común que posteriormente se subdivide de acuerdo con la región evaluada, siendo su alcance geográfico, La Plata, Berisso y Ensenada. El alcance de esta investigación se verá limitado para la ciudad de Berisso.

Para el cálculo de los indicadores se utilizó información del año 2011, proveniente de la Dirección General de Cultura y Educación de la Provincia de Buenos Aires.

\section{Marco teórico}

En la última década, la escuela secundaria registró un alto grado de deserción, alta repitencia y magros resultados en las evaluaciones internacionales de calidad de los alumnos: por ejemplo las mediciones PISA de calidad educativa (Informe PISA 2009).

Solo el $50 \%$ de los jóvenes termina el secundario. Esto explica por qué uno de cada tres jóvenes está atrasado en la escuela en el marco de una inédita inversión en Educación que superó la meta fijada o en la Ley de Financiamiento Educativo del $6 \%$ del PBI. Pues, si bien casi la totalidad de estos mayores recursos fueron volcados al aumento de la remuneración de los docentes, como 
se puso un énfasis absoluto y excluyente en aumentar la inversión sin establecer reglas que premien los esfuerzos, la dedicación, la superación y el resultado no ha sido satisfactorio.

Otra evidencia es la falta de toma de conciencia del severo déficit educativo que sufre la Argentina y el daño que este déficit genera, sobre todo en los niveles socioeconómicos más desfavorecidos. Por ejemplo, se minimiza que la prueba PISA (evaluación internacional que se toma a jóvenes de 15 años) registró un retroceso de Argentina entre los años 2000 y 2009. Como consecuencia de esta involución, la Argentina pasó de un lugar de liderazgo en la región a ubicarse detrás de Chile, México, Uruguay, Brasil y Colombia en tan sólo una década.

Un dato importante que arroja esta prueba es que los déficits de conocimientos están asociados a los atrasos que producen la repitencia y donde inciden factores internos al sistema educativo y factores asociados al contexto familiar.

\subsection{Antecedentes de esta Investigación}

\section{Evaluaciones Internacionales}

\subsubsection{Programa para la Evaluación Internacional de Alumnos PISA} (OECD)

El nombre PISA corresponde con las siglas del programa según se enuncia en inglés: Programme for International Student Assessment, es decir, Programa para la Evaluación

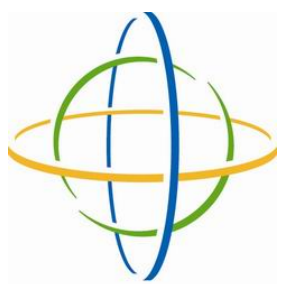
Internacional de Alumnos. Se trata de un proyecto de la OCDE (Organización para la Cooperación y el Desarrollo Económicos), cuyo objetivo es evaluar la formación de los alumnos cuando llegan al final de la etapa de enseñanza obligatoria, hacia los 15 años. 
Se trata de una población que se encuentra a punto de iniciar la educación post-secundaria o que está a punto de integrarse a la vida laboral. Es muy importante destacar que el Programa ha sido concebido como un recurso para ofrecer información abundante y detallada que permita a los países miembros adoptar las decisiones y políticas públicas necesarias para mejorar los niveles educativos.

La evaluación cubre las áreas de lengua, matemáticas y competencia científica. El énfasis de la evaluación está puesto en el dominio de los procesos, el entendimiento de los conceptos y la habilidad de actuar o funcionar en varias situaciones dentro de cada dominio.

\section{Los exámenes}

Los exámenes utilizados en el proceso de evaluación no requieren otra cosa que papel y lápiz y cada estudiante cuenta con dos horas para responderlo. Cada examen es una combinación de preguntas directas con una única respuesta correcta (preguntas que sólo admiten algunas palabras o algunas frases breves por respuesta, o que ofrecen múltiples opciones para que el alumno marque alguna o algunas), y preguntas que requieren que los estudiantes elaboren sus propias respuestas. Las preguntas del primer tipo sólo pueden ser correctas o incorrectas, y las del segundo tipo son de evaluación más compleja y admiten respuestas parcialmente correctas. Es importante destacar que si bien PISA utiliza la herramienta de las preguntas de opción múltiple, una porción importante de las respuestas, particularmente las más complejas, requieren del alumno la redacción de textos e incluso la elaboración de diagramas.

No todos los alumnos tienen el mismo examen sobre la mesa el día de la prueba; a diferentes alumnos les tocan cuadernillos distintos. Tal como se aplicó la prueba en 2006, había 13 cuadernillos de examen diferentes, cada uno de ellos con cuatro capítulos o grupos de actividades de evaluación.

Además del examen propiamente dicho, los estudiantes deben responder un cuestionario en el que se les hacen preguntas sobre sí mismos y sobre sus 
hogares. Este cuestionario de contexto es una herramienta muy importante para el aprovechamiento de la prueba de PISA. Se hará una referencia a este punto más adelante.

\section{La muestra}

Para la realización de PISA se utilizan muestras representativas de entre 4.500 y 10.000 estudiantes por país. Este tamaño de muestra permite realizar inferencias del país en su totalidad pero no permite inferencias por regiones o estados. Algunos países solicitan sobre muestras para utilizar la prueba también en la exploración de las diferencias regionales. Tal fue el caso de México, que en el ciclo de evaluación de 2003 condujo una evaluación con 29,983 estudiantes y en el ciclo 2006 con 30,971 estudiantes.

\section{Los resultados}

Los resultados PISA ofrecen un perfil de las capacidades de los estudiantes de 15 años de todos los países donde se aplica el examen. Además, provee información sobre el contexto personal, familiar y escolar de los participantes en la muestra.

El carácter cíclico (trienal) de la evaluación permite tener indicadores sobre las tendencias en cada país y en el conjunto de los países involucrados en el proyecto. En última instancia, la calidad y riqueza de los datos arrojados en el proceso de evaluación pretende constituirse en la base para la investigación y análisis destinados a mejores políticas en el campo de la educación.

\section{¿Qué evalúa PISA?}

A diferencia de otros exámenes que se han utilizado en el pasado, PISA está diseñado para conocer las competencias, o, dicho en otros términos, las habilidades, la pericia y las aptitudes de los estudiantes para analizar y resolver problemas, para manejar información y para enfrentar situaciones que se les presentarán en la vida adulta y que requerirán de tales habilidades. 
PISA se concentra en la evaluación de tres áreas: competencia lectora, competencia matemática y competencia científica. Si bien la adquisición de conocimientos específicos es importante en el aprendizaje escolar, la aplicación de esos conocimientos en la vida adulta depende rigurosamente de la adquisición de conceptos y habilidades más amplios. En ciencia, tener conocimientos específicos, como los nombres de las plantas y los animales, tiene menor valor que comprender temas más amplios, como el consumo de energía, la biodiversidad y la salud humana, cuando se trata de pensar en los grandes problemas en debate dentro de la comunidad adulta.

\section{Evaluación cíclica}

La evaluación a través del PISA se realiza cada tres años, con el objeto de permitir a los países supervisar adecuadamente su desempeño y valorar el alcance de las metas educativas propuestas. Cada año de su realización el proyecto se ha concentrado en alguna de las tres áreas evaluadas: en la evaluación del año 2000 se dio especial atención a la competencia en lectura, en el 2003 a la competencia en matemáticas y en 2006 a la competencia en el área de ciencias.

Esto quiere decir que la parte más extensa del examen se refiere al área de concentración correspondiente a ese año (Los porcentajes son aproximadamente $66 \%$ para el área de concentración y $17 \%$ para cada una de las otras áreas).

\section{Contexto}

La universalidad que le da a PISA el hecho de no estar ligado a currículos y planes de estudio específicos no implica una indiferencia frente al contexto.

Un cuestionario dirigido al responsable de cada escuela permite recabar información sobre el contexto del estudiante: las condiciones de su entorno, su familia, sus hábitos de estudio, las condiciones de su escuela. 


\section{Lo que evalúa PISA}

PISA no está diseñado para evaluar el aprendizaje de los contenidos específicos fijados en los programas de las escuelas o de los distritos o regiones correspondientes. Tampoco está pensado para evaluar el desempeño de los docentes ni los programas vigentes. PISA se centra en el reconocimiento y valoración de las destrezas y conocimientos adquiridos por los alumnos al llegar a sus quince años. La adquisición de tales destrezas y conocimientos es fruto de numerosas circunstancias familiares, sociales, culturales y escolares. PISA trata de recoger información sobre esas circunstancias para que las políticas que pudieran desprenderse del análisis de los resultados de la prueba atiendan a los diferentes factores involucrados.

Los resultados de la prueba describen el grado en el que se presentan las competencias estudiadas y permiten observar la ubicación de los resultados de cada país en el contexto internacional.

\section{Evaluar las competencias}

La evaluación de competencias no se dirige a la verificación de contenidos; no pone la atención en el hecho de que ciertos datos o conocimientos hayan sido adquiridos. Se trata de una evaluación que busca identificar la existencia de ciertas capacidades, habilidades y aptitudes que, en conjunto, permiten a la persona resolver problemas y situaciones de la vida. No interesa, pues, en el enfoque de la evaluación de competencias, sólo si una persona lee y cuánto lee, por ejemplo, sino más bien qué competencia tiene en la lectura: qué capacidad para identificar ideas y argumentos en el texto, qué destreza para reconocer problemas y planteamientos distintos.

Hay competencias muy generales, que preceden a la formación escolar, como la competencia comunicativa, o las competencias de colaboración o de creatividad. Algunas competencias básicas ligadas a la enseñanza escolar son, por ejemplo, la lectura, la escritura y el cálculo. La exploración del proyecto PISA 
se refiere a competencias específicas (lectura, matemáticas, ciencia), detalladas y divididas en sub-competencias, dentro de cada área.

La definición de competencia utilizada en México por el Instituto Nacional para la Evaluación de la Educación es la siguiente: "un sistema de acción complejo que abarca las habilidades intelectuales, las actitudes y otros elementos no cognitivos, como motivación, valores y emociones, que son adquiridos y desarrollados por los individuos a lo largo de su vida y son indispensables para participar eficazmente en diferentes contextos sociales". La clave del concepto de competencia, tal como se utiliza para el PISA y lo ha explicado el INEE, está en valorar la capacidad del estudiante para poner en práctica sus habilidades y conocimientos en diferentes circunstancias de la vida.

Al examinar los conocimientos y habilidades cerca del final de la enseñanza básica, PISA examina el grado de preparación de los jóvenes para la vida adulta y, hasta cierto punto, la efectividad de los sistemas educativos. Su ambición es evaluar el éxito con relación a los objetivos subyacentes (definidos por la sociedad) del sistema educativo, y no con relación a la enseñanza de un cuerpo de conocimientos determinado.

\section{Escalas de puntaje en PISA}

Los puntajes obtenidos en PISA van de 0 a los 800 puntos y se distribuyen en 6 niveles, donde el sexto nivel es el de mejor desempeño

En ellos se describen habilidades típicas que pueden desarrollar los estudiantes que se ubican en cada uno, de acuerdo con el puntaje en las escalas.

Los estudiantes que al menos alcanzan el nivel 2, tienen las competencias mínimas para desenvolverse en el mundo e integrarse productivamente a la sociedad. 


\begin{tabular}{|c|c|c|c|}
\hline Nivel & Matemáticas & Lengua & Ciencias \\
\hline 1 & 358 a 419 & 262 a $406\left(^{*}\right)$ & 335 a 409 \\
\hline 2 & 420 a 481 & 407 a 480 & 410 a 483 \\
\hline 3 & 482 a 544 & 481 a 552 & 484 a 557 \\
\hline 4 & 545 a 606 & 553 a 625 & 558 a 632 \\
\hline 5 & 607 a 669 & 626 a 698 & 633 a 707 \\
\hline 6 & 670 a 800 & 699 a 800 & 708 a 800 \\
\hline
\end{tabular}

$\left(^{*}\right)$ Cabe destacar que para el área "Lengua", PISA desglosa el Nivel 1 en $1 b(262$ a 334) y $1 a(335$ a 406).

Para el área de Matemática en PISA se distinguen seis niveles de desempeño, cada uno de los cuales aporta información respecto del tipo de tareas que son capaces de desarrollar los estudiantes que se ubican en ellos, y respecto de la dificultad de las mismas.

\section{Descripción de Niveles de desempeño en la escala de Matemática}

\begin{tabular}{|c|l|}
\hline \multirow{2}{*}{$\begin{array}{c}\text { Nivel } 6 \\
(670 \text { y } \\
\text { más }\end{array}$} & $\begin{array}{l}\text { conceptudiantes ubicados en este nivel, son capaces de } \\
\text { investigaciones y en el modelamiento de situaciones problemáticas } \\
\text { puntos }) \\
\text { representaciones y hacer traducciones entre ellas de manera flexible. }\end{array}$ \\
& $\begin{array}{l}\text { Poseen un razonamiento y pensamiento matemático avanzado, y pueden } \\
\text { aplicarlo, junto con el dominio de las operaciones y relaciones } \\
\text { matemáticas simbólicas y formales, en el desarrollo de nuevas } \\
\text { aproximaciones y estrategias para enfrentar situaciones novedosas. } \\
\text { Asimismo, son capaces de formular y comunicar con precisión las }\end{array}$ \\
\hline
\end{tabular}


acciones y reflexiones que les surgen de sus descubrimientos, interpretaciones y argumentos, y de adecuarlas a situaciones distintas de las originales.

Los estudiantes ubicados en et Nivel 5, son capaces de abordar situaciones complejas, desarrollando y utilizando modelos, identificando sus limitaciones y especificando sus supuestos. Adicionalmente, son capaces de seleccionar, comparar y evaluar estrategias de resolución de

Nivel 5 problemas, para abordar situaciones problemáticas complejas referidas a (de 607 estos modelos. Estos estudiantes también son capaces de trabajar de a 669 manera estratégica estas situaciones, usando habilidades de puntos) pensamiento y razonamiento amplias y correctamente desarrolladas; representaciones adecuadamente vinculadas, y caracterizaciones simbólicas y formales. Finalmente, también son capaces de reflexionar sobre sus acciones, y de formular y comunicar sus interpretaciones y razonamientos.

Los estudiantes ubicados en el Nivel 4, son capaces de trabajar de manera eficiente con modelos explícitos de situaciones complejas Nivel 4 (de 545 a 606 puntos) concretas, que involucran condicionantes o la necesidad de reconocer supuestos. Pueden seleccionar e integrar diferentes representaciones (incluyendo las simbólicas), relacionándolas directamente con situaciones del mundo real. Asimismo, poseen la habilidad de razonar flexiblemente y de lograr cierta profundización de los contextos, y pueden elaborar y comunicar sus explicaciones y razonamientos, sobre la base de sus propias interpretaciones, argumentos y acciones.

Nivel 3 Los estudiantes ubicados en el Nivel 3 de la escala, son capaces (de 482 a 544 puntos) de ejecutar procedimientos claramente descritos (incluyendo tos que requieren decisiones secuenciales); de seleccionar y aplicar estrategias simples de resolución de problemas; de interpretar, y de usar representaciones basadas en diferentes fuentes de información y razonar 


\begin{tabular}{|c|c|}
\hline & $\begin{array}{l}\text { directamente a partir de ellas. Asimismo, son capaces de elaborar } \\
\text { comunicaciones breves para reportar sus interpretaciones, resultados y } \\
\text { razonamientos. }\end{array}$ \\
\hline $\begin{array}{c}\text { Nivel } 2 \\
\text { (de } 420 \\
\text { a } 481 \\
\text { puntos) }\end{array}$ & $\begin{array}{l}\text { Los estudiantes que se ubican en este Nivel, son capaces de } \\
\text { interpretar y reconocer situaciones en contextos que requieren solo } \\
\text { inferencia directa, extraer información relevante de solo una fuente de } \\
\text { información a la vez y hacer uso de una sola forma de representación. } \\
\text { Pueden utilizar algoritmos, fórmulas, procedimientos o convenciones } \\
\text { básicas, son capaces de razonar directamente y de hacer } \\
\text { interpretaciones literales de los resultados. }\end{array}$ \\
\hline $\begin{array}{c}\text { Nivel } 1 \\
\text { (de } 358 \\
\text { a } 419 \\
\text { puntos) }\end{array}$ & $\begin{array}{l}\text { Los estudiantes que se ubican en este Nivel, pueden responder } \\
\text { preguntas claramente definidas, que involucren contextos familiares, en } \\
\text { los cuales toda la información relevante está presente. También son } \\
\text { capaces de identificar información y de llevar a cabo procedimientos } \\
\text { rutinarios, siguiendo instrucciones directas, en situaciones explícitas. } \\
\text { Finalmente, estos estudiantes pueden realizar acciones obvias o aquellas } \\
\text { que se desprenden directamente de los estímulos presentados. }\end{array}$ \\
\hline
\end{tabular}

Para el área de Lengua, en la evaluación PISA se distinguen siete niveles de desempeño, cada uno de los cuales aporta información respecto del tipo de tareas que son capaces de desarrollar los estudiantes que se ubican en ellos, de la dificultad de las mismas, y de las características que poseen los materiales de lectura que logran abordar los estudiantes que se ubican en ellos. 


\section{Descripción de Niveles de desempeño en la escala de Lengua}

\begin{tabular}{|c|c|}
\hline $\begin{array}{c}\text { Nivel } 6 \\
\text { (699 y } \\
\text { más }\end{array}$ & $\begin{array}{l}\text { Los estudiantes ubicados en el Nivel } 6 \text { son lectores } \\
\text { experimentados; capaces, por una parte, de hacer análisis muy precisos } \\
\text { sobre los textos que leen, y de tener una comprensión detallada de la } \\
\text { información explícita e implícita; y por otra, de reflexionar sobre lo que } \\
\text { leen y evaluar el contenido de los textos a nivel general. En términos del } \\
\text { material de lectura, estos estudiantes comprenden prácticamente todos } \\
\text { los tipos de textos y pueden manejar la información de varios textos a la } \\
\text { vez. Otra particularidad de esta clase de lectores es su capacidad para } \\
\text { superar prejuicios al enfrentarse a información nueva, incluso cuando } \\
\text { dicha información se opone a sus expectativas. }\end{array}$ \\
\hline $\begin{array}{c}\text { Nivel } 5 \\
\text { (de } 626 \\
\text { a } 698 \\
\text { puntos) }\end{array}$ & $\begin{array}{l}\text { Los estudiantes ubicados en el Nivel } 5 \text { son capaces de } \\
\text { comprender textos que tienen formas y contenidos que les resultan } \\
\text { familiares y también no familiares. Pueden encontrar información } \\
\text { detallada y realizar inferencias, así como también evaluar críticamente los } \\
\text { textos, formular hipótesis sobre los mismos (basándose en conocimiento } \\
\text { especializado) y manejar conceptos que pueden ser contrarios a sus } \\
\text { expectativas. }\end{array}$ \\
\hline $\begin{array}{c}\text { Nivel } 4 \\
\text { (de } 553 \\
\text { a } 625 \\
\text { puntos) }\end{array}$ & $\begin{array}{l}\text { Los estudiantes ubicados en el Nivel } 4 \text { son capaces de realizar } \\
\text { tareas de lectura que requieren acceder a información explícita e implícita } \\
\text { (por ejemplo, localizar y organizar múltiples fragmentos con información } \\
\text { implícita), captar el significado de expresiones que usan giros no } \\
\text { familiares o matices del idioma, (basándose en información del texto y/o } \\
\text { aplicando categorías en contextos desconocidos o novedosos), formular } \\
\text { hipótesis y evaluar textos de una manera crítica (utilizando conocimiento } \\
\text { especializado y/o público). En cuanto at material de lectura, los } \\
\text { estudiantes de este nivel comprenden de manera exacta textos extensos } \\
\text { y complejos, cuyos contenidos o formas pueden no resultarles familiares. }\end{array}$ \\
\hline
\end{tabular}


Los estudiantes ubicados en el Nivel 3 son capaces de localizar fragmentos múltiples de información; establecer relaciones entre las distintas partes de un texto; relacionar el contenido del texto con conocimientos previos, asociados a tareas de la vida cotidiana, e integrar

Nivel 3 las partes del texto para identificar la idea principal, para comprender (de 481 una relación y/o para construir el significado de palabras y oraciones. En a 552 este nivel, los estudiantes pueden comparar, contrastar o clasificar puntos) información en diversas categorías y en función de distintos criterios. En términos del material de lectura, los textos de este nivel suelen contener mucha información implícita, o bien, explícita de difícil localización; pueden contener ideas que son contrarias a las expectativas o ideas expresadas en forma negativa.

Los estudiantes ubicados en el Nivel 2 son capaces de localizar

Nivel 2 información que satisfaga varios criterios, contrastar información en (de 407 relación con una característica, comprender el significado de un fragmento a 480 específico del texto, identificar información explícita de distintos niveles de puntos) dificultad (destacada, próxima a otras, etc.) y relacionar el contenido de los textos con su experiencia personal.

Los estudiantes ubicados en el Nivel 1a, son capaces de localizar Nivel 1a información explícitamente declarada, de fácil localización; también (de 335 pueden reconocer la idea principal de un texto y establecer conexiones a 406 entre la información de un texto y su experiencia cotidiana. En cuanto al puntos) material de lectura, estos estudiantes solo son capaces de abordar textos de contenidos familiares.

Nivel 1b (de 262 a 334 puntos)

Los estudiantes ubicados en el Nivel 1b, identifican información explícitamente declarada y realizan inferencias de bajo nivel, como reconocer una relación causal entre dos oraciones, aun cuando esta relación no haya sido declarada. En términos del material de lectura, en este nivel el alumno es capaz de comprender textos cortos, simples, y 
con estilo y contenido familiares. En los textos de este nivel, generalmente se apoya al lector con información repetida, imágenes o símbolos que son familiares, etc.

La escala de Ciencias Naturales tiene seis niveles de desempeño, cada uno de los cuales informa acerca del tipo de tareas que son capaces de desarrollar los estudiantes que se ubican en ellos, y su nivel de dificultad.

\section{Descripción de Niveles de desempeño en la escala de Ciencias Naturales}

\begin{tabular}{|c|c|}
\hline $\begin{array}{c}\text { Nivel } 6 \\
\text { (708 y } \\
\text { más } \\
\text { puntos) }\end{array}$ & $\begin{array}{l}\text { Los estudiantes ubicados en el Nivel } 6 \text {, consistentemente son } \\
\text { capaces de identificar, explicar y aplicar conocimientos científicos y } \\
\text { conocimientos sobre la ciencia, en una variedad de situaciones complejas. } \\
\text { Asimismo, son capaces de justificar sus decisiones, utilizando evidencia } \\
\text { proveniente de diversas fuentes de información. Estos estudiantes tienen } \\
\text { la capacidad de demostrar, de manera clara y consistente, pensamientos } \\
\text { y razonamientos científicos avanzados, y de usar su comprensión para } \\
\text { respaldar la búsqueda de soluciones a situaciones científicas y } \\
\text { tecnológicas poco habituales. Finalmente, pueden usar conocimiento } \\
\text { científico en las argumentaciones orientadas a respaldar } \\
\text { recomendaciones y decisiones sobre situaciones locales (personales o } \\
\text { sociales) y globales. }\end{array}$ \\
\hline $\begin{array}{c}\text { Nivel } 5 \\
\text { (de } 633 \\
\text { a } 707 \\
\text { puntos) }\end{array}$ & $\begin{array}{l}\text { Los estudiantes ubicados en el Nivel } 5 \text { pueden identificar los } \\
\text { componentes científicos de muchas situaciones complejas y responder a } \\
\text { situaciones cotidianas, aplicando conceptos científicos y conocimiento } \\
\text { sobre la ciencia, para comparar, seleccionar y evaluar evidencia. Además, } \\
\text { poseen habilidades de indagación bien desarrolladas, son capaces de } \\
\text { establecer adecuadamente relaciones entre conocimientos y poseen }\end{array}$ \\
\hline
\end{tabular}


una comprensión lúcida y relevante de diversas situaciones. Finalmente, son capaces de elaborar explicaciones fundadas en evidencia y de desarrollar argumentos basados en un análisis crítico.

Los estudiantes que se sitúan en el Nivel 4, son capaces de enfrentar con éxito, diversas situaciones y problemas que involucran Nivel 4 además de fenómenos explícitos, la necesidad de realizar inferencias (de 558 acerca del rol de la ciencia o la tecnología. Pueden seleccionar e integrar a 632 explicaciones de diferentes disciplinas científicas o tecnológicas y puntos) relacionarlas directamente con aspectos de la vida cotidiana. Asimismo, reflexionan sobre sus acciones y pueden comunicar sus decisiones, usando conocimiento y evidencia científica.

Los estudiantes ubicados en el Nivel 3 de la escala, son capaces de ejecutar procedimientos claramente descritos (incluyendo los que Nivel 3 requieren decisiones secuenciales), de seleccionar y aplicar estrategias (de 484 simples de resolución de problemas, de interpretar, y de usar a 557 representaciones basadas en diferentes fuentes de información y de puntos) razonar directamente a partir de ellas. Asimismo, son capaces de elaborar comunicaciones breves para reportar sus interpretaciones, resultados y razonamientos.

Los estudiantes de Nivel 2, poseen el conocimiento científico

Nivel 2 suficiente para dar explicaciones posibles en contextos habituales o para (de 410 establecer conclusiones basadas en investigaciones simples. Estos a 483 estudiantes son además, capaces de realizar razonamiento directo y de puntos) hacer interpretaciones literales de los resultados de una investigación científica o de la resolución de un problema tecnológico.

Nivel 1 Los estudiantes de Nivel 1, tienen un conocimiento científico (de 335 limitado que sólo pueden aplicar a escasas situaciones de la vida a 409 cotidiana, en la medida en que les resulten habituales. Además son puntos) capaces de presentar explicaciones científicas muy elementales, mientras 


\subsubsection{Laboratorio Latinoamericano de Evaluación de la Calidad de la Educación LLECE (UNESCO)}

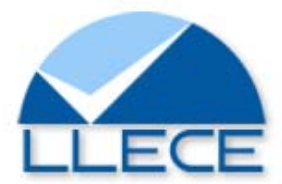

Es una red de sistemas de evaluación de la calidad de la educación de los países de América Latina y el Caribe. Lo coordina la Oficina Regional de Educación de la UNESCO para América Latina y el Caribe.

Constituye un ámbito de discusión técnico-político sobre el aprendizaje, variables relativas al desarrollo personal de los estudiantes y de los factores asociados a estas.

Creado en Ciudad de México en noviembre de 1994, el LLECE marcó un Hito en el desarrollo de nuevas formas de cooperación entre los países. Su objetivo principal es generar conocimientos que contribuyan a que los Ministerios de Educación de la región tomen decisiones informadas en materia de políticas educativas a partir del análisis de los resultados de las investigaciones evaluativas que el LLECE realiza.

En el Laboratorio participa Argentina, Brasil, Chile, Colombia, Costa Rica, Ecuador, Guatemala, Honduras, México, Nicaragua, Panamá, Paraguay, Perú, República Dominicana y Uruguay, junto al estado mexicano de Nuevo León. El LLECE realiza permanentes gestiones para que se integre a sus actividades el resto de los países de la región.

Las prioridades del LLECE son:

- Diseñar, implementar y asegurar el financiamiento del Tercer Estudio Regional Comparativo y Explicativo (TERCE). 
- Diseñar y ejecutar un estudio cualitativo de escuelas con resultados destacables en el Segundo Estudio Regional Comparativo y Explicativo (SERCE).

- Realizar y fomentar la realización de estudios sobre factores asociados, a partir del SERCE.

- Fortalecer el apoyo técnico a los sistemas de evaluación de los países miembros del LLECE y el trabajo en red.

- Generar información sobre evaluación docente.

- Favorecer la generación de conocimientos sobre modelos de evaluación de la calidad educativa que tengan un enfoque holístico.

- Favorecer el debate y la reflexión sobre nuevos modelos de evaluación: sistemas integrales, donde se considere el desarrollo global del estudiante, sus diferencias, etc. en coherencia con el concepto de calidad de la educación de la OREALC/UNESCO Santiago.

- Apoyar las diversas acciones de la UNESCO en materia de evaluación.

\subsubsection{Estudio Internacional de Alfabetización}

\section{Computacional y Manejo de Información ICILS (IEA)}

Hoy por hoy no hay quien niegue el papel transformador que tienen las Tecnologías de la Información y la Comunicación (TIC), prácticamente en todos los campos de la actividad humana. Precisamente, esos cambios acelerados y revolucionarios de las TIC en la sociedad, están demandando de las personas competencia en su uso para poder insertarse efectivamente tanto en el mundo académico como laboral. Estas demandas, las deben atender los sistemas escolares contemporáneos.

A pesar de la urgencia manifiesta, la competencia en TIC y el manejo de información, históricamente han estado desatendidos por los sistemas educativos 
latinoamericanos. Si a esta situación se le agrega la falta de estándares educativos en TIC, la baja penetración de infraestructura TIC en las Instituciones Educativas y el muy desigual desarrollo de competencias en TIC que demuestran los estudiantes Latinoamericanos cuando terminan su último grado escolar, el panorama no resulta alentador.

Sin embargo, dado que tanto el desarrollo de competencia en TIC, como el enriquecimiento de ambientes de aprendizaje con estas, son un proceso gradual, un factor importante de la ecuación es medir el nivel actual en el que se encuentran los estudiantes de la región en su uso efectivo. Medición esta que debe hacerse con total seriedad y de manera periódica, para determinar así, avances o retrocesos.

EI ICILS evaluará los resultados que obtengan los estudiantes, de diferentes países. El alfabetismo en el uso del computador y en información (CIL por su sigla en inglés), hace referencia a la habilidad individual de las personas en el uso de computadores para investigar, crear y comunicarse de manera que puedan participar efectivamente en el hogar, la Institución Educativa, el sitio de trabajo y la comunidad.

La evaluación de ICILS es hecha directamente en la computadora. Incluye preguntas de respuesta múltiple y temas en los que se deben construir las respuestas en base a material de estímulo realista; esto es, simulaciones de software de aplicaciones genéricas en los que se pide al estudiante completar una acción como respuesta a una instrucción dada; además de realizar tareas auténticas que requieren del estudiante modificar y generar productos de información usando aplicaciones de software de computador en "vivo".

El cuestionario que se aplique a los estudiantes recopilará información sobre el uso de computadores dentro y fuera de la Institución Educativa, las actitudes hacia las Tecnologías de la Información y la Comunicación (TIC), autoevaluación de la competencia en el uso de computadores y características del contexto particular de los estudiantes. Los cuestionarios a docentes e Instituciones, preguntarán sobre el uso de computadores, los recursos de 
cómputo y las políticas y prácticas relevantes. Un número de temas enlazarán a SITES 2006.

La encuesta, en el contexto nacional, recopilará datos sistémicos de políticas y prácticas educativas para el desarrollo del alfabetismo en el uso del computador y en información, idoneidad de los docentes y recursos de las tecnologías digitales (TIC) existentes en las instituciones.

\section{Instrumentos}

- Pruebas realizadas en CIL, directamente en el computador, que ofrecerán un rango amplio de módulos de evaluación auténticos en un ambiente coherente.

- Cuestionario para el estudiante

- Cuestionario para el docente (incluyendo enlaces a IEA SITES 2006)

- Cuestionario para la Institución Educativa (incluyendo enlaces a IEA SITES 2006)

- Encuesta nacional de contexto

\section{Programación}

ICILS se inició en el encuentro Nacional de Coordinadores de Investigación, en junio 21 de 2010, en Ámsterdam. El proyecto pretendía elaborar la evaluación marco en el 2010 y terminarla en el 2011, desarrollar y hacer pilotos de esos instrumentos durante el 2011, hacer una prueba de campo en la primera mitad del 2012 y recolectar los datos a principios del 2013 en el Hemisferio Norte y a fines del mismo año en el Hemisferio Sur, para entregar resultados en Noviembre de 2014.

\section{Participantes}

Los sistemas educativos que están considerando participar en ICILS-2013 son: Canadá, Chile, Croacia, Chipre, República Checa, Dinamarca, Alemania, 
Hong Kong-China, Israel, Holanda, Noruega, Polonia, la Federación Rusa, Arabia Saudita, Eslovaquia, Eslovenia, España (Cataluña), Tailandia y los Estados Unidos.

\section{Población objetivo}

El foco de la población a la que se aplicará la encuesta, incluirá a todos los estudiantes matriculados en el grado correspondiente a ocho (8) años de escolarización, contados a partir del primer año de ISCED Nivel 1; siempre y cuando, el promedio de edad en el momento de tomar la prueba sea por lo menos de 13,5 años. Para muchos países correspondería al grado $8^{\circ}$. Además, esta evaluación se ofrecerá como una opción, con un conjunto de temas modificados, para el grado $4^{\circ}$.

\subsubsection{Estudio Internacional de Tendencias en Matemática y Ciencias} TIMSS (IEA)

Es un proyecto de la Asociación Internacional para la Evaluación Educativa (IEA). La IEA es una institución independiente que coopera con las instituciones nacionales de investigación en la realización estudios de evaluación desde 1959.

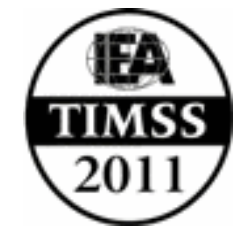

El estudio TIMSS se realiza cada cuatro años y proporciona a los países una oportunidad única para medir el progreso en la enseñanza de Matemáticas y Ciencias.

TIMSS por medio de cuestionarios pregunta a estudiantes, profesorado y miembros de los equipos directivos acerca de los contextos para aprender Matemáticas y Ciencias. Los datos de estos cuestionarios proporcionan un retrato dinámico de los cambios en las prácticas educativas y son una ayuda para mejorar dichas prácticas e implementar normas. 
El modelo curricular de TIMSS tiene tres aspectos:

- El currículo diseñado.

- El currículo aplicado.

- El currículo logrado.

Estos representan, por una parte, lo que la sociedad piensa que los estudiantes tienen que aprender de las Matemáticas y las Ciencias, y por otra parte, cómo el sistema educativo se ha de organizar para facilitar dicho aprendizaje.

- Las pruebas de TIMSS se elaboran mediante un consenso internacional contando con expertos en Didáctica, en Matemáticas, en Ciencias y en Estadística.

- Los diseñadores de la prueba e investigadores, así como la comunidad educativa pueden esperar que los resultados en Matemáticas y en Ciencias.

- Informen sobre comparaciones de los resultados obtenidos por cada país y entre países y, en unión con otros datos de TIMSS, sugieran las razones para establecer diferencias entre ellos.

- Mejoren la evaluación de la eficacia de la enseñanza y el aprendizaje en Matemáticas y en Ciencias dentro de cada país.

- Descubran los aspectos más relevantes del progreso en el conocimiento y habilidades matemáticas y científicas en $2^{\circ}$ curso de la E.S.O.

- Proporcionen datos complementarios acerca de los resultados en distintos sistemas educativos y centros escolares, así como en la mejora de la práctica docente.

\subsubsection{Sistema Nacional de Evacuación de Resultados de aprendizaje} del Ministerio de Educación de Chile SIMCE 
EI SIMCE es el Sistema Nacional de Evaluación de resultados de aprendizaje del Ministerio de Educación de Chile. Su propósito principal es contribuir al mejoramiento de la SIMCE calidad y equidad de la educación, informando sobre el desempeño de los estudiantes en diferentes áreas de aprendizaje del Currículum Nacional, y relacionando estos desempeños con el contexto escolar y social en que aprenden.

Las pruebas SIMCE evalúan el logro de los Objetivos Fundamentales y Contenidos Mínimos Obligatorios (OF-CMO) del Marco Curricular vigente en diferentes sectores de aprendizaje, a través de una medición que se aplica a nivel nacional, una vez al año, a los estudiantes que cursan un determinado nivel educacional. Hasta el año 2005, la aplicación de las pruebas se alternó entre $4^{\circ}$ Básico, $8^{\circ}$ Básico y $2^{\circ}$ Medio. A partir del año 2006, se evalúa todos los años a $4^{\circ}$ Básico y se alternan $8^{\circ}$ Básico y $2^{\circ}$ Medio. Desde el año 2010 se aplica cada dos años la evaluación del sector Inglés en $3^{\circ}$ Medio, y todos los años una evaluación del sector de Educación Física en $8^{\circ}$ Básico, con el objetivo de diagnosticar la condición física de los estudiantes.

Además de las pruebas asociadas al currículum, el SIMCE también recoge información sobre docentes, estudiantes y padres y apoderados a través de cuestionarios de contexto. Esta información se utiliza para contextualizar y analizar los resultados de los estudiantes en las pruebas SIMCE.

\section{Propósito}

El propósito principal de SIMCE es contribuir al mejoramiento de la calidad y equidad de la educación, informando sobre el desempeño de los estudiantes en distintas áreas de aprendizaje y del Currículum Nacional y relacionando estos desempeños con el contexto escolar y social en que aprenden. Para cumplir con este propósito, SIMCE fomenta el uso de la información de las pruebas nacionales e internacionales por parte de distintos usuarios. 
1. - A los profesores, directivos y sostenedores la información entregada por el SIMCE les sirve para:

- Conocer cómo le fue a sus estudiantes en comparación con aquellos del mismo curso evaluado en años anteriores. Los profesores pueden saber, por ejemplo, si al $4^{\circ}$ Básico de este año le fue mejor, peor o similar que al $4^{\circ}$ Básico del año pasado. Esto es importante para saber si las nuevas generaciones de estudiantes alcanzan mejores desempeños en comparación con las generaciones más antiguas.

- Conocer si sus estudiantes obtienen un puntaje promedio mejor, peor o similar que otros alumnos del país, de su comuna, o de establecimientos que atienden a estudiantes con similares características socioeconómicas. Cuando dos establecimientos con similares características socioeconómicas obtienen puntajes promedios significativamente distintos, es más probable que estas diferencias se deban a que una escuela ofrece una educación de mejor calidad que la otra.

- Evaluar si las iniciativas implementadas en la escuela tuvieron un efecto positivo en el nivel de desempeño de los alumnos. Por ejemplo, en una escuela los resultados SIMCE podrían haber subido como consecuencia de un cambio planificado en los énfasis de contenidos que los profesores tratan en clases.

- Conocer qué porcentaje de los estudiantes de $4^{\circ}$ y $8^{\circ}$ Básico del establecimiento se encuentra en el nivel avanzado, intermedio e inicial de los Niveles de Logro. Estos resultados deben ayudar a que los profesores tomen conciencia de la diversidad de rendimientos que presentan sus alumnos.

- Conocer el tipo de problemas que se espera que los alumnos puedan resolver. Al analizar los Niveles de Logro y las preguntas publicadas del SIMCE, los profesores pueden revisar en qué medida los estudiantes han tenido oportunidades de aprender los contenidos y habilidades evaluados. 
Es importante que esta pregunta se la hagan todos los profesores del ciclo de enseñanza, y no solo los profesores del curso evaluado. También pueden revisar si el nivel de exigencia de sus evaluaciones de aula se adecua al nivel de exigencia señalado en el currículo oficial y en las pruebas SIMCE.

- Pensar cómo ofrecer clases más estimulantes y provechosas para estudiantes con distintos Niveles de Logro. Por ejemplo, en clases los profesores podrían armar grupos de alumnos del nivel avanzado, intermedio e inicial; y dar a cada grupo actividades acordes con sus necesidades de aprendizaje.

- Ponerse metas. Por ejemplo, sostenedores, directivos y docentes podrían proponerse disminuir en 10 puntos porcentuales la proporción de estudiantes en el nivel inicial de los Niveles de Logro, junto con aumentar significativamente el puntaje promedio del establecimiento.

- A través de las evaluaciones internacionales, conocer las competencias que manejan los estudiantes chilenos en comparación con los estudiantes de otros países. Los estudiantes en cada país merecen aprender y desarrollarse tanto como los estudiantes de cualquier otro país. El que lo hagan es importante para su desarrollo personal y para el desarrollo económico y social del país.

2. - A los padres y apoderados, la información entregada por el SIMCE les sirve para:

- Conocer cómo le fue a su escuela en comparación con otras escuelas de la misma comuna o dependencia. Los padres pueden preguntarle al director del establecimiento por qué la escuela obtuvo estos resultados, y qué pueden hacer para que mejore.

- Conocer qué porcentaje de los estudiantes de $4^{\circ}$ y $8^{\circ}$ Básico del establecimiento se encuentra en el nivel avanzado, intermedio e inicial de los Niveles de Logro. Conocer qué se espera que sean capaces de hacer 
los alumnos en el curso evaluado. Los padres pueden consultar al profesor si su hijo maneja las competencias de cada Nivel de Logro, y qué pueden hacer para ayudarlo a alcanzarlas.

- Complementar la información sobre las notas. Con las notas, los padres pueden saber cómo es el rendimiento de su hijo en comparación con el de sus compañeros de curso. Con el SIMCE pueden saber cómo es el rendimiento de su escuela en comparación con otras escuelas del país.

3. - Al Ministerio de Educación, la información entregada por el SIMCE le sirve para:

- Realizar el seguimiento de la calidad y equidad de la educación desde la perspectiva de los logros de aprendizaje que alcanzan los estudiantes en distintas áreas curriculares. El Ministerio de Educación puede saber en qué medida los estudiantes están logrando los objetivos curriculares y si ha habido progreso en el logro de estos objetivos a través de los años. También puede monitorear en qué medida distintos grupos de estudiantes (ej. estudiantes de distinto nivel socioeconómico) están alcanzando estos objetivos.

- Identificar establecimientos que presentan sistemáticamente bajos resultados en el SIMCE y que necesitan apoyo externo para mejorar el desempeño de sus estudiantes.

- Evaluar la efectividad de programas de intervención cuyo objetivo es mejorar el desempeño de los estudiantes en distintas áreas curriculares.

- Asignar incentivos a las escuelas que logran mantener altos puntajes en el SIMCE o que los suben sistemáticamente.

- Aprender de la experiencia de países que alcanzan altos estándares de calidad y equidad en educación, a partir de los resultados de las evaluaciones internacionales.

- Conocer las principales características del entorno escolar y familiar en el que estudian los alumnos chilenos y de otros países del mundo. Esta 
información de contexto puede ser muy valiosa para comprender mejor los resultados.

\subsection{Bases Teóricas}

\subsubsection{Calidad Total}

La Gestión de Calidad Total (abreviada TQM, del inglés Total Quality Management) es una estrategia de gestión creada por W. E. Deming orientada a crear conciencia de calidad en todos los procesos organizacionales. La TQM ha sido ampliamente utilizada en manufactura, educación, gobierno e industrias de servicio. Se le denomina «total» porque en ella queda concernida la organización de la empresa globalmente considerada y las personas que trabajan en ella.

\section{Composición de la gestión de calidad total}

La gestión de calidad total está compuesta por tres paradigmas:

- Gestión: el sistema de gestión con pasos tales como planificar, organizar, controlar, liderar, etc.

- Total: organización amplia.

- Calidad: con sus definiciones usuales y todas sus complejidades.

\section{Concepto de calidad total}

En el concepto de calidad se incluye la satisfacción del cliente y se aplica tanto al producto como a la organización. La Calidad Total pretende, teniendo como idea final la satisfacción del cliente, obtener beneficios para todos los miembros de la empresa. Por tanto, no sólo se pretende fabricar un producto con el objetivo de venderlo, sino que abarca otros aspectos tales como mejoras en las condiciones de trabajo y en la formación del personal.

El concepto de la calidad total es una alusión a la mejora continua, con el objetivo de lograr la calidad óptima en la totalidad de las áreas. 
Kaoru Ishikawa, un autor reconocido de la gestión de la calidad, proporcionó la siguiente definición respecto a la Calidad Total: "Filosofía, cultura, estrategia o estilo de gerencia de una empresa según la cual todas las personas en la misma, estudian, practican, participan y fomentan la mejora continua de la calidad".

La calidad total puede entenderse como la satisfacción global aplicada a la actividad empresarial.

\section{Clientes internos y externos}

El concepto de calidad total distingue a dos tipos de clientes, los cuales son identificados como internos y externos.

- Se consideran clientes internos a los departamentos de la empresa que solicitan un producto o servicio a otro departamento de la misma empresa.

- El cliente externo es quien compra los productos o servicios a la empresa, sin necesariamente tener relación con esta.

Por lo mismo la calidad total es un proceso al cual se suman esfuerzos para alcanzar una meta establecida y superarla de forma relevante y mejorar el producto o servicio a oferta.

La calidad total puede ser definida en dos palabras: "Mejora continua".

\section{Dirección de la calidad}

La responsabilidad que recae en la dirección de la calidad juega un papel importante en todo el proceso, puesto que mientras mejor estén organizados y compenetrados todos los miembros, mejor será el trabajo que realicen y mejores resultados se obtienen en su conjunto.

\section{Concepto de percepción de la calidad}

El concepto de calidad total está relacionado con otro concepto: el de la "percepción de la calidad", que es la percepción que se tiene de la calidad de un 
producto o de cómo ve la gente a una empresa o una marca (su forma de vender, el trato hacía los clientes, su implicación en proyectos sociales o con el medio ambiente).

\section{Satisfacción global}

La satisfacción global, como su nombre indica, no solo atañe a los clientes de cada empresa, sino a todo el "universo" de la empresa, es decir: a los propios empleados y a otras empresas que le venden sus productos/servicios (lo que se denomina clientes internos).

\section{Resultados de un sistema de calidad}

La experiencia ha demostrado que tras implantar un sistema de calidad se consiguen resultados tales como:

- Aumento en la satisfacción del cliente.

- Trabajo interno de la empresa más eficaz.

- Incremento de la productividad.

- Mayores beneficios.

- Menores costos.

- Mayor calidad en los productos elaborados.

La calidad de un producto es, por tanto, una consecuencia de cómo una empresa está organizada.

\section{Herramientas para la medición de la calidad}

Existen diversos métodos de medición de la calidad, ya sea mediante herramientas propias o bien herramientas de ayuda de implantación (estadísticas, indicadores de calidad preestablecidos, estándares de producción, peso, tamaño, color). La medición es a la vez el último y el primer paso a la hora de mejorar la calidad de servicio y conseguir ofrecer un servicio excelente. Es muy difícil 
conseguir mejorar un servicio si no se tiene en cuenta los resultados que se están obteniendo con un sistema que permita cuantificarlos.

\section{Valores de una cultura de Administración de Calidad Total}

La transculturalización necesaria para poder sobrevivir y crecer en un contexto turbulento, requiere que las organizaciones adopten como valores permanentes los conceptos de calidad y productividad.

Valores de una cultura organizacional de Calidad Total:

- El éxito viene del compromiso de las personas con el destino de la organización y su creencia en una verdadera y confiable asociación de administradores y trabajadores;

- El objetivo convocante es lograr calidad, es decir, la satisfacción del cliente, interno o externo.

- La generación de valor agregado a largo plazo, para una organización, dependerá del mejoramiento de la productividad;

- El mejoramiento de la calidad reduce los costos y genera un incremento de la participación en el mercado;

- Siendo el valor agregado un producto contabilizado en los índices de productividad, el mejoramiento de la calidad y de la productividad se convierten en sinónimos.

- La diferencia competitiva de una organización está en el potencial de su gente, por ello ha de brindarse entrenamiento y capacitación de manera sistemática.

\section{Calidad total en la educación}

En el sector educativo la cultura de la Calidad Total pareciera ser de dificultosa implementación toda vez que se trata de estructuras burocráticas y no 
resulta sencillo definir quién es el cliente final y la detección de sus requerimientos.

Esto implica asumir que la Calidad Total solamente está destinada a satisfacer las necesidades del cliente, sin embargo, Calidad Total es mucho más que eso: es reducir costos, es incrementar la productividad y es lograr una mejor calidad de vida.

Son estas últimas consideraciones las que permiten afirmar que en el ámbito educativo también es aplicable la Calidad Total.

El proceso de implantación de un sistema de calidad en un centro docente considera las siguientes fases:

- Toma de conciencia de la situación actual del centro, de los problemas, de la necesidad de cambio

- Decisión de empezar que se concreta en dos momentos: ¿qué se va a hacer? (se formará a la dirección y parte del personal sobre el tema de la calidad y los instrumentos que se utilizan en los sistemas de calidad), ¿dónde se está posicionado? (se hará un diagnóstico de la situación actual del centro).

- Declaración de un plan para la mejora del centro y aceptación por todo el colectivo.

- Actuación de todo el personal según los acuerdos

- Seguimiento y control del proceso, con el fin de comprobar el logro de los objetivos, analizar las desviaciones y sus posibles causas; y establecer mecanismos de corrección.

- Establecimiento de un sistema de mejora continua de la calidad. Comprenderá: una estructura organizativa y el empleo de herramientas adecuadas. 


\subsubsection{Calidad en Educación}

La OCDE (Organización para la Cooperación y Desarrollo Económico) define la educación de calidad como aquella que "asegura a todos los jóvenes la adquisición de los conocimientos, capacidades destrezas y actitudes necesarias para equipararles para la vida adulta".

Otra definición: "La escuela de calidad es la que promueve el progreso de sus estudiantes en una amplia gama de logros intelectuales, sociales, morales y emocionales, teniendo en cuenta su nivel socioeconómico, su medio familiar y su aprendizaje previo. Un sistema escolar eficaz es el que maximiza la capacidad de las escuelas para alcanzar esos resultados". Mortimore, J (1998).

La eficacia no estará en conseguir un buen producto a partir de unas buenas condiciones de entrada, sino en hacer progresar a todos los alumnos a partir de sus circunstancias personales. En este sentido conviene enfatizar en la calidad de los procesos escolares, y evitar dar un valor absoluto a los productos obtenidos.

\section{La calidad desde la esfera de los valores}

Un sistema educativo de calidad se caracteriza por su capacidad para:

- Ser accesible a todos.

- Facilitar los recursos personales, organizativos y materiales, ajustados a las necesidades de cada alumno para que todos puedan tener las oportunidades que promoverán lo más posible su progreso académico y personal.

- Promover cambio e innovación en la institución escolar y en las aulas (lo que se conseguirá, entre otros medios, posibilitando la reflexión compartida sobre la propia práctica docente y el trabajo colaborativo del profesorado)

- Promover la participación activa del alumnado, tanto en el aprendizaje como en la vida de la institución, en un marco de valores donde TODOS se sientan respetados y valorados como personas. 
- Lograr la participación de las familias e insertarse en la comunidad

- Estimular y facilitar el desarrollo y el bienestar del profesorado y de los demás profesionales del centro.

\section{Características de los centros docentes eficaces:}

- Compromiso con normas y metas compartidas y claras. Los fines generales de la educación deben considerar las tres categorías básicas:

1. Competencia académica y personal,

2. Socialización de los estudiantes

3. Formación integral.

- Búsqueda y reconocimiento de unos valores propios.

- Liderazgo profesional de la dirección. La actividad directiva se centra en el desarrollo de actividades de información, organización, gestión, coordinación y control. Supone una continua toma de decisiones en aspectos: administrativos y burocráticos, jefatura del personal, disciplina de los alumnos, relaciones externas, asignación de recursos y resolución de problemas. Debe conocer bien lo que pasa en el centro, mediar en la negociación de los conflictos y ver de tomar decisiones compartidas.

- Estabilidad laboral y estrategias para el desarrollo del personal, acorde con las necesidades pedagógicas de cada centro. Procurar el aprendizaje continuo del profesorado y la actualización de los contenidos, recursos y métodos.

- Currículum bien planeado y estructurado, con sistemas de coordinación y actualización periódica.

- Clima de aprendizaje. La enseñanza y el aprendizaje deben constituir el centro de la organización y la actividad escolar. Se debe cuidar el ambiente de aprendizaje buscando el aprovechamiento del estudiante y el empleo eficiente de los tiempos de aprendizaje. La motivación y los logros de cada estudiante están muy influidos por la cultura o clima de cada escuela.

- Profesionalidad de la docencia: organización eficiente del profesorado, conocimiento claro de los propósitos por los alumnos, actividades docentes 
estructuradas, tratamiento de la diversidad, seguimiento de los avances de los estudiantes, uso de refuerzos positivos, claras normas de disciplina, en fin, eficacia docente

- Expectativas elevadas sobre los alumnos y sus posibilidades, comunicación de estas expectativas, proponer desafíos intelectuales a los estudiantes.

- Atención a los derechos y responsabilidades de los estudiantes, darles una cierta responsabilidad en actividades del centro, control de su trabajo, atender a su autoestima.

- Elevado nivel de implicación y apoyo de los padres. Participación de la comunidad educativa

- Apoyo activo y sustancial de la administración educativa

Con todo hay que tener en cuenta que según la perspectiva sobre la noción de calidad que se adopte variará lo que se considere una escuela eficaz; sólo se puede hablar de eficacia en función del logro de unos fines específicos.

\section{Principios de la calidad total en educación}

A lo largo del tiempo ha ido variando la consideración de lo que resulta fundamental en la calidad. Primero fue el "producto", más tarde el "proceso", luego los "trabajadores". Actualmente la calidad total se fundamenta en la idea de la satisfacción del cliente (en el ámbito educativo esto puede considerarse la superación de los principios de las "escuelas eficaces")

- Lo más importante es la satisfacción del cliente, con el costo más bajo posible. La empresa de éxito será la que identifique y satisfaga las expectativas de sus clientes.

- El proceso de calidad total se inicia con la detección de problemas y deficiencias y la propuesta de determinadas soluciones.

- La gestión de la calidad se fundamenta en el desarrollo continuo de planes integrales, no en la ejecución de simples acciones aisladas o puntuales. 
- La toma de decisiones se debe realizar como consecuencia de datos y evidencias, no a partir de suposiciones y opiniones. Por lo tanto es preciso evaluar.

- La calidad depende básicamente de las personas, por ello resulta fundamental atender a aspectos como:

- La participación

- El compromiso

- La implicación voluntaria

- La colaboración

- El trabajo en equipo

- La formación de las personas

- Propiciar el desarrollo/crecimiento personal de cada individuo como clave del crecimiento y enriquecimiento de la organización

- La calidad total implica a toda la organización

Una educación de calidad es aquella que promueve:

- La construcción de conocimientos psicológica, social y científicamente significativos.

- El desarrollo de procesos de pensamiento y estrategias cognitivas que le permitan al sujeto "aprender a aprender".

- La apropiación de instrumentos para participar en la vida económica, política y social, contribuyendo a la construcción de un modelo social democrático.

- El desarrollo de habilidades básicas que posibiliten al educando, la inserción en condiciones adecuadas en el nivel siguiente del sistema educativo o la incorporación a la vida activa.

- La aplicación del conocimiento para operar sobre la realidad.

- La posibilidad de la duda y la discusión. 
- La consideración de las características propias del sujeto de aprendizaje, en sus aspectos cognitivos, socio-afectivos y psicomotrices.

- El crecimiento profesional del docente.

\subsection{Definición de términos Básicos}

\subsubsection{Educación}

La educación, (del latín educere "sacar, extraer" o educare "formar, instruir") puede definirse como:

- El proceso multidireccional mediante el cual se transmiten conocimientos, valores, costumbres y formas de actuar. La educación no sólo se produce a través de la palabra, pues está presente en todas las acciones, sentimientos y actitudes.

- El proceso de vinculación y concienciación cultural, moral y conductual. Así, a través de la educación, las nuevas generaciones asimilan y aprenden los conocimientos, normas de conducta, modos de ser y formas de ver el mundo de generaciones anteriores, creando además otros nuevos.

- Proceso de socialización formal de los individuos de una sociedad.

- La educación se comparte entre las personas por medio de las ideas, cultura, conocimientos, etc. respetando siempre a los demás. Ésta no siempre se da en el aula.

Existen tres tipos de educación: la formal, la no formal y la informal. La educación formal hace referencia a los ámbitos de las escuelas, institutos, universidades, módulos, mientras que la no formal se refiere a los cursos, academias, e instituciones, que no se rigen por un particular currículo de estudios, y la educación informal es aquella que fundamentalmente se recibe en los 
ámbitos sociales, pues es la educación que se adquiere progresivamente a lo largo de toda la vida.

\section{Educación básica}

Preescolar, educación primaria y secundaria es la etapa de formación de los individuos en la que se desarrollan las habilidades del pensamiento y las competencias básicas para favorecer el aprendizaje sistemático y continuo, así como las disposiciones y actitudes que regirán sus respectivas vidas (educación en valores). Lograr que todos los niños, las niñas, y los adolescentes del país tengan las mismas o similares oportunidades de cursar y concluir con éxito la educación básica, para así lograr los aprendizajes que se establecen para cada grado y nivel, son factores fundamentales para sostener el desarrollo de la nación.

En una educación básica de buena calidad el desarrollo de las competencias básicas y el logro de los aprendizajes de los alumnos son los propósitos centrales, son las metas a las cuales los profesores, la escuela y el sistema dirigen sus esfuerzos.

Permiten valorar los procesos personales de construcción individual de conocimiento por lo que, en esta perspectiva, son poco importantes los aprendizajes basados en el procesamiento superficial de la información y aquellos orientados a la recuperación de información en el corto plazo.

Una de las definiciones más interesantes la propone uno de los más grandes pensadores, Aristóteles: "La educación consiste en dirigir los sentimientos de placer y dolor hacia el orden ético."

También se denomina educación al resultado de este proceso, que se materializa en la serie de habilidades, conocimientos, actitudes y valores adquiridos, produciendo cambios de carácter social, intelectual, emocional, etc. en la persona que, dependiendo del grado de concienciación, será para toda su vida o por un periodo determinado, pasando a formar parte del recuerdo en el último de los casos. 


\section{Objetivos}

- Incentivar el proceso de estructuración del pensamiento, de la imaginación creadora, las formas de expresión personal y de comunicación verbal y gráfica.

- Favorecer el proceso de maduración de los niños en lo sensorio-motor, la manifestación lúdica y estética, la iniciación deportiva y artística, el crecimiento socio afectivo, y los valores éticos.

- Estimular hábitos de integración social, de convivencia grupal, de solidaridad y cooperación y de conservación del medio ambiente.

- Desarrollar la creatividad del individuo.

- Fortalecer la vinculación entre la institución educativa y la familia.

- Prevenir y atender las desigualdades físicas, psíquicas y sociales originadas en diferencias de orden biológico, nutricional, familiar y ambiental mediante programas especiales y acciones articuladas con otras instituciones comunitarias.

\section{Concepto de Educación}

Según la enciclopedia de Internet, Wikipedia, define el término de educación como: "un proceso de socialización y endoculturación de las personas a través del cual se desarrollan capacidades físicas e intelectuales, habilidades, destrezas, técnicas de estudio y formas de comportamiento ordenadas con un fin social (valores, moderación del diálogo-debate, jerarquía, trabajo en equipo, regulación fisiológica, cuidado de la imagen, etc.)".

En muchos países occidentales la educación escolar o reglada es gratuita para todos los estudiantes. Sin embargo, debido a la escasez de escuelas públicas, también existen muchas escuelas privadas y parroquiales.

La función de la educación es ayudar y orientar al educando para conservar y utilizar los valores de la cultura que se le imparte, fortaleciendo la identidad nacional. La educación abarca muchos ámbitos; como la educación formal e informal. 
Pero el término educación se refiere sobre todo a la influencia ordenada ejercida sobre una persona para formarla y desarrollarla a varios niveles complementarios; en la mayoría de las culturas es la acción ejercida por la generación adulta sobre la joven para transmitir y conservar su existencia colectiva. Es un ingrediente fundamental en la vida del ser humano y la sociedad. Se remonta a los orígenes mismos del ser humano. La educación es lo que transmite la cultura, permitiendo su evolución.

\subsubsection{Educación Secundaria}

La educación secundaria es la que tiene como objetivo capacitar al alumno para proseguir estudios superiores o bien para incorporarse al mundo laboral. $\mathrm{Al}$ terminar la misma se pretende que el alumno desarrolle las suficientes habilidades, valores y actitudes para lograr un buen desenvolvimiento en la sociedad. En particular, la enseñanza secundaria debe brindar formación básica para responder al fenómeno de la universalización de la matrícula; preparar para la universidad pensando en quienes aspiran y pueden continuar sus estudios; preparar para el mundo del trabajo a los que no siguen estudiando y desean o necesitan incorporarse a la vida laboral; y formar la personalidad integral de los jóvenes, con especial atención en los aspectos relacionados con el desempeño ciudadano.

Puede ser una educación secundaria común para todos los alumnos o diversificada en vías formativas según las salidas posteriores. Las modalidades, a la vez, pueden tener diversas especializaciones y orientaciones que permiten formarse en temas específicos. Por ejemplo, en la educación técnico profesional se prepara mayoritariamente para el trabajo después de terminar la escuela secundaria, en esta modalidad se entrena al alumno para que aprenda una carrera técnica o industrial. 
En muchos países no es obligatoria y las edades varían mucho de una nación a otra, si bien por lo común cubre la etapa de la adolescencia, en general se comienza con 12 o 13 años y se termina con 17 o 18 .

\section{Argentina}

A través del tiempo, el sistema de educación secundaria en Argentina ha sido modificado varias veces.

La ciudad de Buenos Aires y algunas otras provincias aún conservan el sistema de siete años de Primaria y cinco años de Secundaria (Ley 26.206). En 4to los alumnos deben escoger una orientación, cada una tiene sus materias específicas y diferencias en los horarios:

- Ciencias Sociales: Psicología, Sociología, Filosofía, Economía, Cultura, Historia, Geografía (en las otras hasta 5to)

- Ciencias Naturales: Genética, Biología, Astronomía, Física, Química (en las otras Física y Biología 4to, Química en 5to)

- Economía y Administración: Contabilidad, Derecho, Informática, Teoría del desarrollo, Elementos de la Microeconomía y Macroeconomía, Gestión Organizacional, Filosofía, Cultura, Política y Ciudadanía.

- Artes Visuales y Escénicas: Arte, Música, Danza, Teatro, Expresión Corporal, Historia del arte

- Arte y Diseño: Arte, Producción De Imágenes, Informática

- Salud y Deporte: Salud y Adolescencia, Deportes, Gimnasia, Biología, higiene, nutrición

- Lenguas Extranjeras: Ingles, Italiano, Francés, Alemán, Latín, Portugués

Para la Educación Secundaria Técnica se definen las siguientes tecnicaturas:

- Técnico en Electromecánica

- Técnico en Administración de las Organizaciones 
- Técnico Químico

- Técnico en Tecnología de los Alimentos

- Técnico en Electrónica

- Técnico en Informática Personal y Profesional

- Maestro Mayor de Obras

- Técnico en Aeronáutica

- Técnico en Automotores

- Técnico en Servicios Turísticos

- Técnico en Multimedios

- Técnico Constructor Naval

\subsection{Definición de las variables}

En este trabajo se puede observar que la variable dependiente, es decir, el objeto de investigación, el cual se intenta explicar en función de otras variables, es el nivel de calidad educativa en el nivel secundario. Por otra parte, hay muchas variables independientes o sea, aquellos factores susceptibles de explicar la razón del nivel de calidad. Algunas de estas pueden ser el presupuesto, el cumplimiento del programa, el compromiso de los directivos, profesores, alumnos, etc.

A continuación se presentan los indicadores correspondientes a cada tasa evaluada:

\section{Matriculación Bruta Combinada}

\section{Cantidad de alumnos matriculados Total población en edad correspondiente -100}

Se calcula esta tasa para cada curso, luego para cada nivel Educativo y luego se hace un Promedio simple de la Tasa Bruta de Matriculación por Niveles. 
Esta tasa, particularmente en los primeros cursos de la educación formal puede ser superior al $100 \%$ ya que calcula la proporción entre los matriculados y la población con la edad correspondiente para cada año de la educación formal. En países o regiones en los cuales la sobre-edad es un fenómeno de relevancia, esto se ve con frecuencia.

\section{Sobre edad escolar}

\section{$\frac{\text { Cantidad de allumnos mayores a la edad correspondiente }}{\text { Cantidad de matriculados en el año }} 100$}

Esta tasa hace referencia a la cantidad de alumnos que se encuentran cursando el secundario y tienen una edad mayor a la correspondiente, de acuerdo con el nivel que debería cursar.

\section{$\underline{\text { Tasa de Alfabetización }}$}

$$
\frac{\text { Cantidad de alumnos que reportan leer y escribir: }{ }^{(1)}}{\text { Total de alumnos }} \cdot 100
$$

(1) Alumnos de Nivel secundario mayores de 11 (12) años y menores de 17 (18) años.

(2) Población general de la región mayores de 11 (12) años y menores de 17 (18) años.

Mediante esta indicador se utiliza para evaluar el nivel de alfabetización, esto es la habilidad que tiene la persona de utilizar texto para comunicarse a través del espacio y el tiempo. Esto se reduce a la habilidad de leer y escribir.

\section{$\underline{\text { Tasa de Analfabetismo }}$}

$\frac{\text { Cantidad de alumnos que reportar no leer ni escribir: }}{\text { T'otal de alumnos }}=100$ 
Es justamente lo contrario a la tasa anterior. El analfabetismo es la incapacidad de leery escribir, lo cual se debe generalmente a la falta de aprendizaje.

\section{Metodología de la investigación}

\subsection{Población y muestra}

La técnica de investigación utilizada fue la de "Panel de Expertos"6 (o especialistas) el cual, como su nombre lo indica, está formado por un grupo de personas expertas en educación secundaria, con un gran bagaje profesional en el tema en cuestión y potenciales clientes del producto a evaluar -"siguientes en la etapa del proceso", acorde con el concepto de evaluación de calidad.

Es decir, que la población está compuesta por los docentes de nivel terciario y empresarios de la región de Berisso, y la muestra seleccionada para la formación del panel de expertos fue de 10 docentes y 9 empresarios de dicha localidad.

Se tuvieron en cuenta algunas características esenciales al seleccionar la muestra bajo estudio. Entre éstas se pueden contar las siguientes:

- Homogeneidad: todos los consultados debían contar con similares conocimientos acerca del nivel de educación presentado por los egresados del secundario.

- Tiempo: para el cálculo de los indicadores se utilizó información del año 2011, la cual fue proporcionada por la Dirección General de Cultura y Educación.

- Espacio: el estudio se basa en especialistas de la región de La Plata, Berisso y Ensenada; provincia de Buenos Aires.

- Cantidad: El tamaño de la población de los especialistas a consultar se limitó a dos grupos de paneles de expertos que brindaron respuestas, luego de comprender la metodología y consigna propuesta. Uno de los paneles está

${ }^{6}$ Personas especialistas independientes y reputadas que conocen en profundidad la temática del campo al que concierne el objeto que se pretende evaluar, a quienes se recurre para que emitan un juicio sobre dicho objeto.

Autor: Ing. Lucas F. Gambino 
compuesto por profesores de universidades y escuelas terciarias, debido a que son quienes reciben a los egresados del secundario, y son capaces de evaluar el nivel de educación que estos presentan. El otro panel está conformado por empresarios, ya que saben acerca de las capacidades, habilidades y conocimiento que poseen los egresados, y su respectivo desempeño en el mercado laboral.

\subsection{Tipo de investigación}

La investigación que se llevó a cabo es de tipo exploratoria y descriptiva. Es exploratoria debido a que la investigación se efectúa sobre un tema u objeto desconocido o poco estudiado, por lo que sus resultados constituyen una visión aproximada de dicho objeto, es decir, un nivel superficial de conocimiento.

El objetivo de la investigación descriptiva consiste en llegar a conocer las situaciones, costumbres y actitudes predominantes a través de la descripción exacta de las actividades, objetos, procesos y personas. Su meta no se limita a la recolección de datos, sino a la predicción e identificación de las relaciones que existen entre dos o más variables. Consiste, fundamentalmente, en caracterizar un fenómeno o situación concreta indicando sus rasgos más peculiares o diferenciadores.

\subsection{Técnica de recolección de datos}

La investigación se basó en la recolección de datos primarios y secundarios. Los datos secundarios fueron recabados de la Dirección General de Cultura y Educación de la Provincia de Buenos Aires y los datos primarios se obtuvieron mediante la realización de encuestas a un panel de expertos.

Un panel es una técnica de investigación de mercados cuantitativa que obtiene información de una muestra de población. La muestra está formada por personas (físicas o jurídicas) que colaboran libre y voluntariamente en el estudio; 
se comprometen a permanecer en el panel durante un tiempo mínimo (variable según el tipo de panel de que se trate).

\section{Ventajas del uso de paneles de expertos:}

Las ventajas de esta herramienta radican fundamentalmente en el profundo conocimiento que tienen los expertos sobre los temas objeto de evaluación. Entre ellos:

- Un ahorro de tiempo considerable.

- Un costo reducido.

- Una gran credibilidad de las conclusiones.

- Una gran capacidad de adaptación a las diferentes situaciones.

\section{Desventajas del uso de paneles de expertos:}

- El funcionamiento del panel puede tender por estructura a omitir las opiniones minoritarias y a suavizar las conclusiones.

- La opinión de determinados expertos puede llegar a primar sobre el resto, a costa de otras opiniones.

- La tendencia de los expertos a exceder el campo de sus competencias reconocidas.

Es por ello que se decidió recurrir a un Panel de Expertos o Especialistas profesionales, el cual estará formado por un grupo de personas expertas en educación secundaria y potenciales clientes del producto, con el objeto de contar con información confiable a un costo mucho menor que el de herramientas de investigación de mercados tradicionales.

Los paneles se consideran una técnica de investigación socialmente responsable, ya que reducen la necesidad de realizar encuestas "masivas" a la sociedad en general cada vez que se necesita obtener información cuantitativa de un determinado grupo selecto de personas.

La realización de la encuesta, se basó en la metodología de PISA (Programa para la Evaluación Internacional de Alumnos), debido a que es un 
programa de evaluación internacional ya utilizado en varios países, que permite la comparación de los resultados obtenidos. Este se trata de un programa de evaluación continuada que a largo plazo, conduce al desarrollo de una información que sirve para llevar un control de las tendencias que marca la evolución de los conocimientos y las habilidades de los alumnos de varios países, así como de diversos subgrupos poblacionales dentro de cada país.

Se analizaron los conocimientos, las habilidades, capacidades y otros atributos pertenecientes a los individuos que influyen de forma significativa en el bienestar personal, social y económico. Esta forma de enfocar el rendimiento educativo se hace necesaria si se desea fomentar que los centros de enseñanza y los sistemas educativos se centren en los desafíos que plantea la sociedad contemporánea.

La investigación se dividió en cuatro áreas:

- Competencia matemática: La capacidad que tiene un individuo de identificar y comprender el papel que desempeñan las matemáticas en el mundo, emitir juicios bien fundados y utilizar e implicarse en las matemáticas de una manera que satisfaga sus necesidades vitales como un ciudadano constructivo, comprometido y reflexivo.

\begin{tabular}{|c|l|l|l|l|l|l|}
\hline El individuo... & 1 & 2 & 3 & 4 & 5 & 6 \\
\hline $\begin{array}{c}\text { 1.1.- Realización de cuentas básicas sin } \\
\text { uso de tecnología... }\end{array}$ & & & & & & \\
\hline $\begin{array}{c}\text { 1.2.- Ante un cálculo de porcentajes } \\
\text { simples, responde... }\end{array}$ & & & & & & \\
\hline $\begin{array}{c}\text { 1.3.- Realiza conversiones con unidades } \\
\text { de medidas... }\end{array}$ & & & & & & \\
\hline $\begin{array}{c}\text { 1.4.- Conocimiento de los tipos de } \\
\text { triángulos existentes... }\end{array}$ & & & & & \\
\hline 1.5.- Distingue los distintos tipos de & & & & & & \\
\hline
\end{tabular}




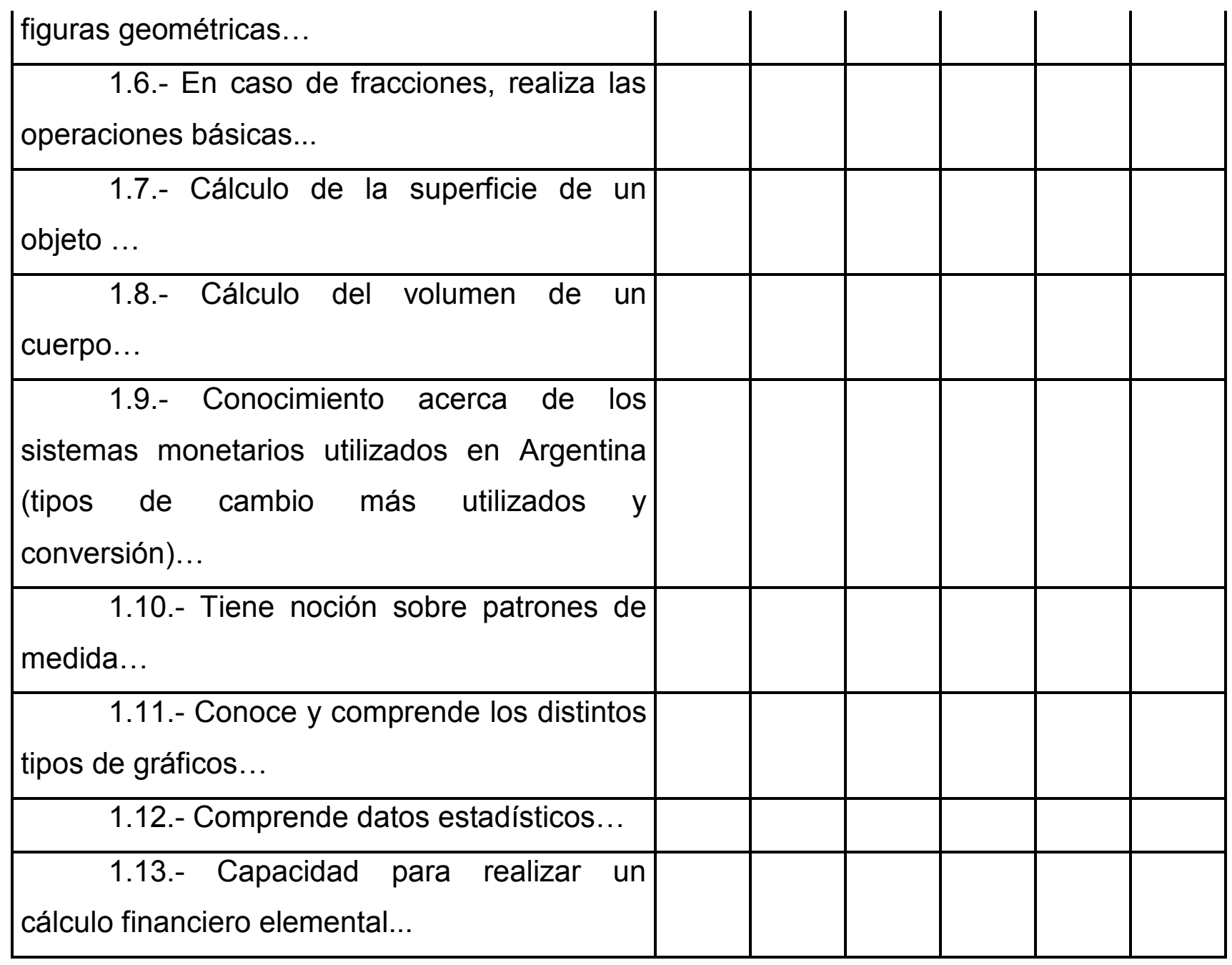

- Competencia lectora: La capacidad que tiene un individuo de comprender, utilizar y analizar textos escritos con objeto de alcanzar sus propias metas, desarrollar sus conocimientos y posibilidades de participar en la sociedad.

\begin{tabular}{|l|l|l|l|l|l|l|}
\hline El individuo... & 1 & 2 & 3 & 4 & 5 & 6 \\
\hline 2.1.- La comprensión de textos es... & & & & & & \\
\hline $2.2 .-$ La redacción de textos es... & & & & & & \\
\hline $2.3 .-$ La capacidad de lectura es... & & & & & & \\
\hline 2.4.- La caligrafía es... & & & & & & \\
\hline $2.5 .-$ La ortografía es... & & & & & & \\
\hline
\end{tabular}




\begin{tabular}{|c|c|l|l|l|l|l|}
\hline $\begin{array}{l}\text { 2.6.- Conocimientos sobre historia de } \\
\text { Argentina... }\end{array}$ & & & & \\
\hline 2.7.- El nivel de información sobre la & & & & & & \\
actualidad es... & & & & \\
\hline 2.8.- Conocimiento acerca de la división & & & & & & \\
de poderes en Argentina... \\
(interés por participar, opinar, etc.) es... El grado de responsabilidad cívica & & & & & & \\
\hline 2.10.- Capacidad para comprender & & & & & & \\
catálogos técnicos y manuales...
\end{tabular}

- Competencia científica: Hace referencia a los conocimientos científicos de un individuo y al uso de ese conocimiento para identificar problemas, adquirir nuevos conocimientos, explicar fenómenos científicos y extraer conclusiones basadas en pruebas sobre cuestiones relacionadas con la ciencia. Asimismo, comporta la comprensión de los rasgos característicos de la ciencia, entendida como un método del conocimiento y la investigación humanas, la percepción del modo en que la ciencia y la tecnología conforman el entorno material, intelectual y cultural, y la disposición a implicarse en asuntos relacionados con la ciencia y con las ideas de la ciencia como un ciudadano reflexivo.

\begin{tabular}{|c|l|l|l|l|l|l|}
\hline El individuo... & 1 & 2 & 3 & 4 & 5 & 6 \\
\hline $\begin{array}{l}\text { 3.1.- Conocimiento acerca de los estados de la } \\
\text { materia... }\end{array}$ & & & & & \\
\hline 3.2.- Conocimiento sobre primeros auxilios... & & & & & & \\
\hline 3.3.- Conocimiento sobre seguridad e higiene... & & & & & & \\
\hline 3.4.- Conocimiento sobre las principales & & & & & & \\
\hline
\end{tabular}


|enfermedades de Argentina...

3.5.- Conocimiento sobre los elementos de medición...

3.6.- Conocimiento de los tipos de energía existentes...

3.7.- Conocimiento sobre el sistema solar...

3.8.- Conocimiento sobre el uso de Internet para búsquedas de información relevante es...

3.9.- El uso de los programas básicos de computación es...

3.10.- Conocimiento sobre las principales vías de contagio del SIDA...

3.11.- Conocimiento acerca de los principales elementos de la economía (inflación, tasas de interés, sistema cambiario, canasta básica)...

3.12.- Conocimiento de la tasa de mortalidad (edad promedio en argentina)...

- $\quad$ Aptitudes personales: capacidad que tiene el individuo para poder realizar satisfactoriamente una tarea. Hay que destacar que la aptitud está estrechamente relacionada con la inteligencia y con las habilidades tanto innatas como adquiridas fruto de un proceso de aprendizaje.

\begin{tabular}{|l|l|l|l|l|l|l|}
\hline El individuo... & 1 & 2 & 3 & 4 & 5 & 6 \\
\hline 4.1.- Responsabilidad & & & & & & \\
\hline 4.2.- Creatividad & & & & & & \\
\hline 4.3.- Flexibilidad & & & & & & \\
\hline 4.4.- Puntualidad & & & & & & \\
\hline 4.5.- Respeto & & & & & \\
\hline
\end{tabular}




\begin{tabular}{|l|l|l|l|l|l|l|}
\hline \hline 4.6.- Compañerismo & & & & & & \\
\hline 4.7.- Valores & & & & & & \\
\hline 4.8.- Interés y motivación & & & & & & \\
\hline 4.9.- Presencia & & & & & & \\
\hline 4.10.- Le interesa trabajar en equipo & & & & & & \\
\hline 4.11.- Grado de adaptación al trabajo & & & & & & \\
\hline 4.12.- Grado de aprendizaje para comunicarse y & & & & & & \\
\hline 4.13.- Capacidad pus & & & & & & \\
transmitir sus conocimientos & & & & & & \\
\hline 4.14.- Desempeño en el cumplimiento de sus & & & & & & \\
tareas $\quad$ 4.15.- Orden y prolijidad & & & & & & \\
\hline 4.16.- Capacidad de resolución de problemas & & & & & & \\
\hline y comunicación del mismo & & & & & & \\
\hline $4.17 .-$ Capacidad de negociación & & & & & & \\
\hline 4.18.- Uso de herramientas apropiadas & & & & & & \\
\hline
\end{tabular}

Las encuestas se realizaron a dos grupos de paneles de expertos, un grupo conformado por profesores de instituciones de enseñanza superior, ya sea universidades o escuelas terciarias; y otro compuesto por empresarios con gran conocimiento acerca de la inserción de los egresados al mundo laboral y el nivel educativo que presentan. La encuesta a este último panel de expertos es más reducida, debido a que se pregunta acerca de los conocimientos generales, no tan específicos como lo es en el caso de los profesores.

Para ello, se le entregó a cada uno de los especialistas una encuesta donde debían contestar los interrogantes acerca del nivel educativo. Los expertos debían marcar la respuesta que consideraba que representa su opinión al respecto. 
Las distintas opciones de respuestas presentes en la encuesta son las siguientes:

\begin{tabular}{|c|c|c|c|c|c|}
\hline Mal & Regular & Bien & Muy Bien & Excelente & NS/NC \\
\hline $\mathbf{1}$ & $\mathbf{2}$ & $\mathbf{3}$ & $\mathbf{4}$ & $\mathbf{5}$ & $\mathbf{6}$ \\
\hline $\begin{array}{c}\text { (calificación } \\
0 \text { a 2) }\end{array}$ & $\begin{array}{c}\text { (calificació } \\
\text { n más de 2 2 } \\
\text { hasta 4) }\end{array}$ & $\begin{array}{c}\text { (calificación } \\
\text { más de 4 } \\
\text { hasta 6) }\end{array}$ & $\begin{array}{c}\text { (calificación } \\
\text { más de 6 } \\
\text { hasta 8) }\end{array}$ & $\begin{array}{c}\text { (calificación } \\
\text { más de 8 } \\
\text { hasta 10) }\end{array}$ & $\begin{array}{c}\text { (No sabe } \\
\text { / No } \\
\text { contesta) }\end{array}$ \\
\hline
\end{tabular}

La encuesta, además de estar dividida en cuatro áreas, y en dos grupos de paneles de expertos (docentes y empresarios), se realizó en la región de La Plata, Berisso y Ensenada, lo cual permitió la comparación de los resultados de ambos paneles, y a su vez con los resultados de la región.

\subsection{Técnicas de análisis}

Con los datos obtenidos de la Dirección General de Cultura y Educación de la provincia de Buenos Aires se generaron coeficientes indicativos del grado de desempeño de los alumnos del nivel secundario. Tales indicadores son la Matrícula bruta combinada, Sobre-edad escolar, Alfabetización y Analfabetismo.

Por otra parte, a las encuestas al panel de expertos se les aplicó un análisis estadístico univariado. Una vez obtenidos los indicadores pertinentes, los resultados fueron volcados en tablas y gráficos.

Los resultados de la encuesta fueron contabilizados y volcados en una tabla con el siguiente formato: 


\begin{tabular}{|l|c|c|c|c|c|c|c|c|}
\hline \hline \multicolumn{10}{c|}{ Área } \\
\hline & Mal & Regular & Bien & Muy Bien & Excelente & NS/NC & & \\
\hline & 1 & 2 & 3 & 4 & 5 & 6 & Total & $\begin{array}{c}\text { Saldo de } \\
\text { Respuesta }\end{array}$ \\
\hline ¿El alumno...? & & & & & & & & \\
\hline Total & & & & & & & & \\
\hline Porcentaje & & & & & & & & \\
\hline
\end{tabular}

Luego se calculó el "Saldo de respuesta" de cada pregunta realizada, en función de la fórmula siguiente:

Saldo de Respuesta $=\frac{\sum_{i=1}^{n} F_{i} \cdot i}{\sum_{i=1}^{n} F_{i}}$

Donde:

$\mathrm{F}_{\mathrm{i}}=$ Es la cantidad de respuestas (frecuencias) de cada ítem para cada valor de las opciones de respuesta

$\mathrm{i}=$ Es el valor de cada uno de las opciones de respuesta

${ }^{7}$ El cálculo de ese promedio sigue idéntica metodología que la del Global Competitiveness Index del World Economic Forum para el procesamiento de la Executive Opinion Survey en que se pregunta sobre una serie de cuestiones y se solicita que se califique en un rango que va de 1 a 7 en que 1 es lo peor y 7 lo mejor y que luego se sintetiza a través de un promedio. Xavier Sala-iMartin (Cabrera de Mar, Barcelona, España, 1963), es un economista de origen español y de nacionalidad estadounidense, articulista, catedrático de economía en la Universidad de Columbia y Asesor Jefe ("Chief Advisor") del World Economic Forum donde, además, es coautor del Global Competitiveness Report y el padre intelectual del Global Competitiveness Index que ordena a más de 140 países del mundo según su competitividad.

Cabe aclarar que se utiliza el término de "Saldos" en vez de promedios (o medias) atento que estos términos son de frecuente uso cuando se trabaja con variables cuantitativas. 
El cálculo consiste en multiplicar los componentes de las cantidades de respuestas (frecuencias) por el tipo de respuesta dado y luego sumar esos productos. Posteriormente a ese número se lo divide por la sumatoria de la cantidad de respuestas.

Tanto en el cálculo del saldo de respuesta y del porcentaje, no se tuvo en cuenta la cantidad de respuestas obtenidas del tipo "No sabe/No contesta" ya que se busca evaluar el conocimiento que presenta el alumno, con el mínimo error o desvío posible.

A efectos de realizar la comparación con los datos de la última publicación disponible de PISA, fue necesario realizar un re-escalamiento de variables, toda vez que PISA utiliza una escala que va de 0 a 800 puntos y en la encuesta se usó un rango de 1 a 5 .

Fue necesario establecer la ecuación de la recta de transformación en función de los ejes cartesianos de los extremos.

\begin{tabular}{|l|c|c|}
\hline & Encuesta & PISA \\
\hline Mínimo & 1 & 0 \\
\hline Máximo & 5 & 800 \\
\hline
\end{tabular}

Los extremos conforman los pares siguientes:

$$
\begin{aligned}
& \left(x_{0} ; y_{0}\right)=(1 ; 0) \\
& \left(x_{1} ; y_{1}\right)=(5 ; 800)
\end{aligned}
$$

De tal modo, la pendiente de la recta de transformación "m" es:

$$
m=\frac{\left(y_{1}-y_{0}\right)}{\left(x_{1}-x_{0}\right)}=\frac{(800-0)}{(5-1)}=200
$$

Y la ordenada al origen "b" es: 
$b=-m \cdot x_{0}+y_{0}=-200 \cdot 1+0=-200$

Y la ecuación de la recta de transformación es:

$y=m \cdot x+b=200 \cdot x-200=200 \cdot(x-1)$

7. Resultados de la Investigación

\subsection{Datos de Fuente Secundaria}

\section{Berisso}

Tasa de Matricula Bruta Combinada $=$

$\frac{\text { Cantidad de alumnas matriculadas }}{\text { Tatal de población en la edad conrespondiente }} \times 100$

Tasa de Matricula Bruta Combinada $=(9.786 / 10.313) \times 100=94,89 \%$

Tasa de Alfabetización $=\frac{\text { Cantidad de personas que reportan leer y escribir }{ }^{(1)}}{\text { Cantidad de persomas }(2)} \times 100$

Tasa de Alfabetización $=(10.186 / 10.313) \times 100=98,77 \%$

Tasa de Sobre-edad escolar $=$

Cantidad de alumnos mayores a la edad correspondiente

Cantidad de matriculadas en el año $\quad x 100$

Tasa de Sobre-edad escolar $=(2.051 / 7.560) \times 100=27,13 \%$ 
Tasa de Analfabetismo $=\frac{\text { Cantidlad de alumnos que reportar no leer mi escribirr }}{\text { Total de alumnos }} \cdot 100$

Tasa de Analfabetismo $=(127 / 10.313) \times 100=1,23 \%$

\section{Comparación con la región}

\begin{tabular}{|l|r|r|r|r|}
\hline \multicolumn{4}{|c|}{ Tasa de Matriculación Bruta Combinada } \\
\hline & \multicolumn{2}{|c|}{$\mathbf{2 0 1 0}$} & \multicolumn{2}{|c|}{$\mathbf{2 0 1 1}$} \\
\cline { 2 - 5 } & Región I & \multicolumn{1}{|c|}{ Berisso } & Región I & Berisso \\
\hline Cant. de alumnos matriculados & 65.154 & 10.582 & 71.867 & 9.786 \\
\hline Total de población en la edad correspondiente & 84.886 & 10.366 & 82.922 & 10.313 \\
\hline Tasa de Matriculación Bruta Combinada & $\mathbf{7 6 , 7 5 \%}$ & $\mathbf{1 0 2 , 0 8 \%}$ * & $\mathbf{8 6 , 6 7 \%}$ & $\mathbf{9 4 , 8 9 \%}$ \\
\hline
\end{tabular}

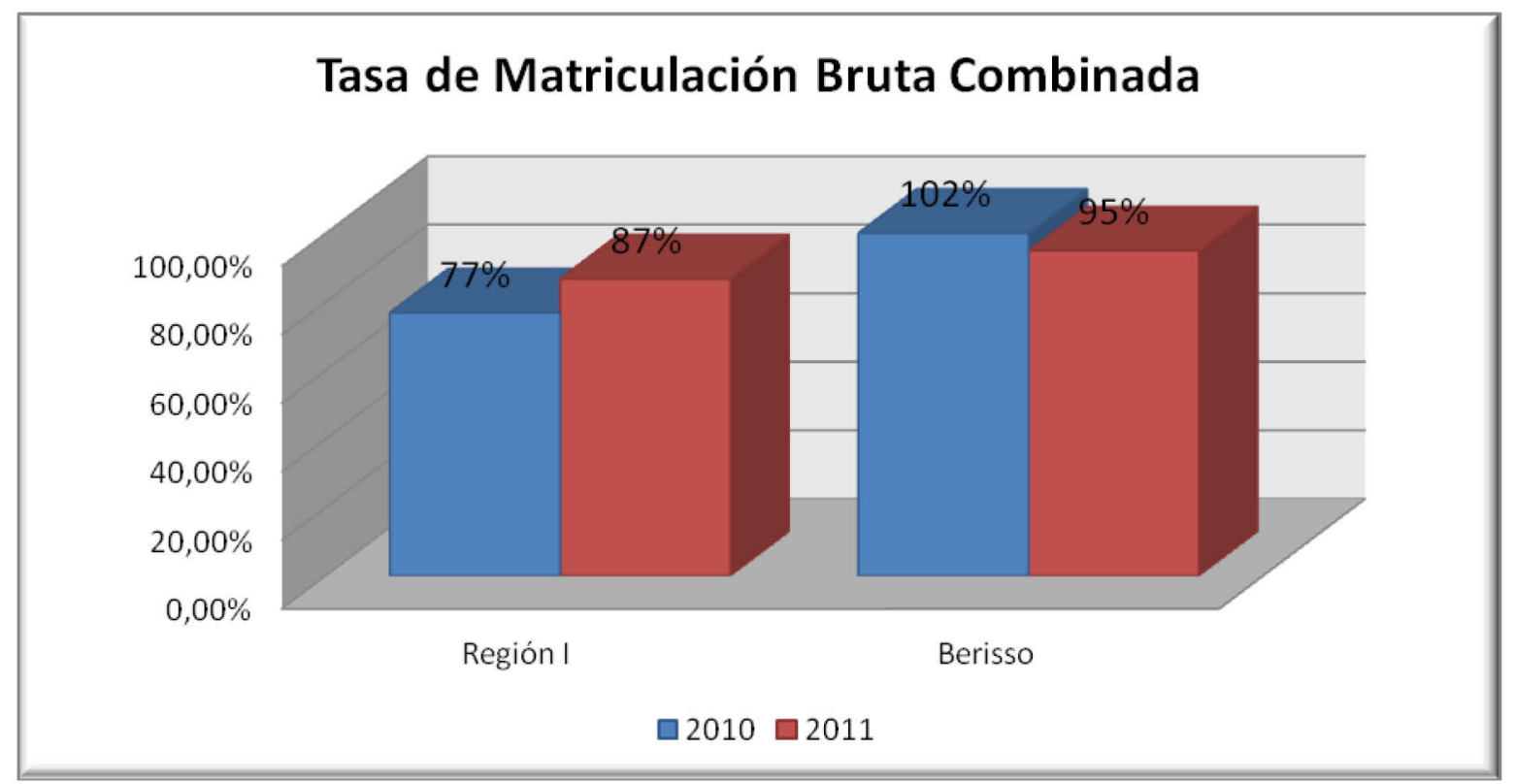

Fuente: Elaboración propia

Región I, está comprendida solo por La Plata, Berisso y Ensenada

El porcentaje 102,08 en la Tasa de Matriculación Bruta Combinada se debe a que en el 2010 se inscribieron mayor cantidad de alumnos (con edad correspondiente y no) que el total de la población con la edad correspondiente. 


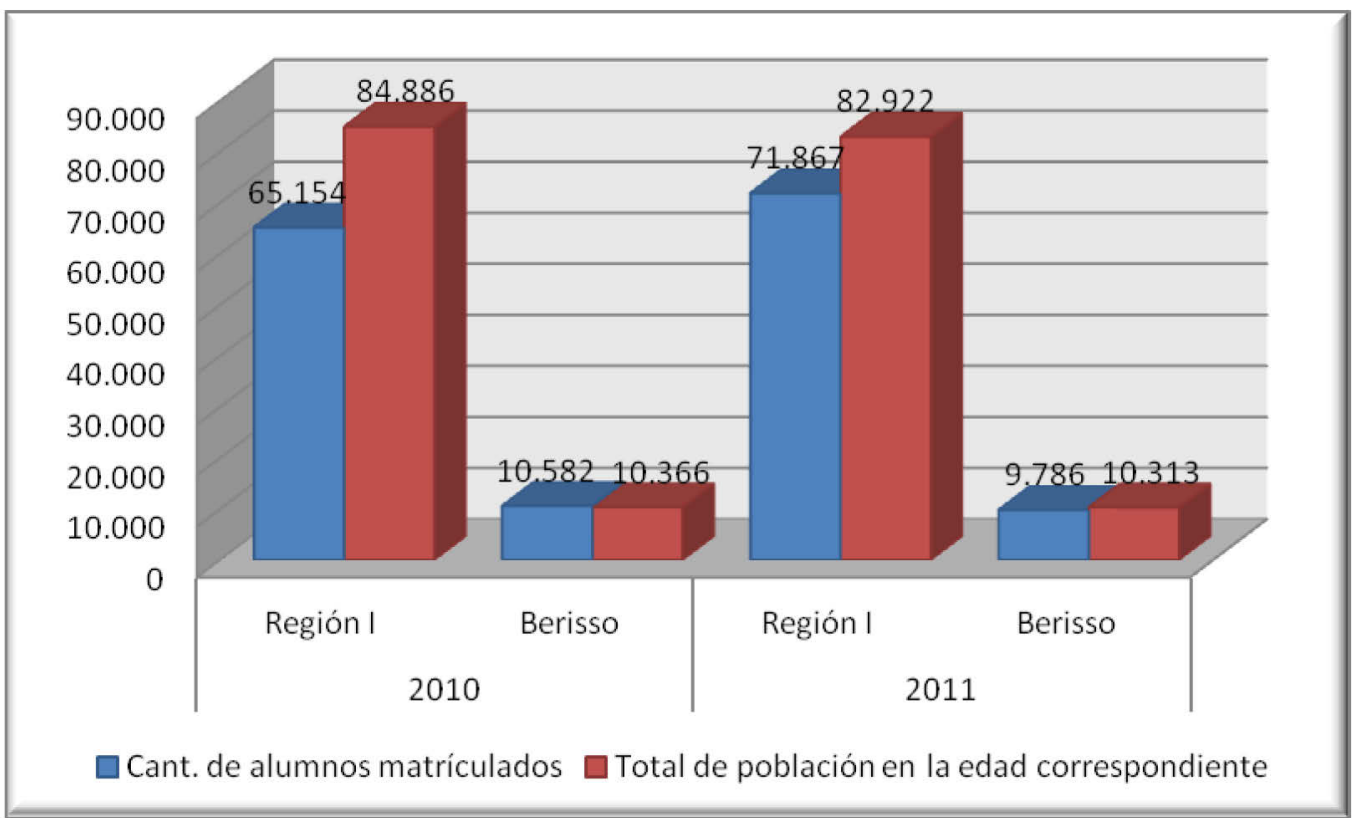

Fuente: Elaboración propia

\begin{tabular}{|l|r|r|r|r|}
\hline \multicolumn{4}{|c|}{ Tasa de Sobre-edad escolar } \\
\hline & \multicolumn{2}{|c|}{$\mathbf{2 0 1 0}$} & \multicolumn{2}{|c|}{$\mathbf{2 0 1 1}$} \\
\cline { 2 - 5 } & Región I & Berisso & Región I & Berisso \\
\hline Cant. de alumnos mayores a la edad correspondiente & 18.314 & 2.696 & 13.870 & 2.051 \\
\hline Cant. de matriculados en el curso & 45.876 & 7.281 & 52.934 & 7.560 \\
\hline Tasa de Sobre-edad Escolar & $39,92 \%$ & $\mathbf{3 7 , 0 3 \%}$ & $\mathbf{2 6 , 2 0 \%}$ & $\mathbf{2 7 , 1 3 \%}$ \\
\hline
\end{tabular}

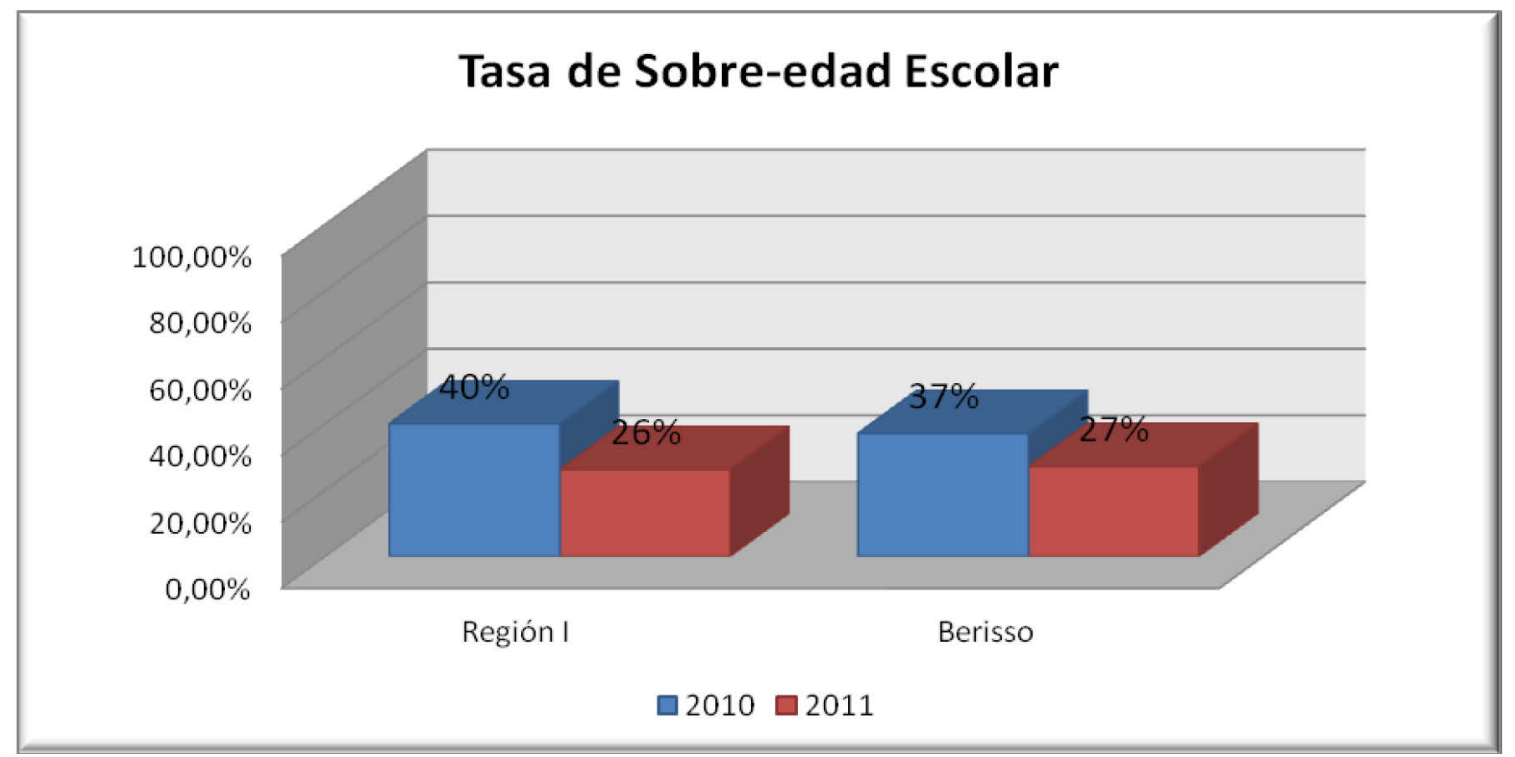

Fuente: Elaboración propia 

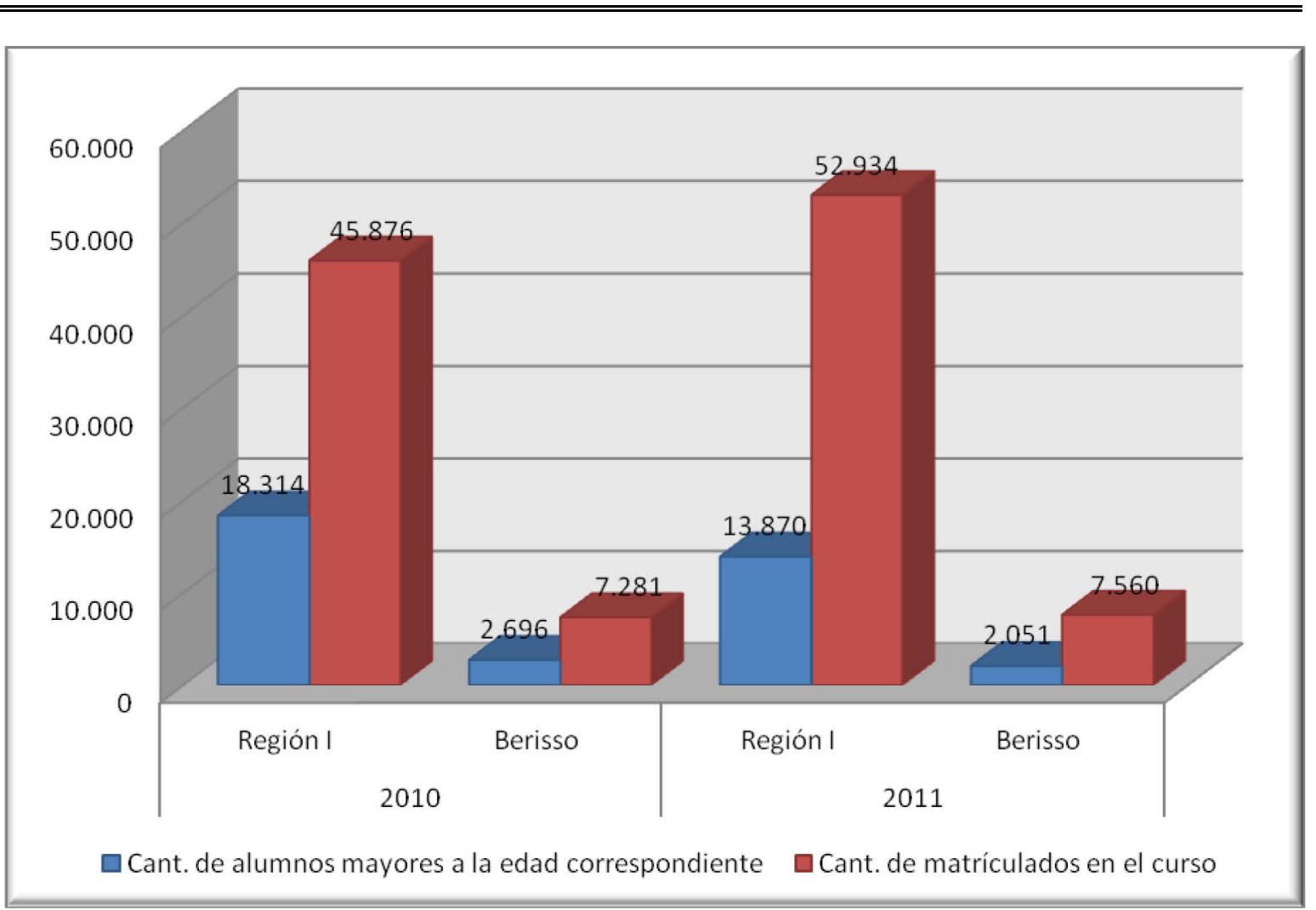

Fuente: Elaboración propia

Tasa de Alfabetización

\begin{tabular}{|l|r|r|r|r|}
\hline & \multicolumn{2}{|c|}{2010} & \multicolumn{2}{|c|}{2011} \\
\cline { 2 - 5 } & Región I & Berisso & Región I & Berisso \\
\hline Cantidad de personas que reportan leer y escribir & 83.856 & 10.236 & 81.923 & 10.186 \\
\hline Total de población en la edad correspondiente & 84.886 & 10.366 & 82.922 & 10.313 \\
\hline Tasa de Alfabetización & $\mathbf{9 8 , 7 9 \%}$ & $\mathbf{9 8 , 7 5 \%}$ & $\mathbf{9 8 , 8 0 \%}$ & $\mathbf{9 8 , 7 7 \%}$ \\
\hline
\end{tabular}




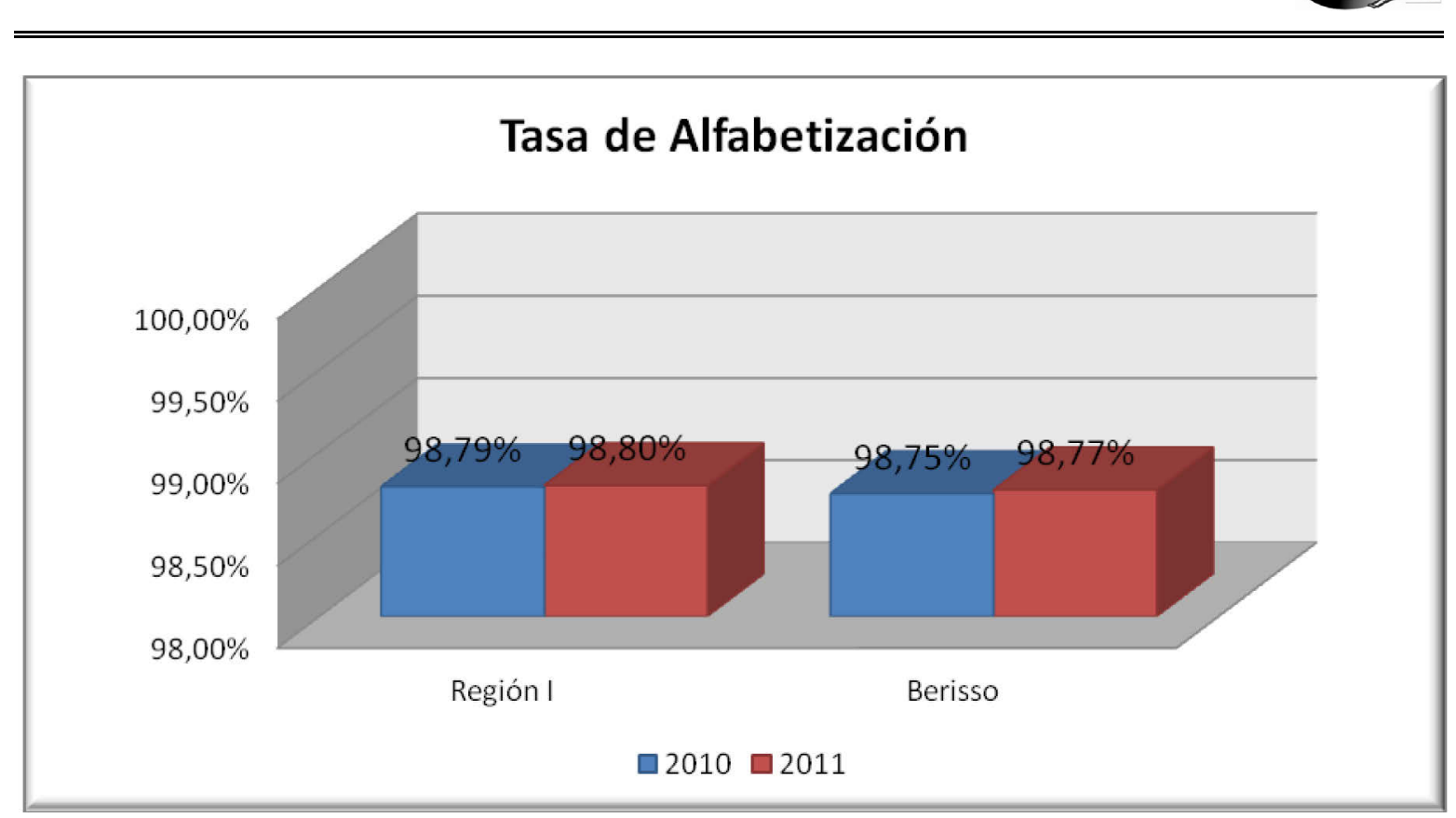

Fuente: Elaboración propia

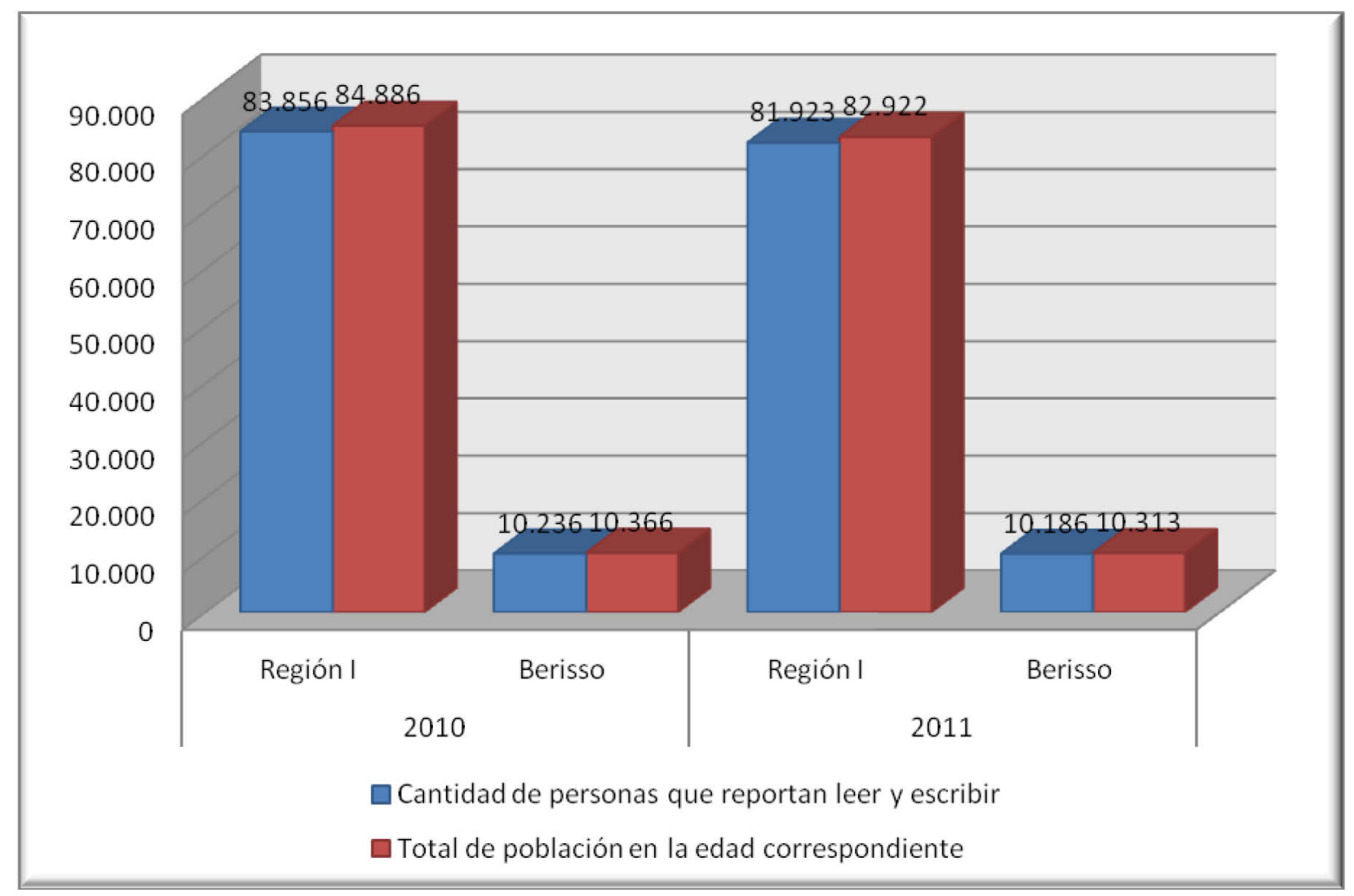

Fuente: Elaboración propia 


\begin{tabular}{|l|r|r|r|r|}
\hline \multicolumn{4}{|c|}{ Tasa de Analfabetismo } \\
\hline \multicolumn{2}{|c|}{$\mathbf{2 0 1 0}$} & \multicolumn{2}{|c|}{$\mathbf{2 0 1 1}$} \\
\cline { 2 - 6 } & Región I & Berisso & Región I & Berisso \\
\hline Cantidad de personas que reportan no leer, ni escribir & 1.030 & 130 & 999 & 127 \\
\hline Total de población en la edad correspondiente & 84.886 & 10.366 & 82.922 & 10.313 \\
\hline Tasa de Analfabetismo & $\mathbf{1 , 2 1} \%$ & $\mathbf{1 , 2 5} \%$ & $\mathbf{1 , 2 0} \%$ & $\mathbf{1 , 2 3 \%}$ \\
\hline
\end{tabular}

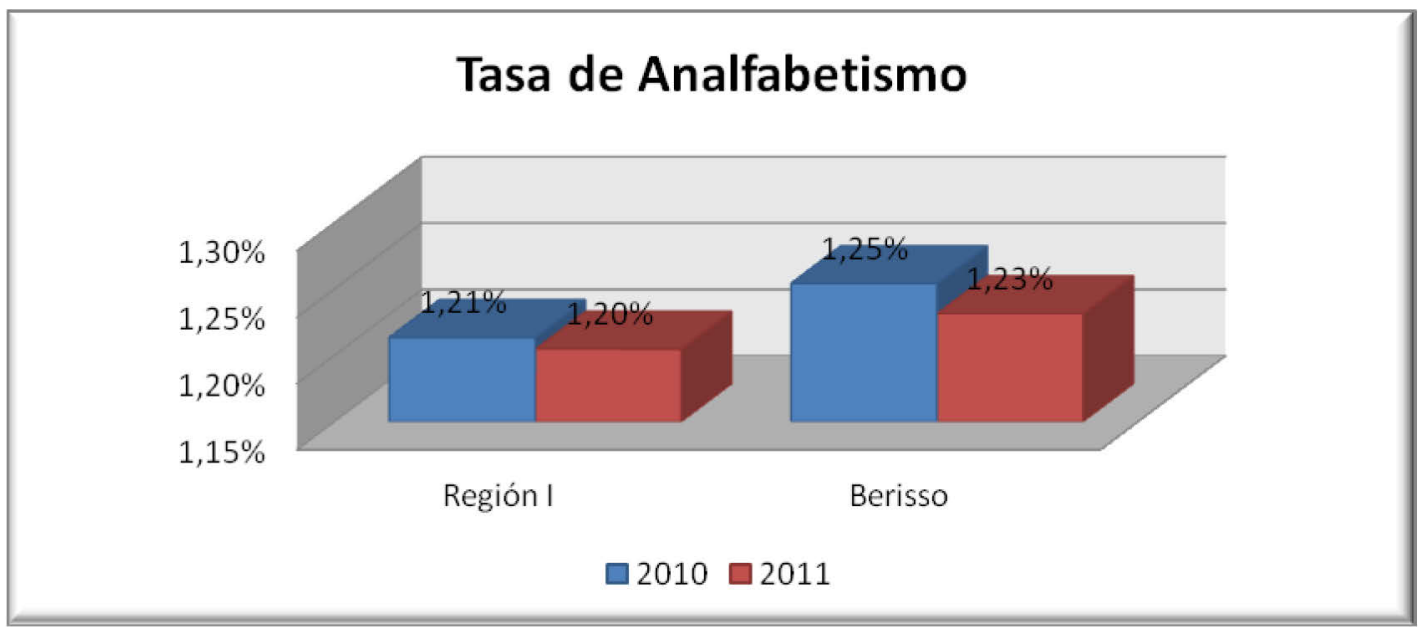

Fuente: Elaboración propia

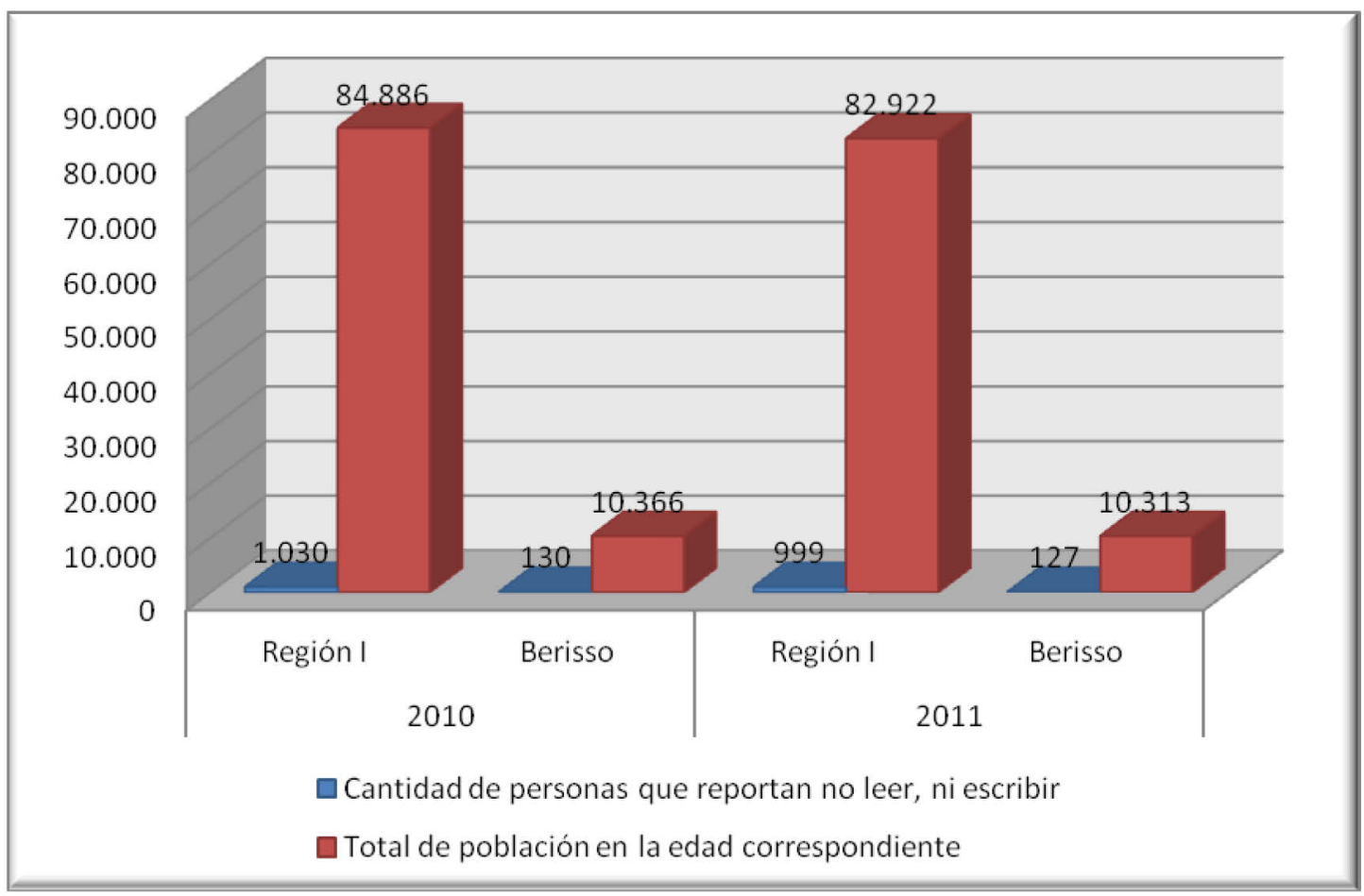

Fuente: Elaboración propia

Autor: Ing. Lucas F. Gambino 


\subsection{Datos de Fuente Primaria}

\subsubsection{Docentes}

Área Matemáticas

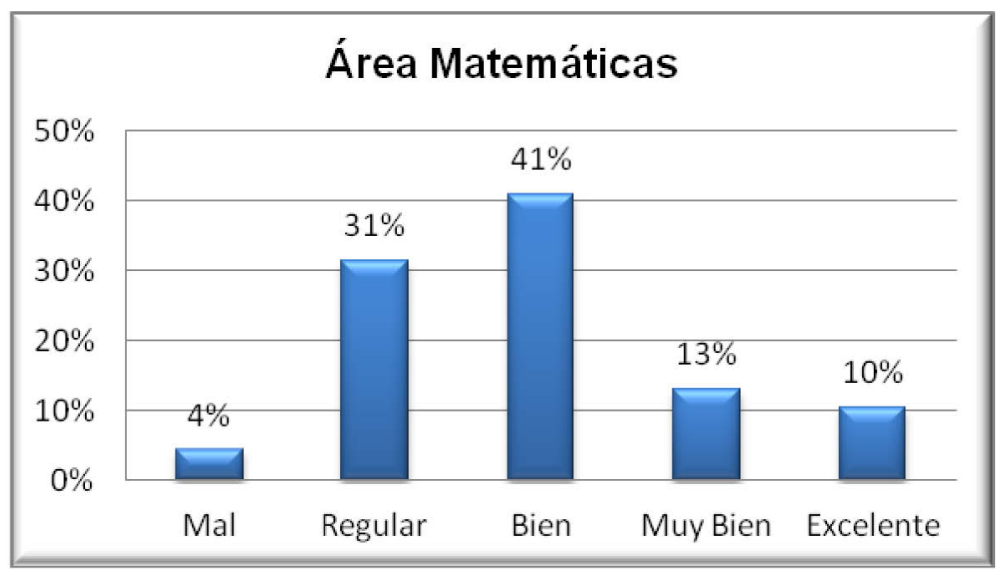

Fuente: Elaboración propia

En el gráfico se refleja que la aglomeración de datos se encuentra entre Regular (31\%) y Bien (41\%) obteniendo más del $70 \%$ de la evaluación dada por el panel de expertos docentes, le siguen Muy Bien (13\%), Excelente (10\%) y Mal $(4 \%)$.

Los puntos donde obtuvieron mayor puntuación son en: conocimiento $y$ comprensión de los distintos tipos de gráficos, conocimiento de los distintos tipos de figuras geométricas, y conocimiento de los tipos de triángulos existentes. En cambio, los puntos más bajos se dieron en la realización de un cálculo financiero elemental y en la capacidad para calcular el volumen de un cuerpo. 


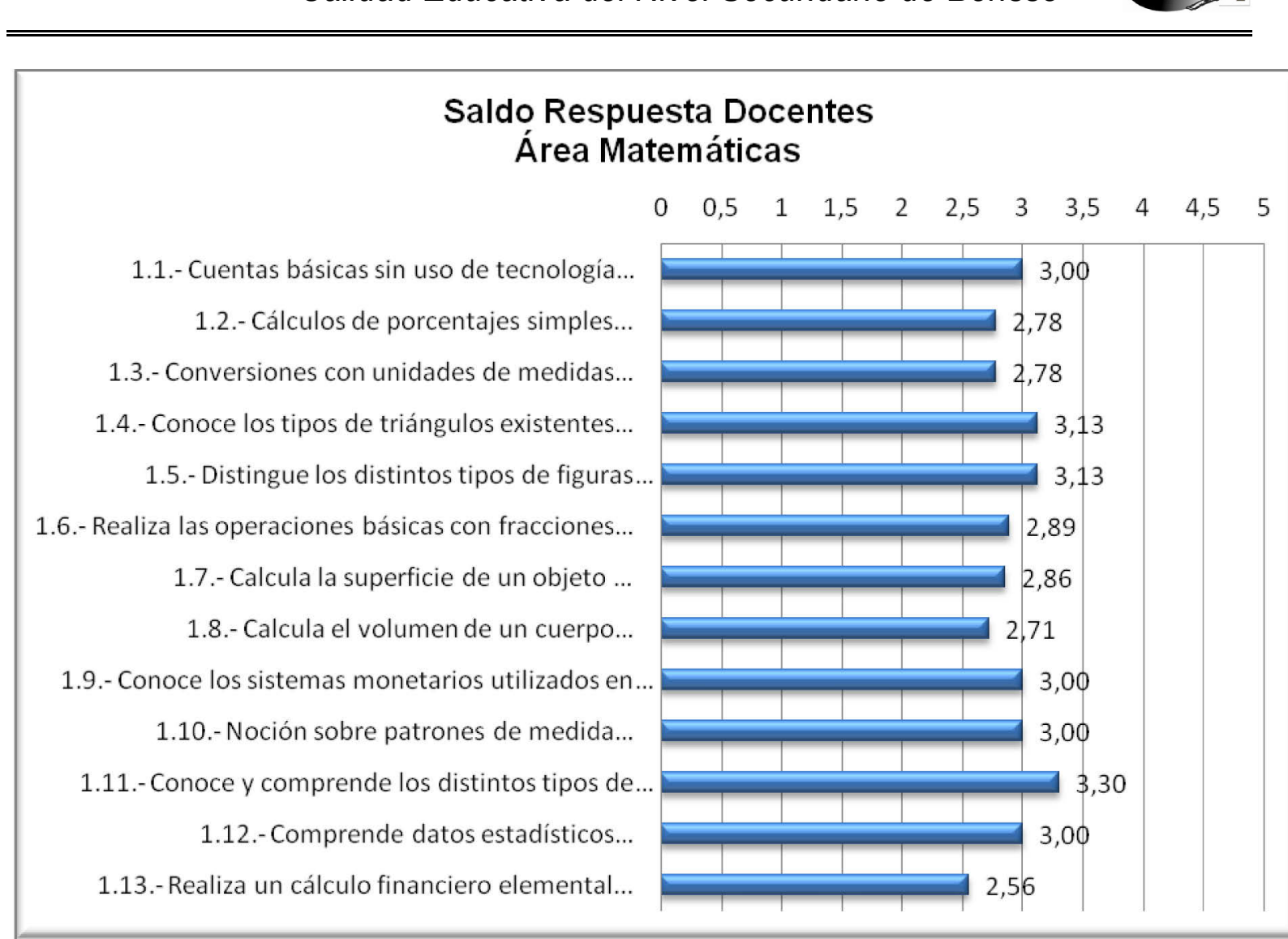

Fuente: Elaboración propia

\section{$\underline{\text { Área Lengua }}$}

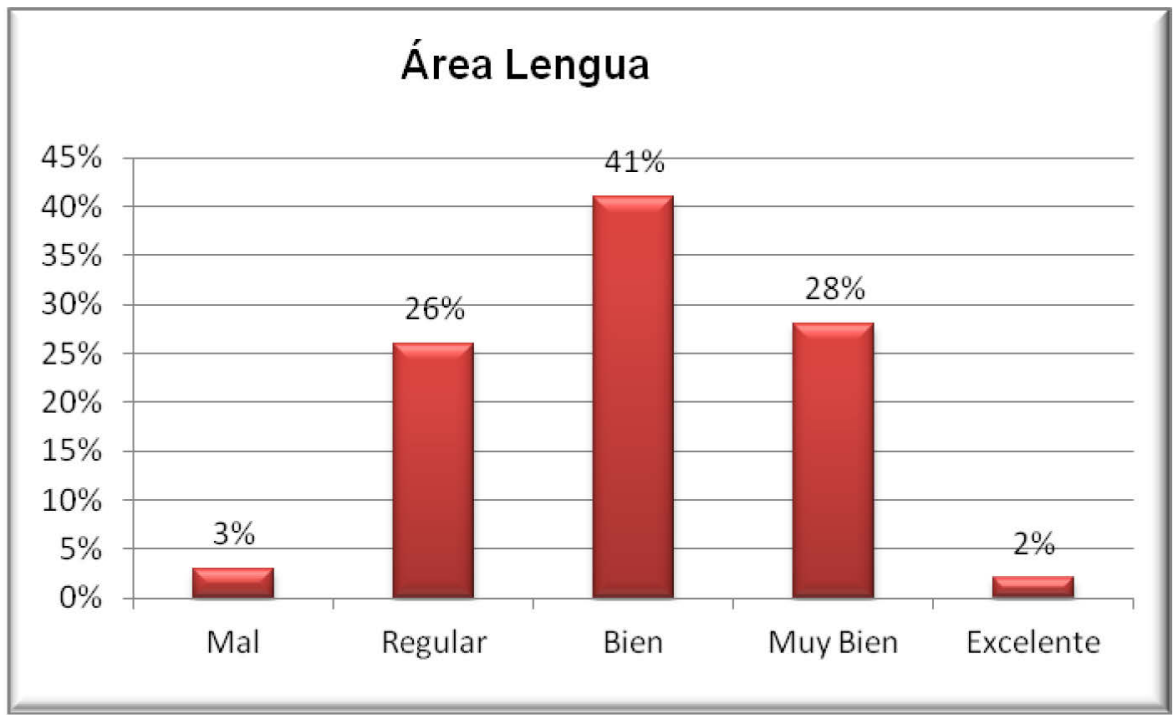

Fuente: Elaboración propia 
En el Área Lengua, los resultados la respuestas recaen en su mayoría en Bien (41\%), Muy Bien (28\%) y Regular (26\%) obteniendo el $95 \%$ de las respuestas de los expertos docentes.

Según los docentes, los puntos donde más se destacan los egresados, son la caligrafía, exposición de una idea en forma oral/escrita y en la organización y jerarquización conceptos, mientras que los puntos más defavorables se encuentran la ortografía y la redacción de un texto.

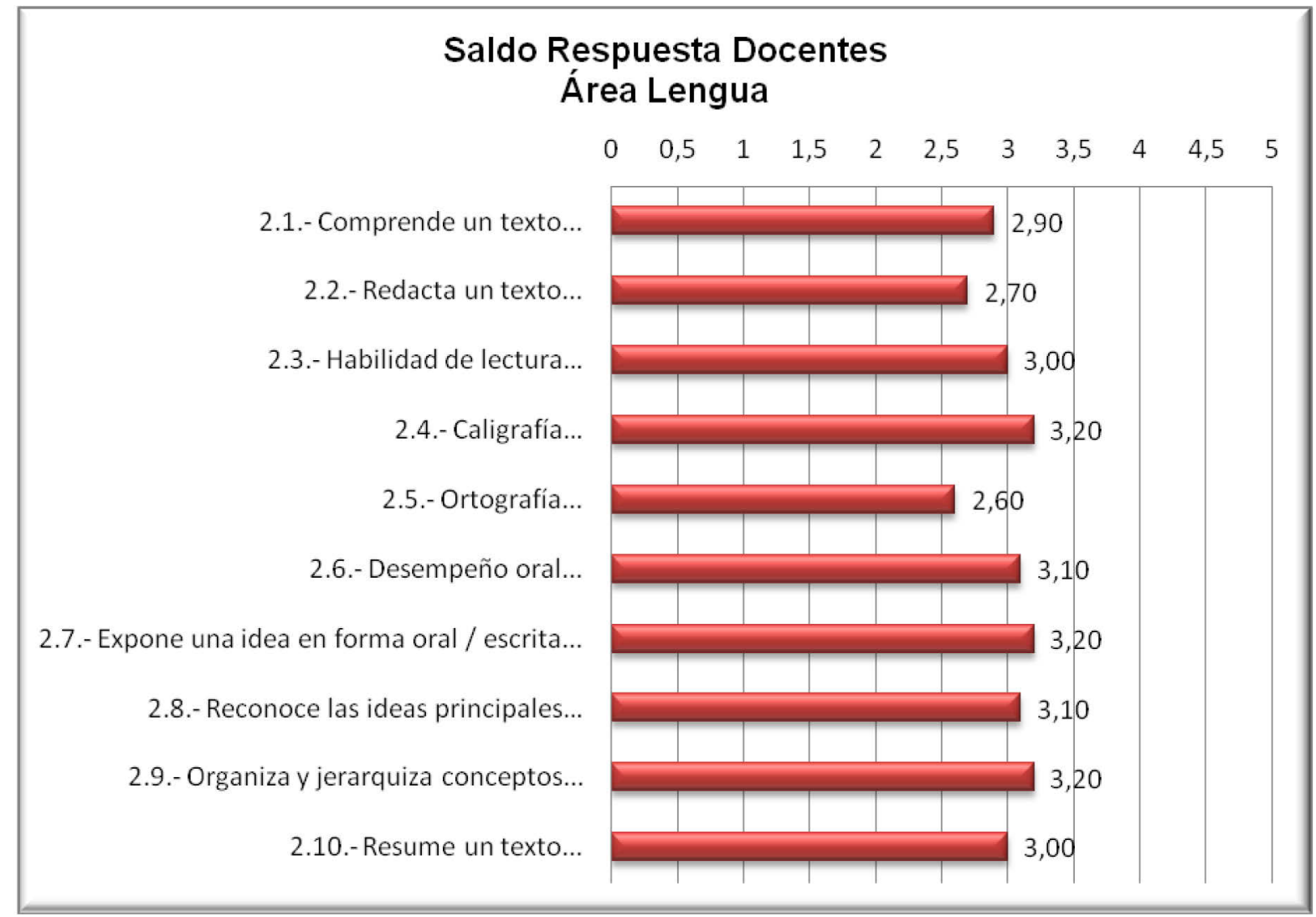

Fuente: Elaboración propia 


\section{Área Ciencias}

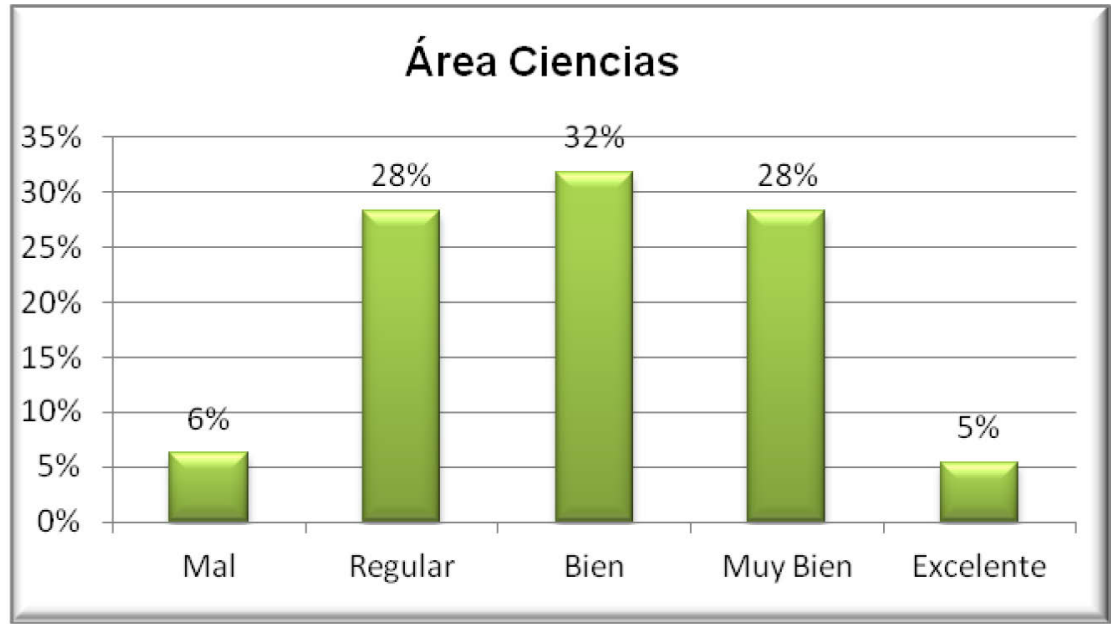

Fuente: Elaboración propia

En Ciencias, las respuestas se centraron en Bien (32\%), la paridad entre Regular (28\%) y Muy Bien (28\%) obteniendo más del $75 \%$ de las evaluaciones.

Los puntos más destacados fueron los relacionados con la informática como ser el uso de internet para búsquedas y uso de los programas de computación. A diferencia de esto, los temas de menor conocimiento son el conocimiento acerca de los elementos de la economía y la tasa de mortalidad de Argentina. 


\section{Saldo Respuesta Docentes Área Ciencias}

3.1.- Conoce los estados de la materia...

3.2.- Sabe sobre primeros auxilios...

3.3.- Sabe sobre seguridad e higiene...

3.4.- Conoce las principales enfermedades de

3.5.- Conoce los elementos de medición..

3.6.- Conoce los tipos de energía existentes...

3.7.- Sabe sobre el sistema solar...

3.8.- Uso de Internet para búsquedas...

3.9.- Usa los programas de computación...

3.10.- Conoce sobre las vías de contagio del SIDA...

3.11.- Conoce acerca de los elementos de la...

3.12.- Conoce la tasa de mortalidad en Argentina...

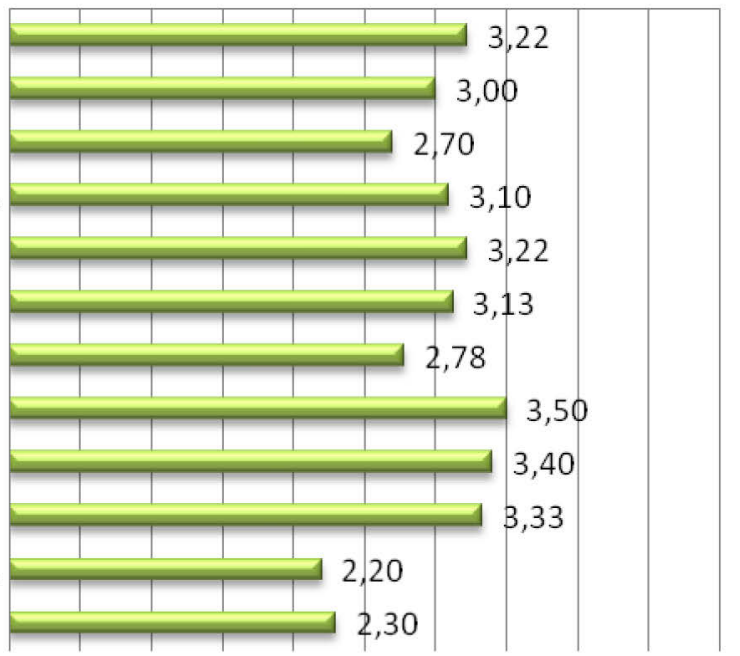

Fuente: Elaboración propia

\section{$\underline{\text { Aptitudes Personales }}$}

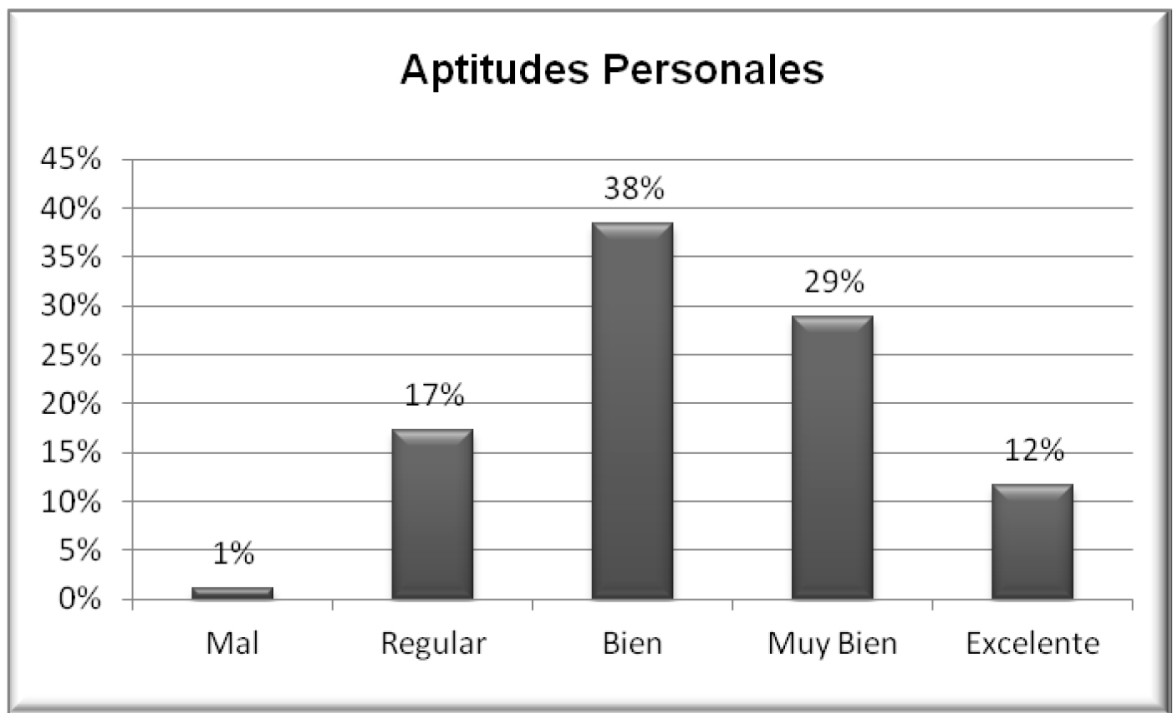

Fuente: Elaboración propia

En la opinión del panel de expertos sobre las aptitudes que presentan los egresados, se observa que un gran porcentaje de las respuestas se encuentran 
centradas entre las Bien (38\%) y las Muy Bien (29\%) obteniendo más del $65 \%$ del total de las respuestas. Luego le siguen Regular (17\%), Excelente (12\%) y Mal (1\%).

Los puntos más destacados fueron el compañerismo, respeto y flexibilidad, mientras que los puntos donde más dificultades tienen los egresados son la Capacidad de resolución de problemas y su comunicación y la Capacidad para comunicarse y transmitir sus conocimientos.

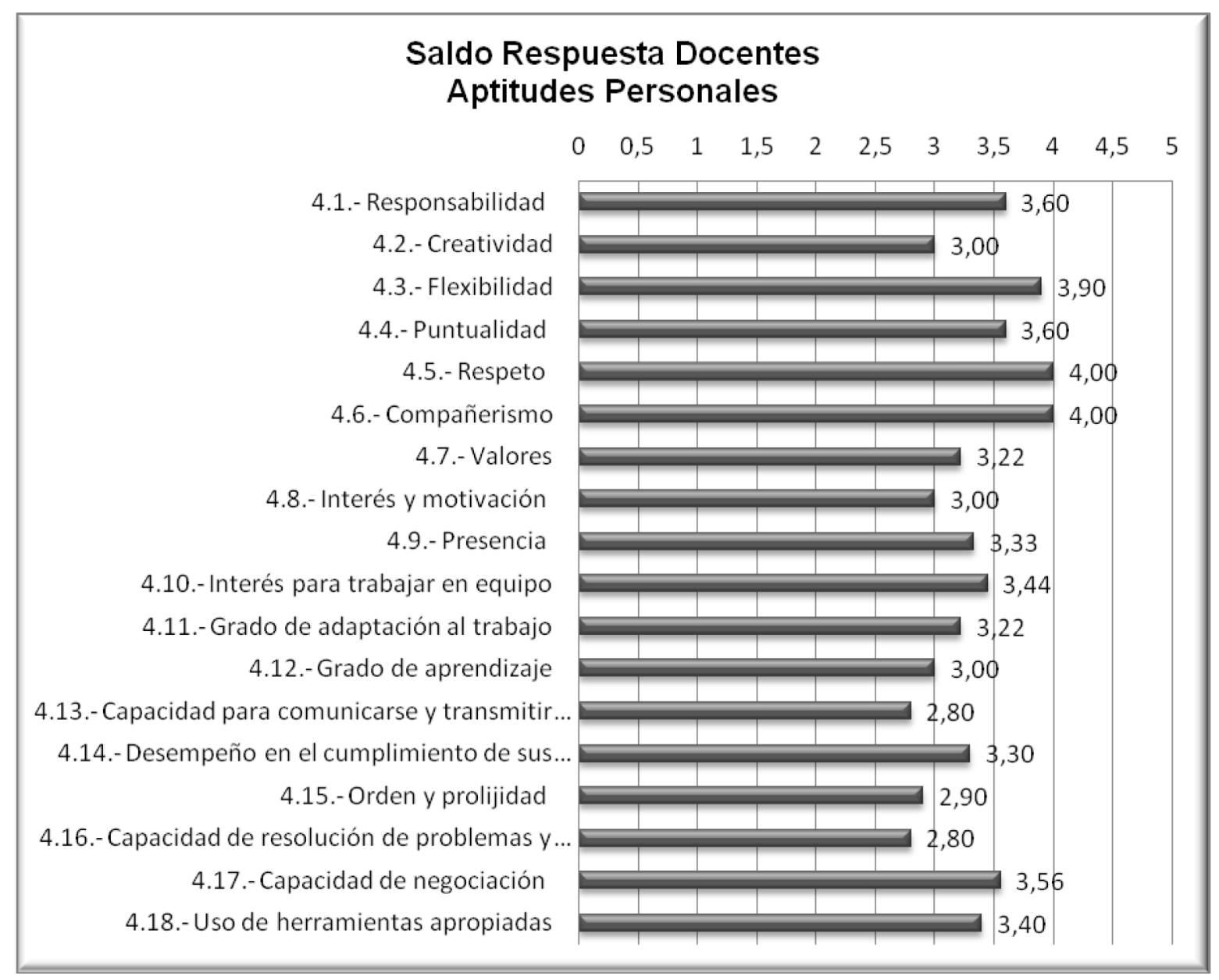

Fuente: Elaboración propia

Autor: Ing. Lucas F. Gambino

Director: Dr. Aldo H. Alonso 


\section{Calificación Global de Docentes}

En la calificación global del panel de expertos compuesto por docentes, es posible apreciar los resultados totales, es decir la sumatoria de todas las áreas evaluadas.

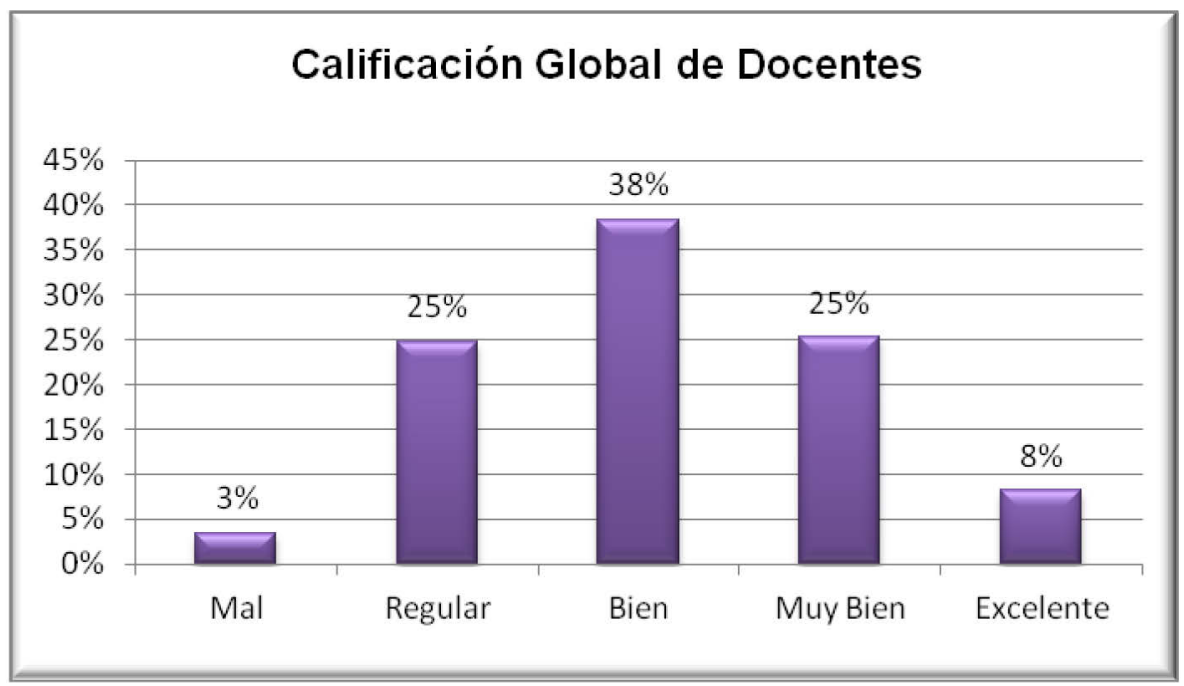

Fuente: Elaboración propia

En el gráfico se aprecia que la respuesta con mayor porcentaje es Bien (37\%), seguido por la paridad entre Regular y Muy Bien con $(25 \%)$, luego le siguen Excelente (8\%) y por último Mal (3\%). 


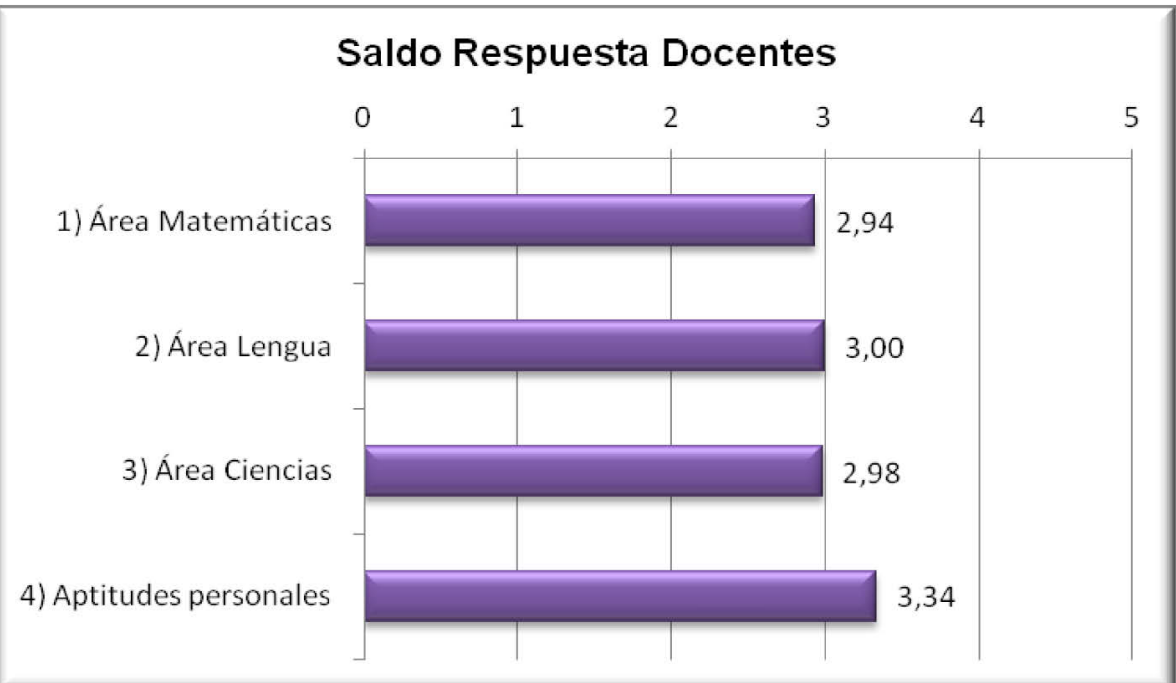

Fuente: Elaboración propia

En el área que los egresados presentaron mejores resultados fue en las aptitudes personales, con un saldo de respuesta de 3,34, seguido por Lengua, con 3, Ciencias con 2,98 y por último Matemáticas con 2,94, sin existir mucha diferencia entre estas tres últimas.

\subsubsection{Empresarios}

\section{Área Matemáticas}

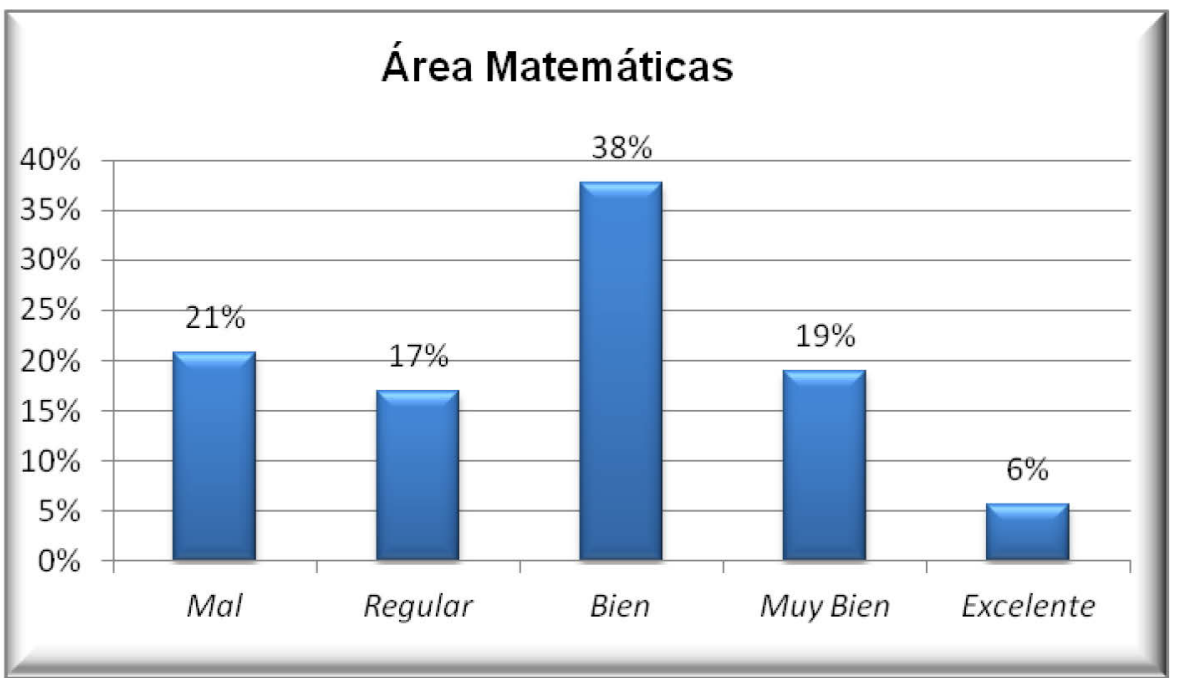

Fuente: Elaboración propia

Autor: Ing. Lucas F. Gambino

Director: Dr. Aldo H. Alonso 
El panel de expertos compuesto por empresarios, opinó que en el área de Matemáticas los egresados, en su mayoría, presentan un nivel Bien (38\%). Luego, en menor porcentaje, los conocimientos son Mal (21\%), Muy Bien (19\%), Regular (17\%) y por último Excelente (6\%).

Los puntos más relevantes en esta área, son la realización de cuentas básicas sin uso de tecnología y la noción sobre patrones de medida. Por otra parte las respuestas con menor puntaje son el conocimiento y comprensión de los distintos tipos de gráficos y la realización de cálculos de porcentajes.

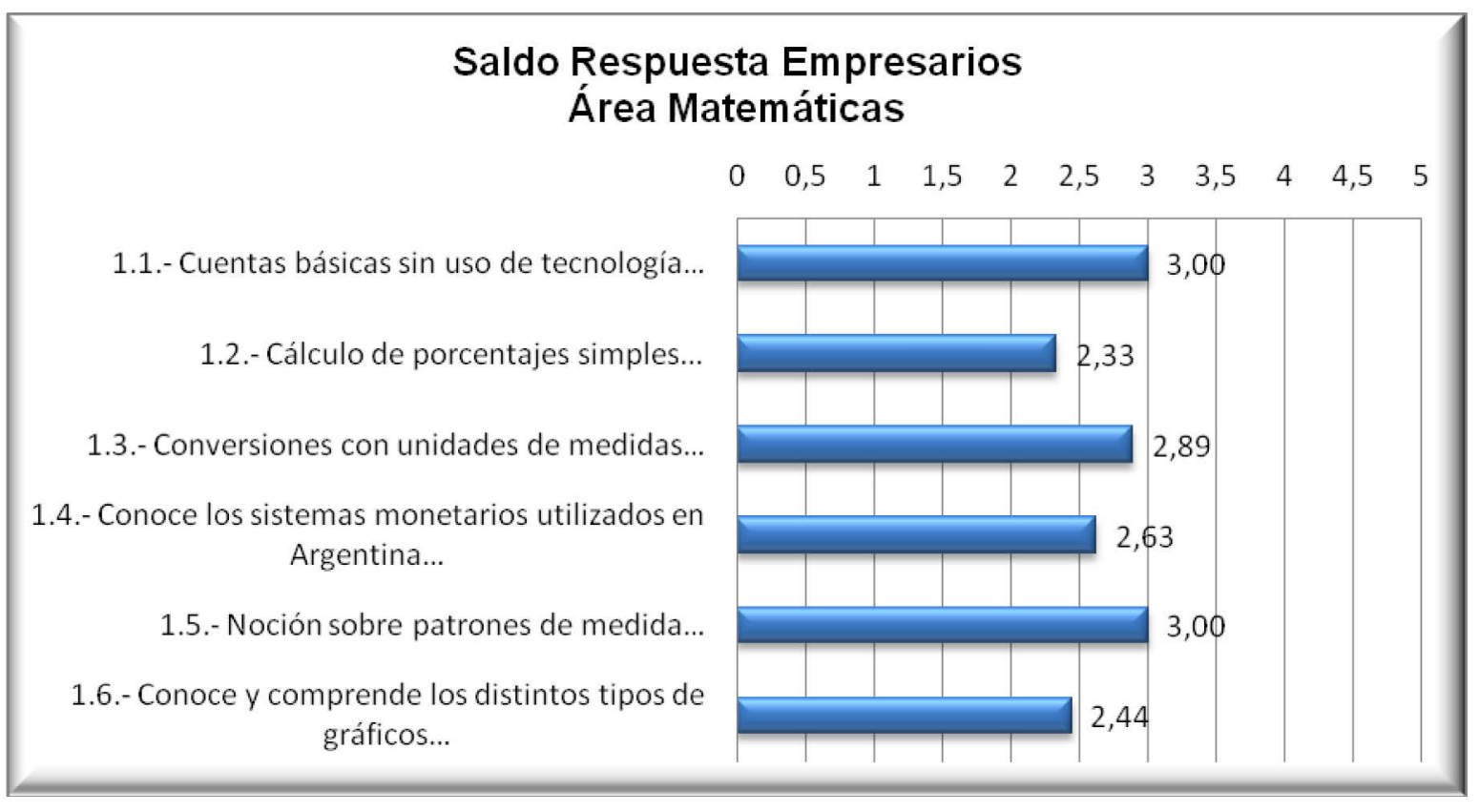

Fuente: Elaboración propia 


\section{Área Lengua}

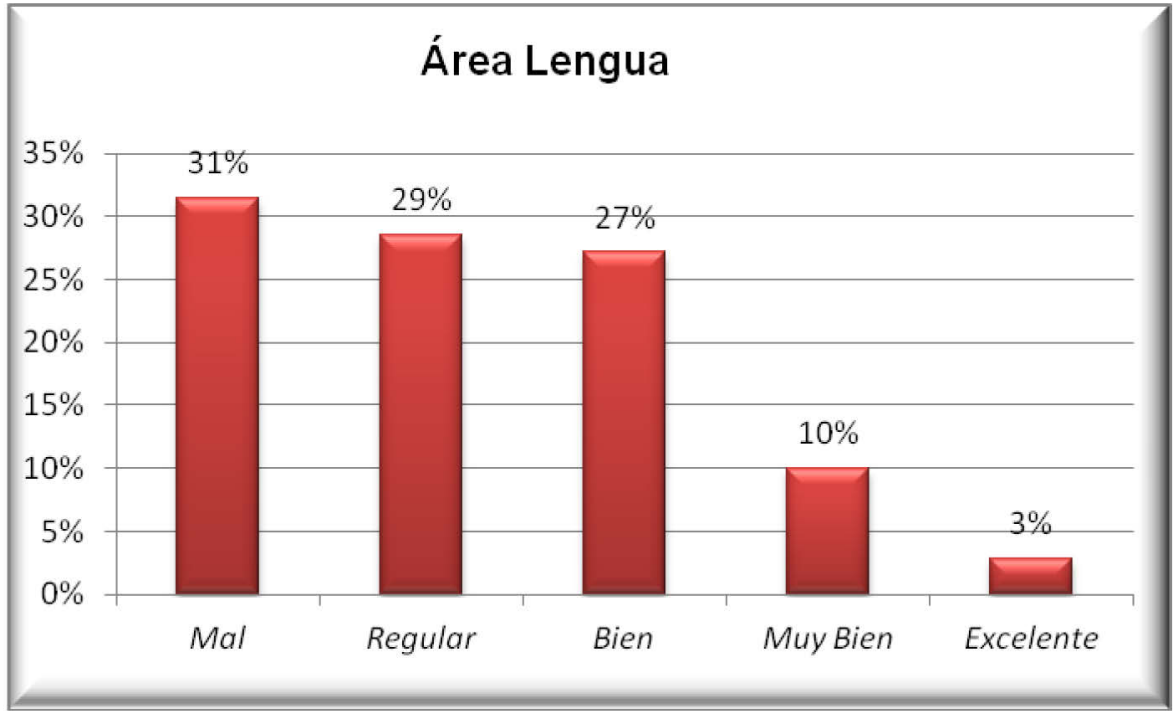

Fuente: Elaboración propia

En esta área, la respuesta del panel de expertos predominante fue Mal (31\%), no muy lejos la siguen Regular (29\%) y Bien (27\%), en este sentido los empresarios tienen un concepto del egresado de Mal a Regular en esta área.

Según los empresarios, en el área de Lengua, los egresados se desempeñan mejor en la exposición de una idea en forma oral/escrita. Por otra parte, en cambio, el punto donde presentan más problemas es en la habilidad de lectura. 


\section{Saldo Respuesta Empresarios} Área Lengua

2.1.- Comprende un texto...

2.2.- Redactar un texto...

2.3.- Habilidad de lectura... 2.4.- Caligrafía... 2.5.- Ortografía...

2.6.- Desempeño oral...

2.7.- Expone una idea en forma oral/escrita...

2.8.- Resumir un texto...

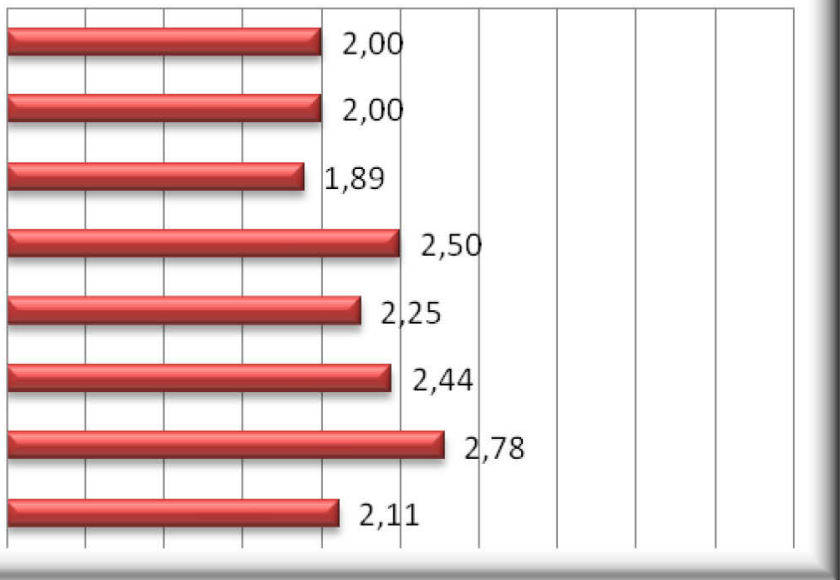

Fuente: Elaboración propia

\section{Área Ciencias}

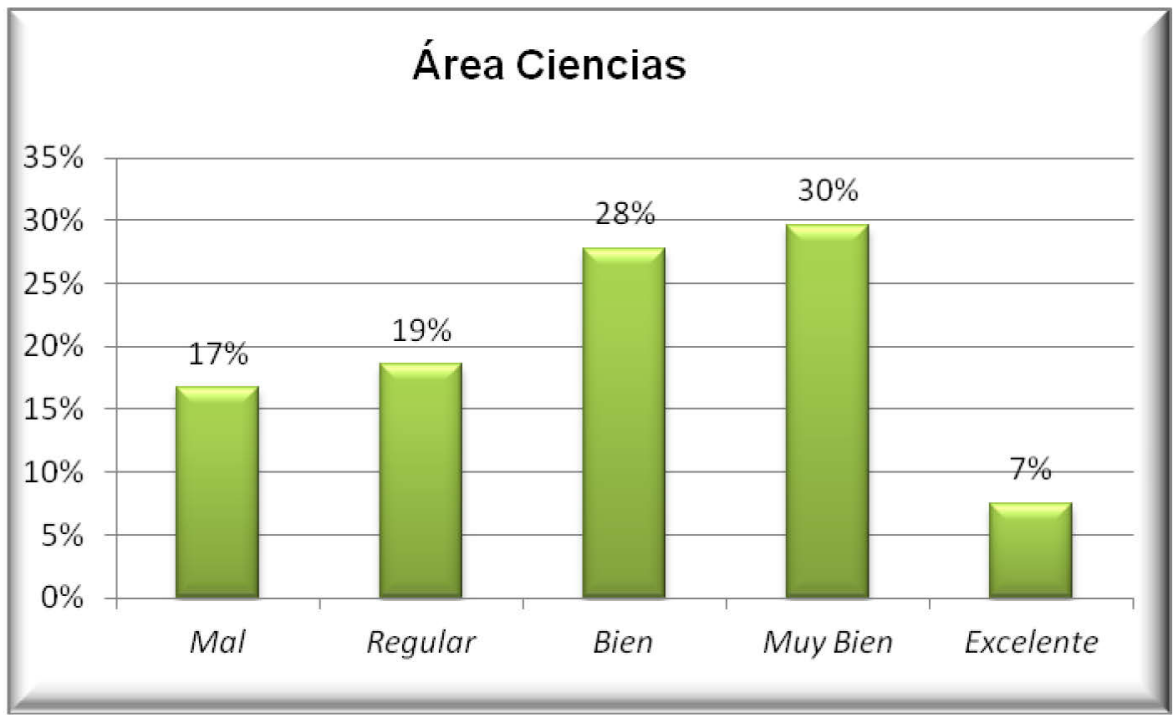

Fuente: Elaboración propia

En esta área y contradiciendo la anterior las respuestas de los empresarios se concentraron Muy Bien (30\%) y Bien (28\%) con más de la mitad de sus 
respuestas entre estas dos. Luego le siguen Regular (19\%), Mal (17\%) y por último Excelente (7\%).

En el gráfico que presentamos a continuación, se puede observar que los egresados obtuvieron mayor cantidad de respuestas en Uso de los programas básicos de computación y Uso de Internet para búsquedas de información predominando nuevamente la disciplina informática como en el caso de los expertos Docentes. En cambio, la respuesta con calificación menor fue acerca del conocimiento que presentan sobre primeros auxilios.

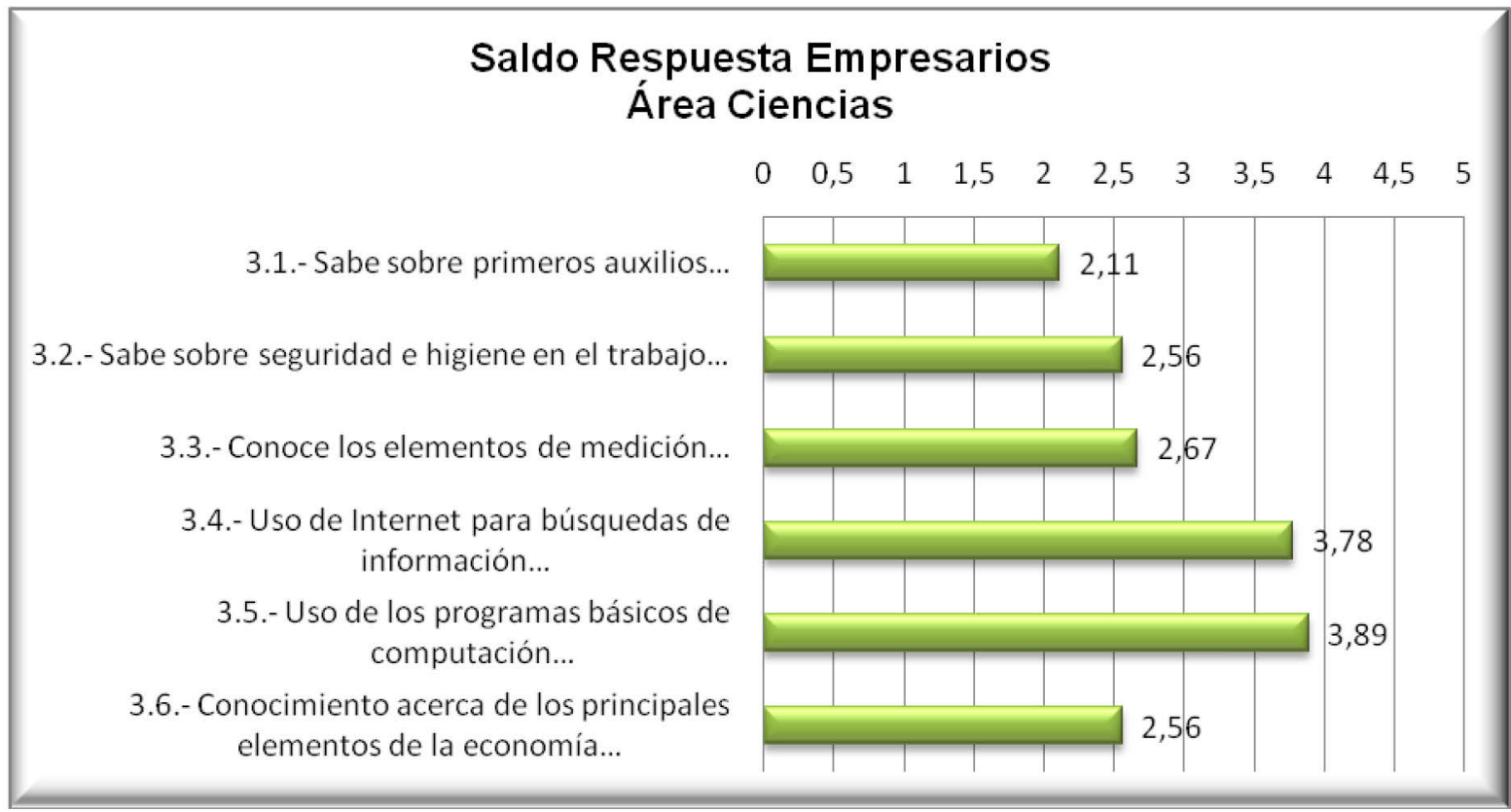

Fuente: Elaboración propia 


\section{Aptitudes Personales}

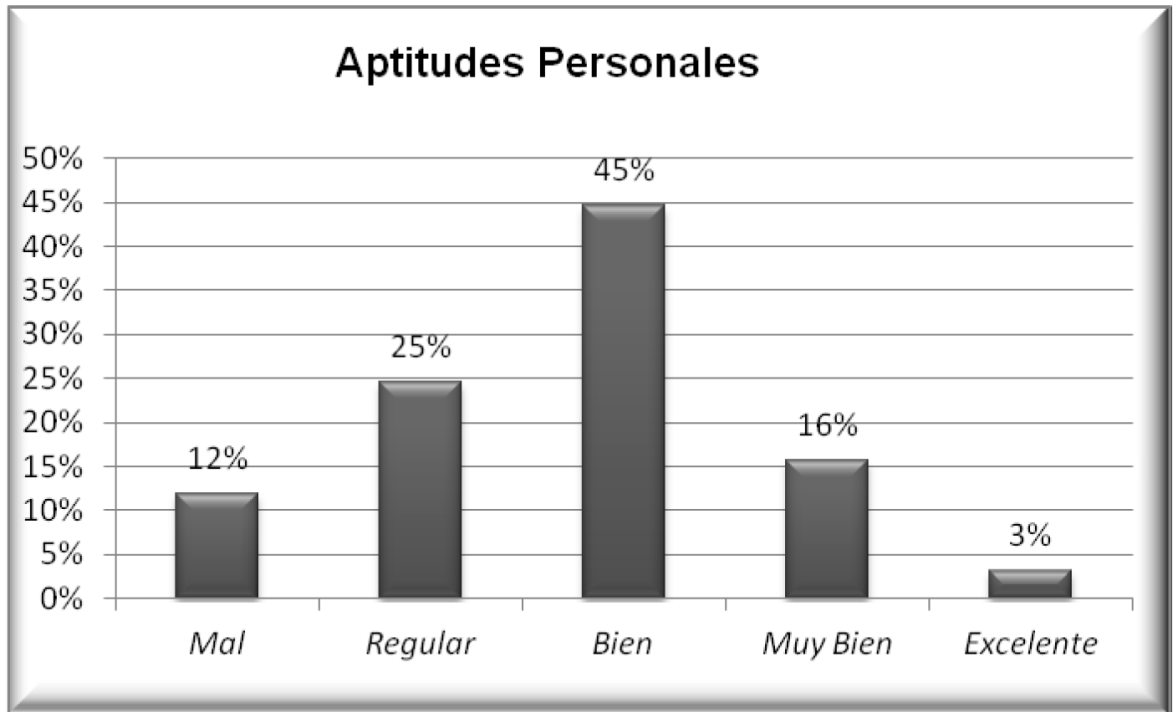

Fuente: Elaboración propia

En el área de aptitudes personales, se observa que la opinión de los empresarios con respecto a los egresados tienen buenas referencias por lo que en este caso predomina ampliamente la respuesta Bien (45\%), mientras que luego vienen seguidas por Regular (25\%), Muy Bien (16\%), Mal (12\%) y por último Excelente (3\%).

En el siguiente gráfico se puede observar que el punto más relevante es el uso de herramientas apropiadas, mientras que el individuo frente a la mirada del empresario presenta dificultades en el respeto. 


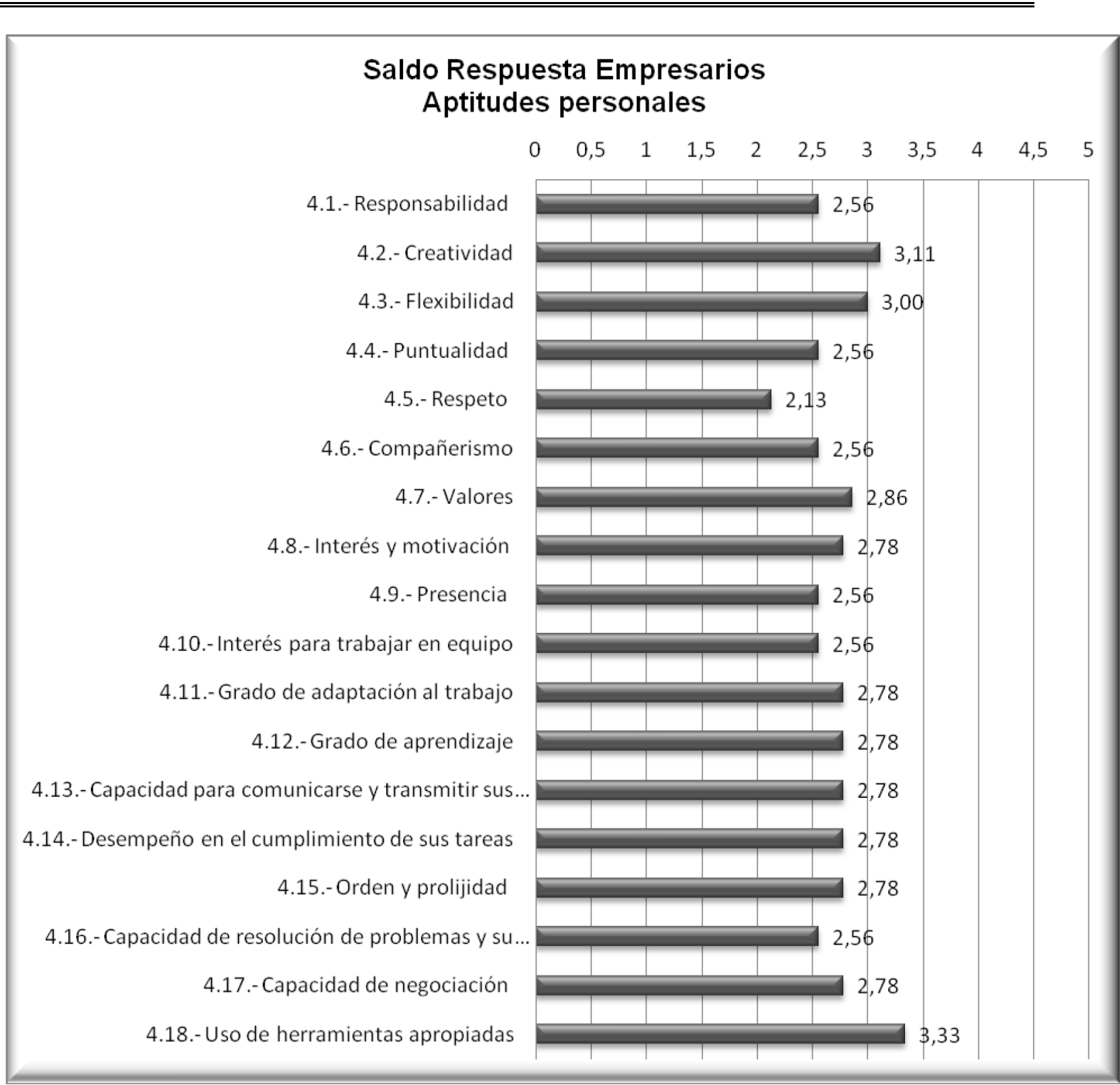

Fuente: Elaboración propia

\section{Calificación Global de Empresarios}

En el siguiente gráfico queda representada la calificación global del panel de expertos de empresarios, es decir, aquel que reune los resultados de todas las áreas, se puede observar que el nivel que presentan los egresados es la 
respuesta Bien (37\%), luego se dividen en Regular (23\%), Mal (18\%), Muy Bien (17\%) y por último la respuesta Excelente (4\%).

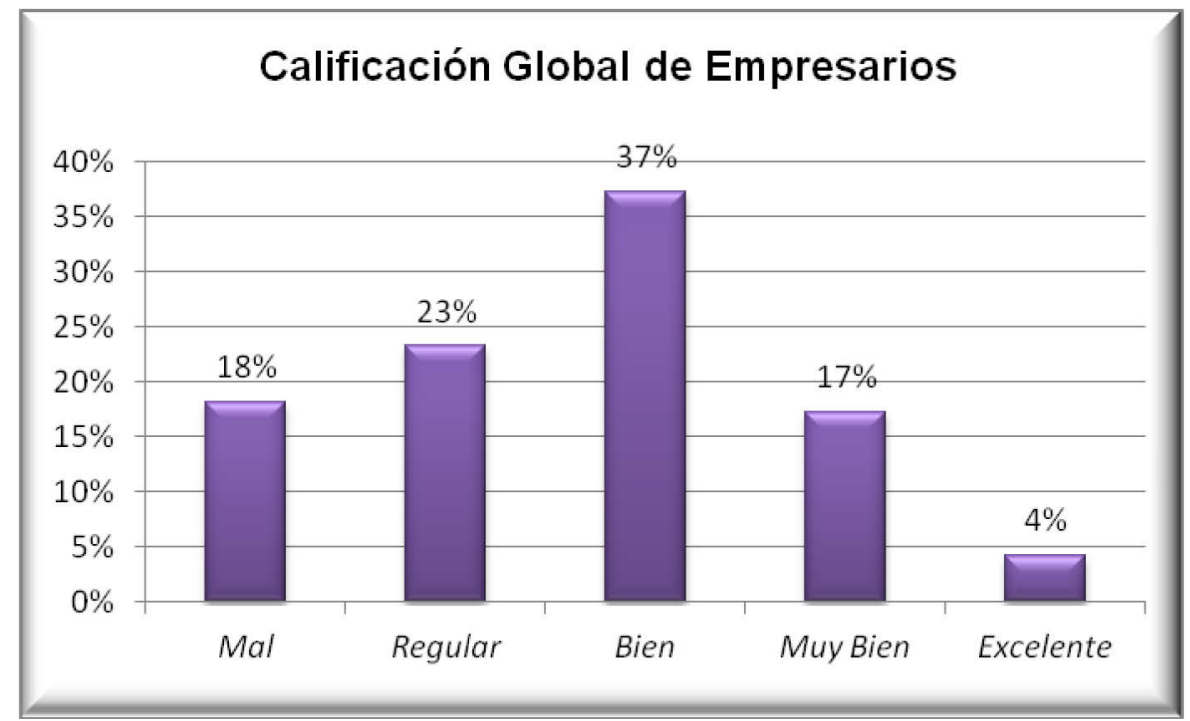

Fuente: Elaboración propia

En el gráfico de Saldo de respuesta empresarios, se puede observar que el área predominante (en cuanto a respuestas favorables) es Ciencias, mientras que el área de menor respuestas positivas fue Lengua.

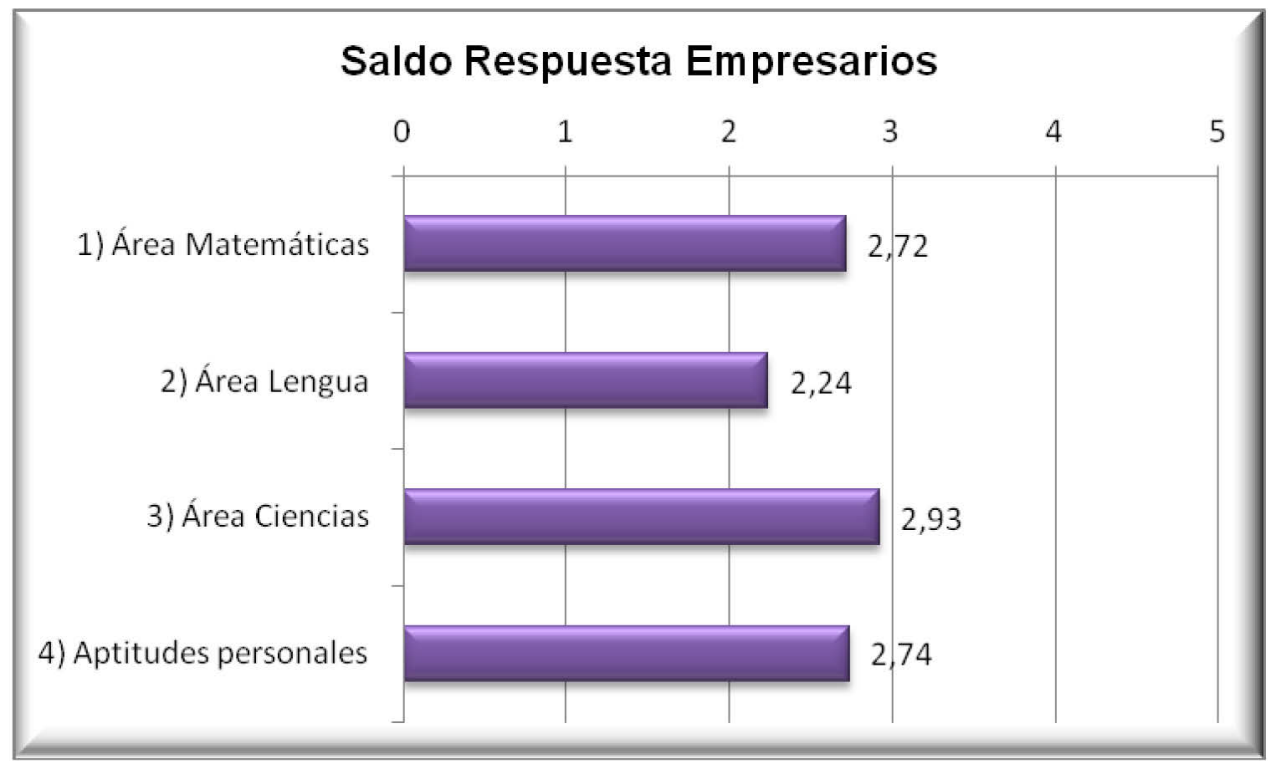

Fuente: Elaboración propia

Autor: Ing. Lucas F. Gambino

Director: Dr. Aldo H. Alonso 


\subsubsection{Total Global}

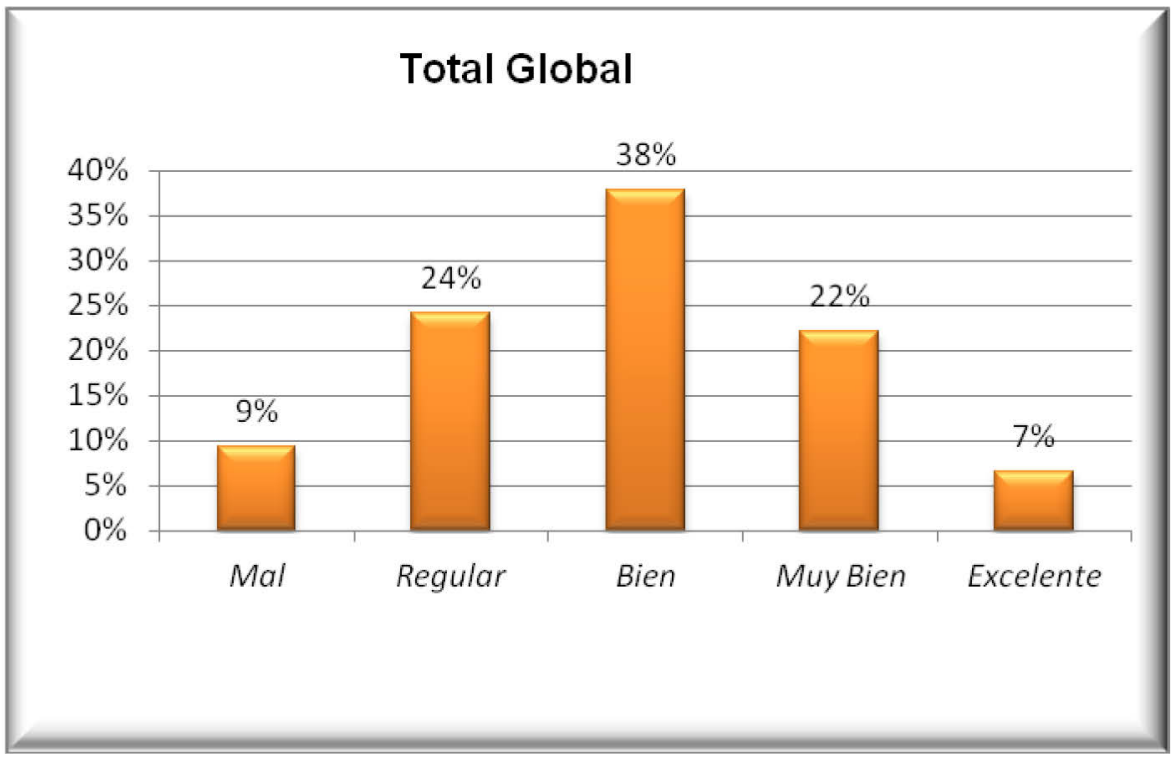

Fuente: Elaboración propia

El Total Global hace referencia a la sumatoria de los resultados de ambos paneles de expertos, docentes y empresarios. En este punto, se aprecia que en líneas generales el nivel de educación de los egresados del secundario es Bueno (38\%), existe una similitud entre los resultados Regular (24\%) y Muy Bien (22\%), más atrás en menor porcentaje quedan los resultados Mal (9\%) y Excelente $(7 \%)$.

En ambos paneles de expertos muestran resultados análogos en cuanto al nivel de educación de los egresados de escuelas secundarias, es decir, que tanto los docentes como los empresarios consideran que el nivel es Bueno, con una marcada inclinación a Regular. Mientras tanto hay una disparidad en el saldo de respuesta entre los empresarios y docentes ya que en los primeros el valor es de 2,66, mientras que el de los segundos el valor es de 3,10. 


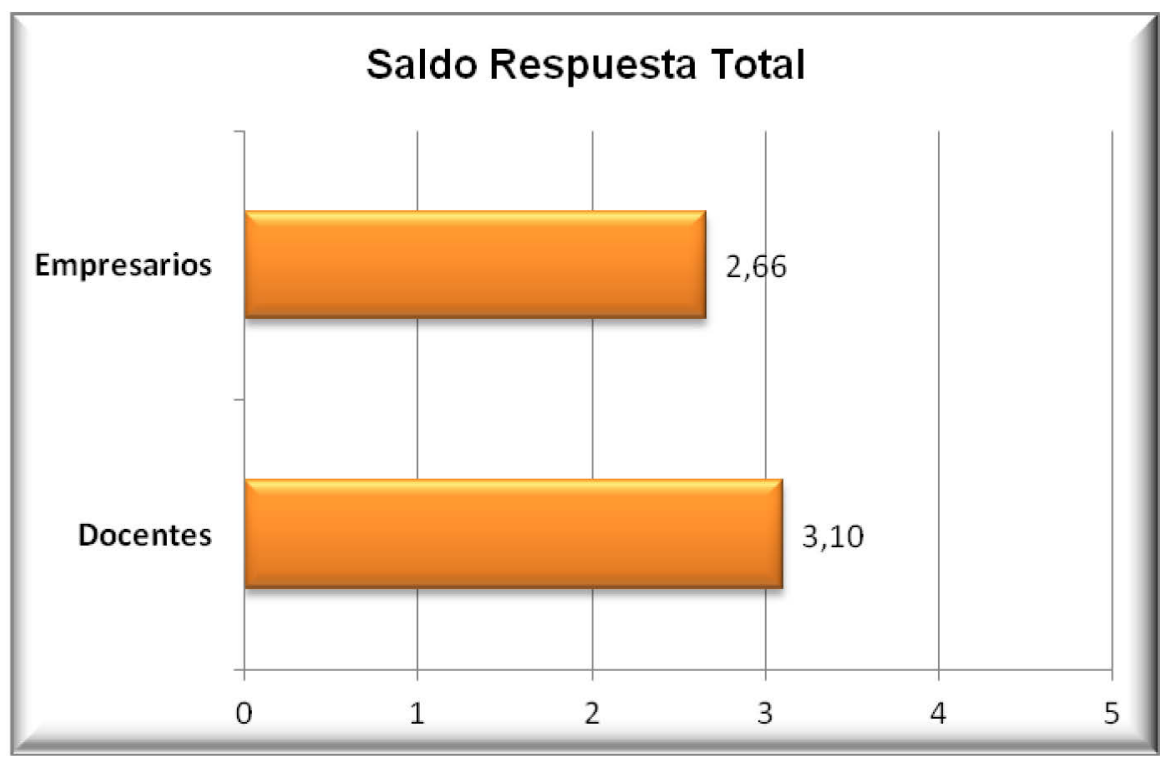

Fuente: Elaboración propia

\subsubsection{Comparación respuestas de Docentes y Empresarios}

\section{Área Matemáticas}

En ésta área se puede observar que el panel de expertos docentes tiene una mejor calificación que el panel de expertos Empresarios en los siguientes puntos: "realiza cálculos de porcentajes simples...", "Conoce los sistemas monetarios utilizados en Argentina..." y "Conoce y comprende los distintos tipos de gráficos...". En cambio el panel de expertos Empresarios tiene mejor calificación que el panel de expertos Docentes solo en el punto: "Realiza conversiones con unidades de medidas...". Mientras que poseen una paridad de calificación de respuestas entre ambos paneles de expertos en los puntos: "Realiza cuentas básicas sin uso de tecnología..." y "Tiene noción sobre patrones de medida...". 


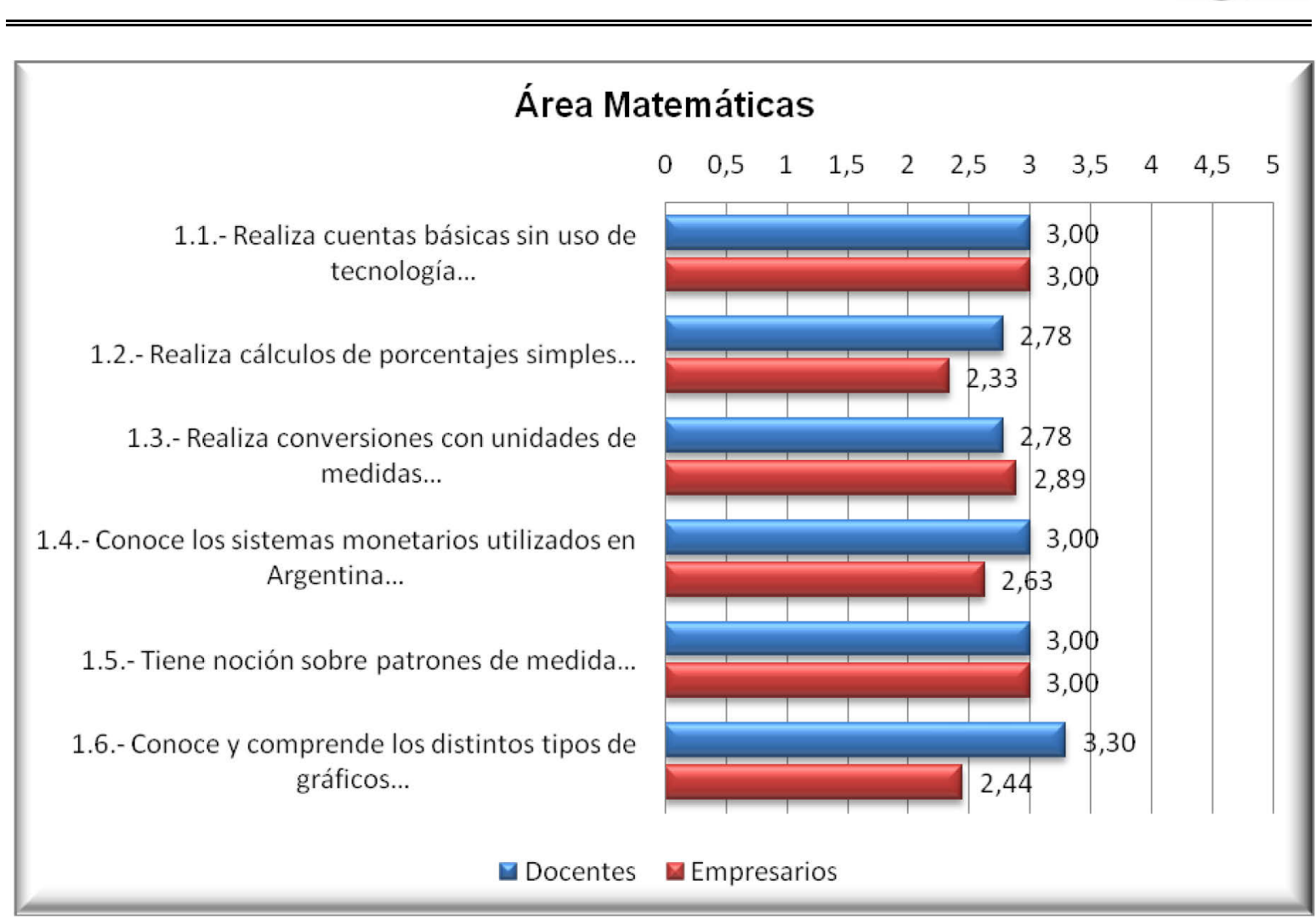

Fuente: Elaboración propia

\section{$\underline{\text { Área Lengua }}$}

En ésta área se da que todas las calificaciones del panel de expertos docentes son mayores que el panel de expertos empresarios. Existe una diferencia bien marcada en la mayoría de los puntos, esto se debe a que los empresarios fueron más críticos a la hora de contestar, mientras que en los docentes se nota el grado de compromiso que poseen en el aprendizaje de los alumnos y de ahí se ve reflejada una mejor calificación. 


\section{Área Lengua}

2.1.- Es capaz de comprender un texto..

2.2.- Es capaz de redactar un texto...

2.3.- Presenta una habilidad de lectura...

2.4.- Presenta una caligrafía...

2.5.- Presenta una ortografía...

2.6.- Presenta un desempeño oral...

2.7.- Es capaz de exponer una idea en forma oral / escrita...

2.8.- Presenta una capacidad de resumir un texto...

$\begin{array}{lllllllllll}0 & 0,5 & 1 & 1,5 & 2 & 2,5 & 3 & 3,5 & 4 & 4,5 & 5\end{array}$

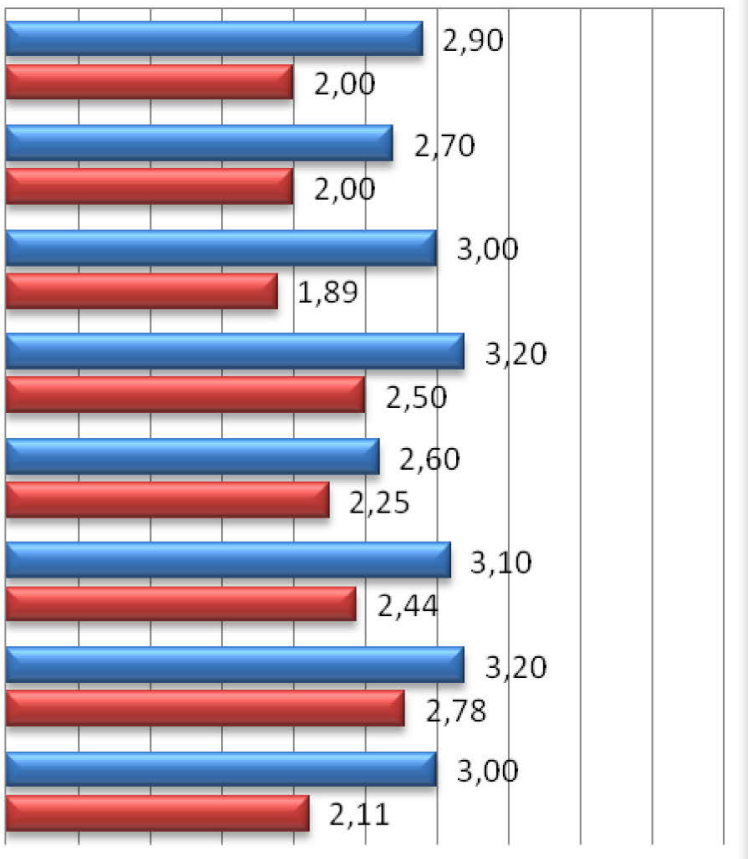

Docentes

Empresarios

Fuente: Elaboración propia

\section{$\underline{\text { Área Ciencias }}$}

En ciencias fueron variadas las respuestas, se puede observar que el panel de expertos docentes tiene una mejor calificación que el panel de expertos empresarios en los puntos: "Conocimiento sobre primeros auxilios...", "Conocimiento sobre seguridad e higiene en el trabajo..." y "Conocimiento sobre los elementos de medición...".

Mientras que el panel de expertos empresarios tiene mejor calificaciones frente a sus pares docentes en los siguientes puntos: "Conocimiento sobre el uso de Internet para búsquedas de información relevante...", "Uso de los programas 
básicos de computación..." y "Conocimiento acerca de los principales elementos de la economía...".

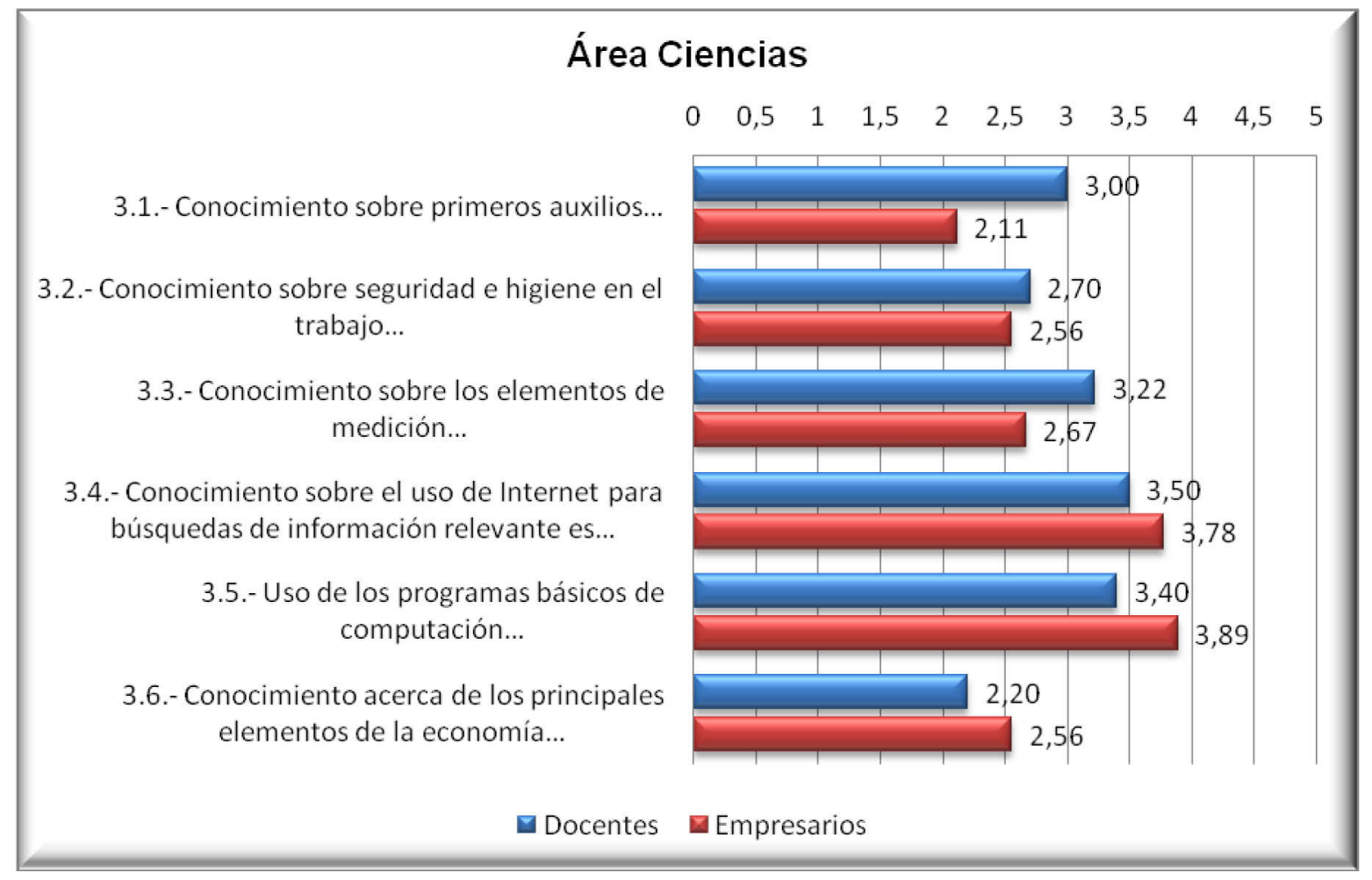

Fuente: Elaboración propia

\section{Aptitudes Personales}

En aptitudes personales la mayoría de las calificaciones del panel de expertos docentes obtuvieron mejor calificación que el panel de expertos empresarios, mientras que el panel de expertos empresarios tiene una mejor calificación en creatividad.

Existen puntos donde tienen una marcada diferencia y puntos donde las calificaciones son parejas. 


\section{Aptitudes Personales}

$\begin{array}{lllllllllll}0 & 0,5 & 1 & 1,5 & 2 & 2,5 & 3 & 3,5 & 4 & 4,5 & 5\end{array}$

4.1.- Responsabilidad

4.2.- Creatividad

4.3.- Flexibilidad

4.4.- Puntualidad

4.5.- Respeto

4.6.- Compañerismo

4.7.- Valores

4.8.- Interés y motivación

4.9.- Presencia

4.10.- Interés para trabajar en equipo

4.11.- Grado de adaptación al trabajo

4.12.-Grado de aprendizaje

4.13.- Capacidad para comunicarse y transmitir sus conocimientos

4.14.- Desempeño en el cumplimiento de sus tareas

4.15.- Orden y prolijidad

4.16.- Capacidad de resolución de problemas y su comunicación

4.17.- Capacidad de negociación

4.18.- Uso de herramientas apropiadas

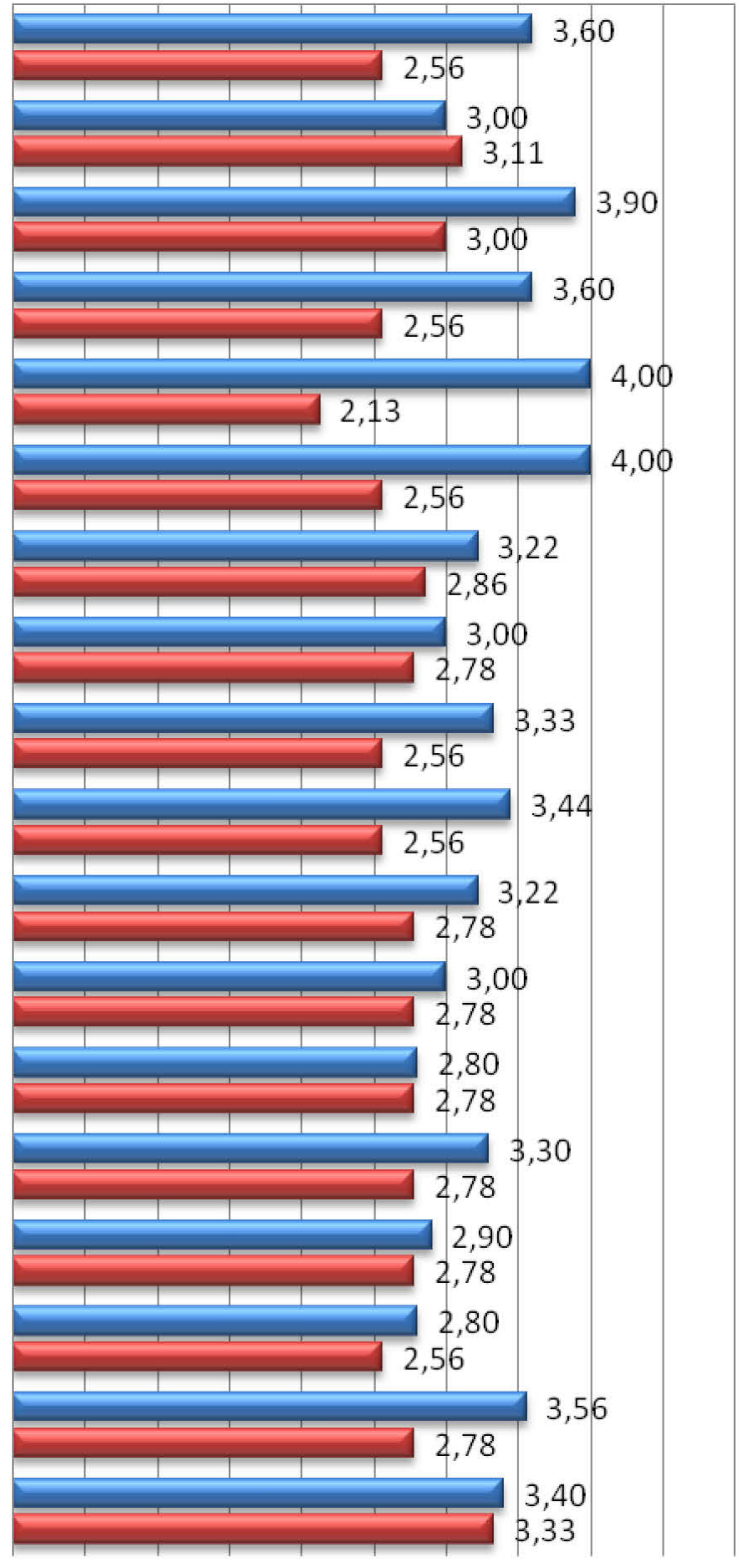

Docentes

Empresarios

Fuente: Elaboración propia 


\subsubsection{Comparación Total respuesta Docentes y Empresarios}

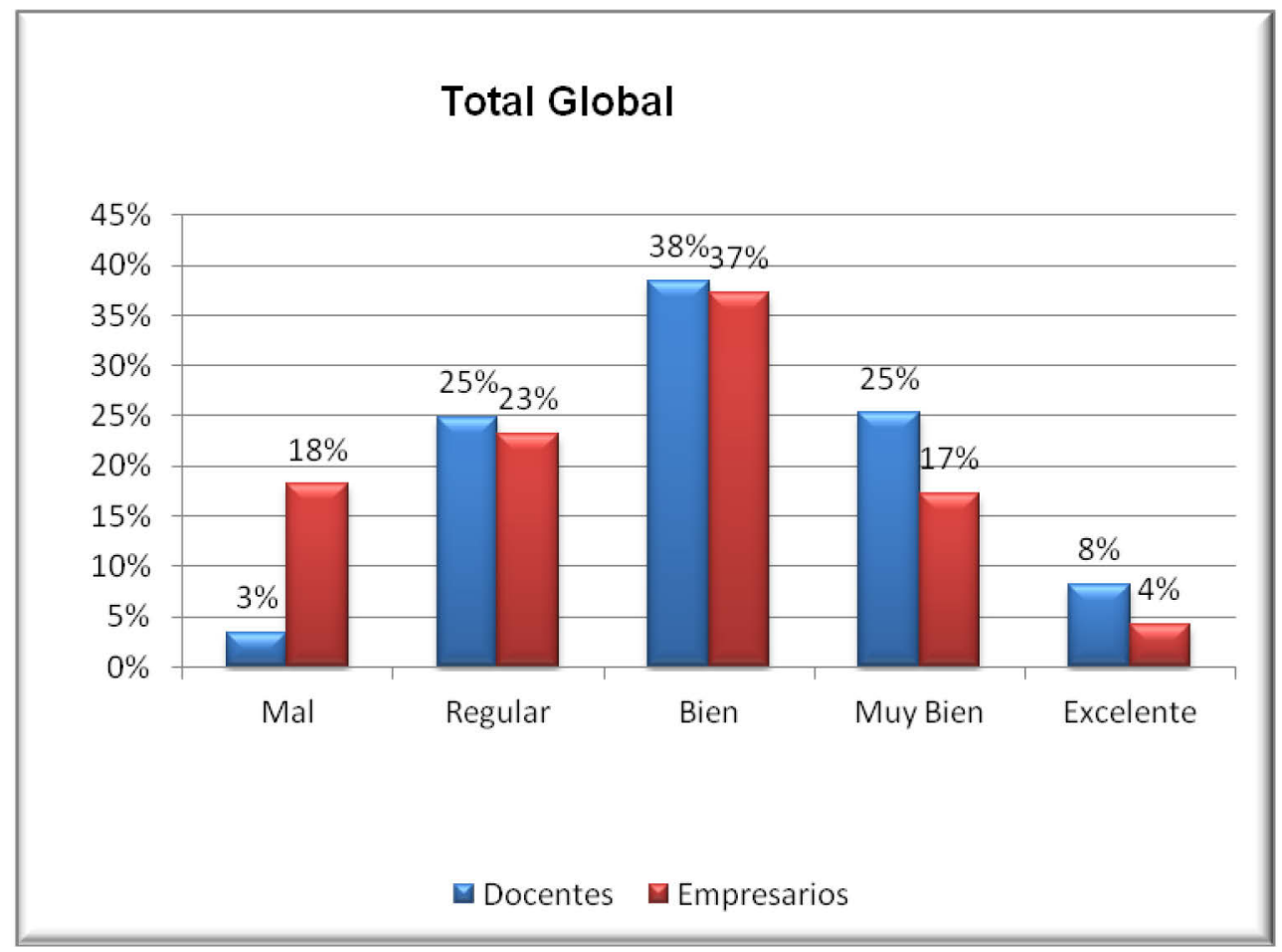

Fuente: Elaboración propia

En el gráfico Total Global hace referencia a la sumatoria de los resultados de ambos paneles de expertos (docentes y empresarios).

En el mismo se observa que en la mayoría de las calificaciones la opinión crítica del panel compuesto por Empresarios en comparación con los docentes, tienen una calificación menor (en porcentaje). Solo en la calificación Mal los empresarios presentan un mayor porcentaje (esto nos dice que tienen una visión de menor calidad en la educación secundaria).

En el siguiente gráfico se observa el valor del saldo de respuestas de cada panel de expertos por disciplina. En el mismo los resultados del panel de expertos de los empresarios son menores que los del panel de expertos docentes, existe una paridad en Lengua, pero de igual manera la diferencia es mínima a favor de los docentes. 


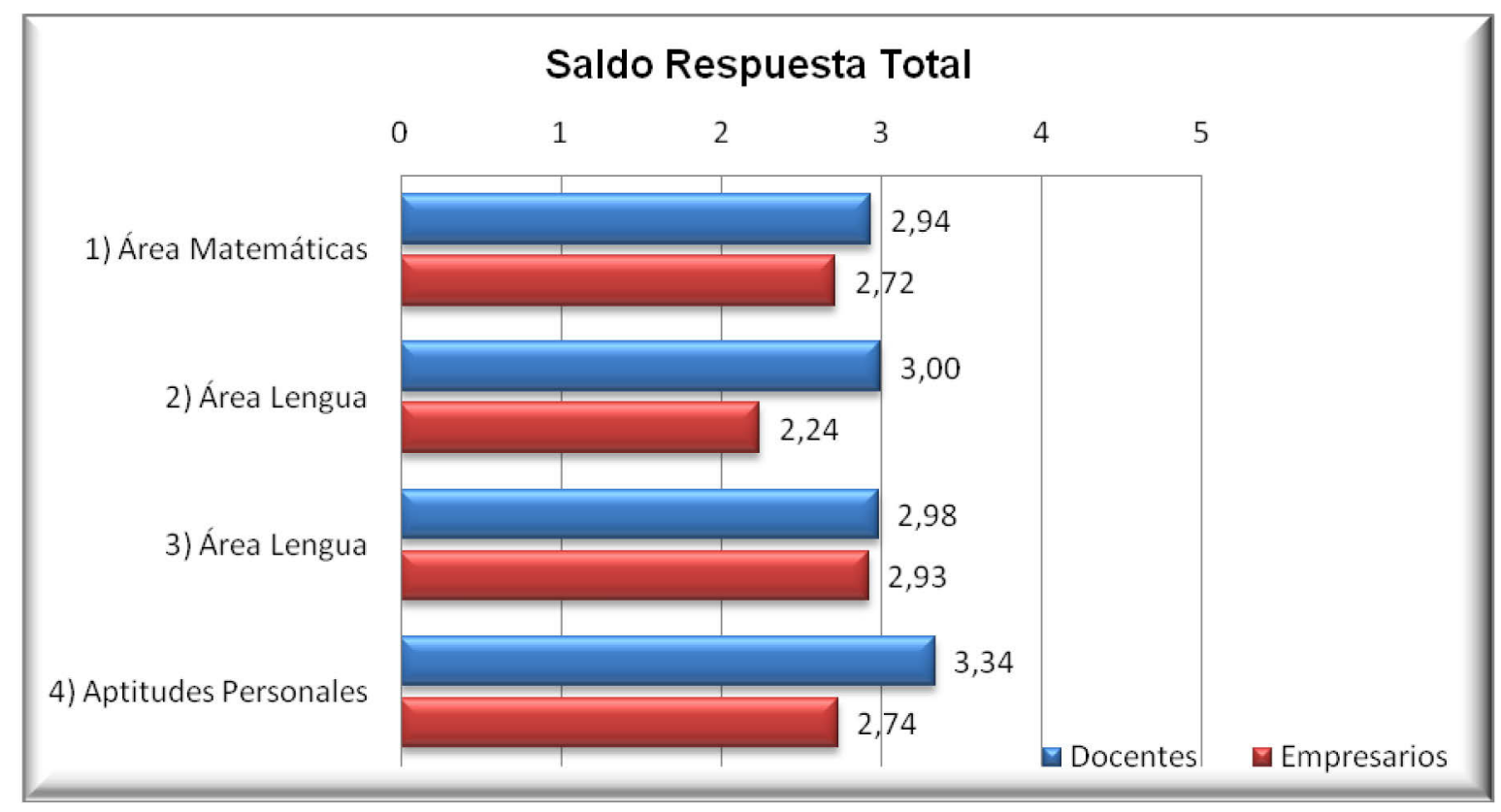

Fuente: Elaboración propia

\subsubsection{Comparación regional respuestas de docentes}

En esta comparación, se tiene en cuenta el nivel de la calidad educativa del secundario, según el panel de expertos de docentes, de la Región I compuesta por los partidos de La Plata, Berisso y Ensenada. A su vez, en los gráficos, se

puede apreciar las diferencias que presentan estos resultados, en relación a Berisso. 


\section{Área Matemáticas}

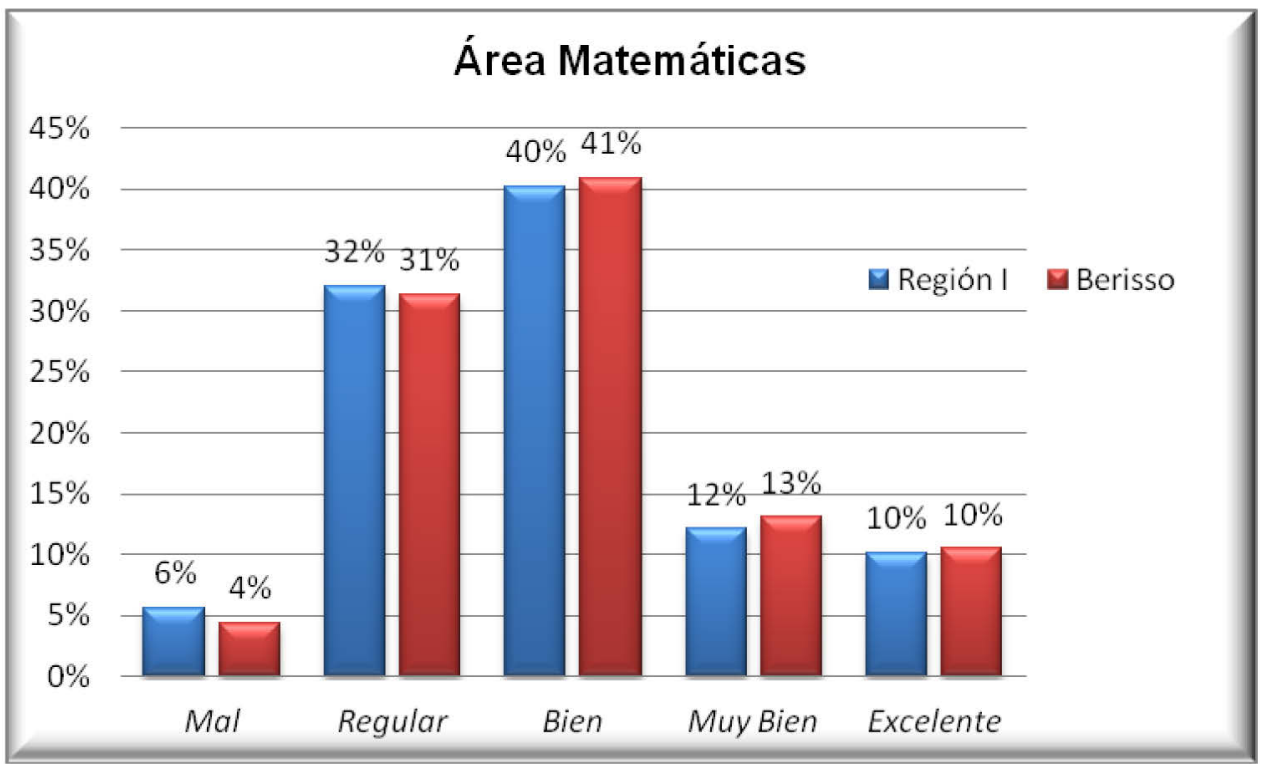

Fuente: Elaboración propia

En Matemáticas, se observa que Berisso presenta un mayor porcentaje en las respuestas Bueno y Muy bueno, luego presenta mínimas diferencias a favor de la Región I en las calificaciones Regular y Mal, y en Excelente tienen el mismo porcentaje.

En el siguiente gráfico, se observa que en varios puntos donde el nivel del Berisso está por debajo de la Región I, como ser en: "Realización de cuentas básicas sin usar tecnología...", "Cálculo de porcentajes simples...", "Distingue los distintos tipos de figuras geométricas..." y "conoce los sistemas monetarios utilizados en la Argentina...". Por otra parte en los demás puntos Berisso se encuentra con mayor puntaje. 


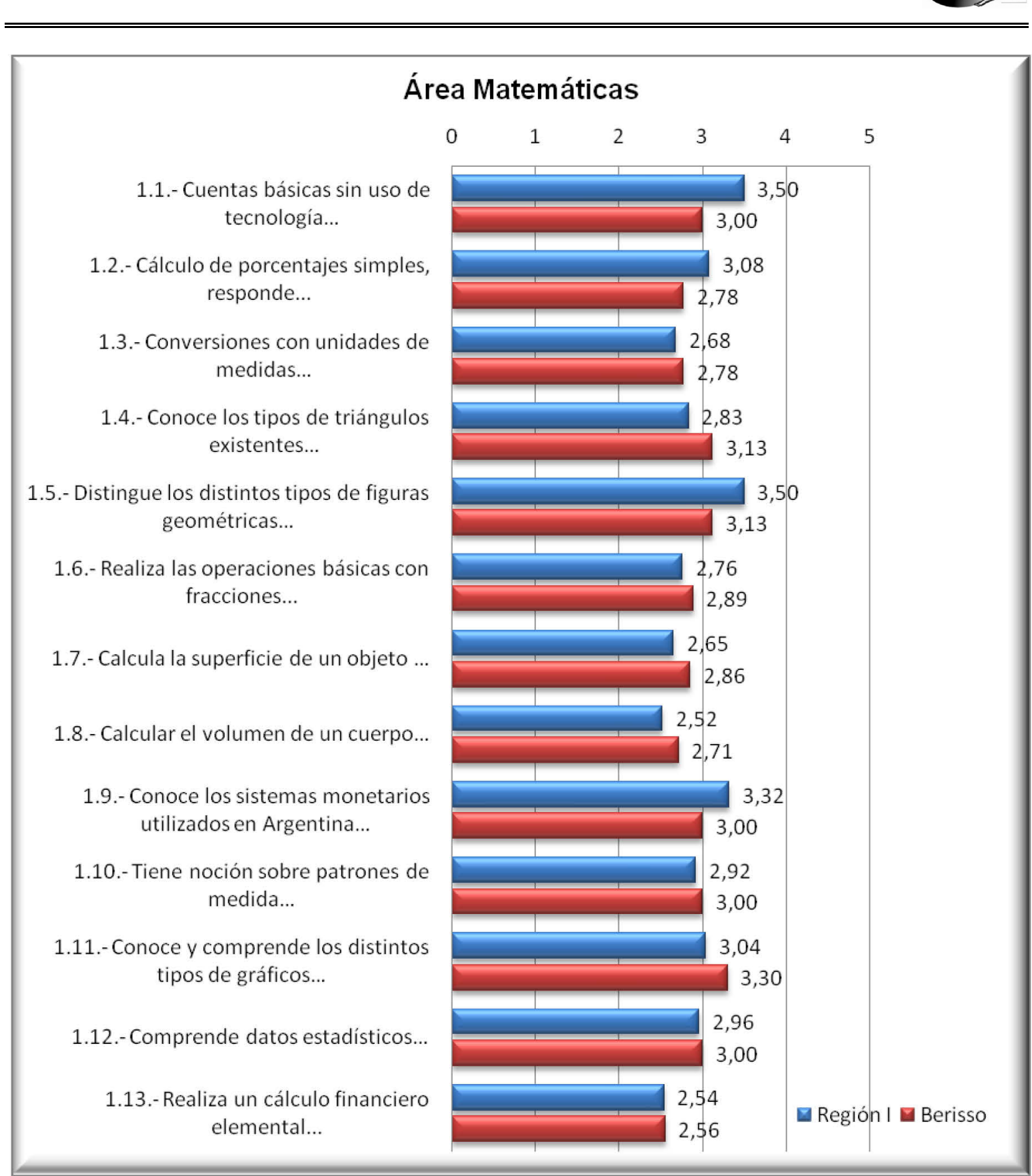

Fuente: Elaboración propia 


\section{Área Lengua}

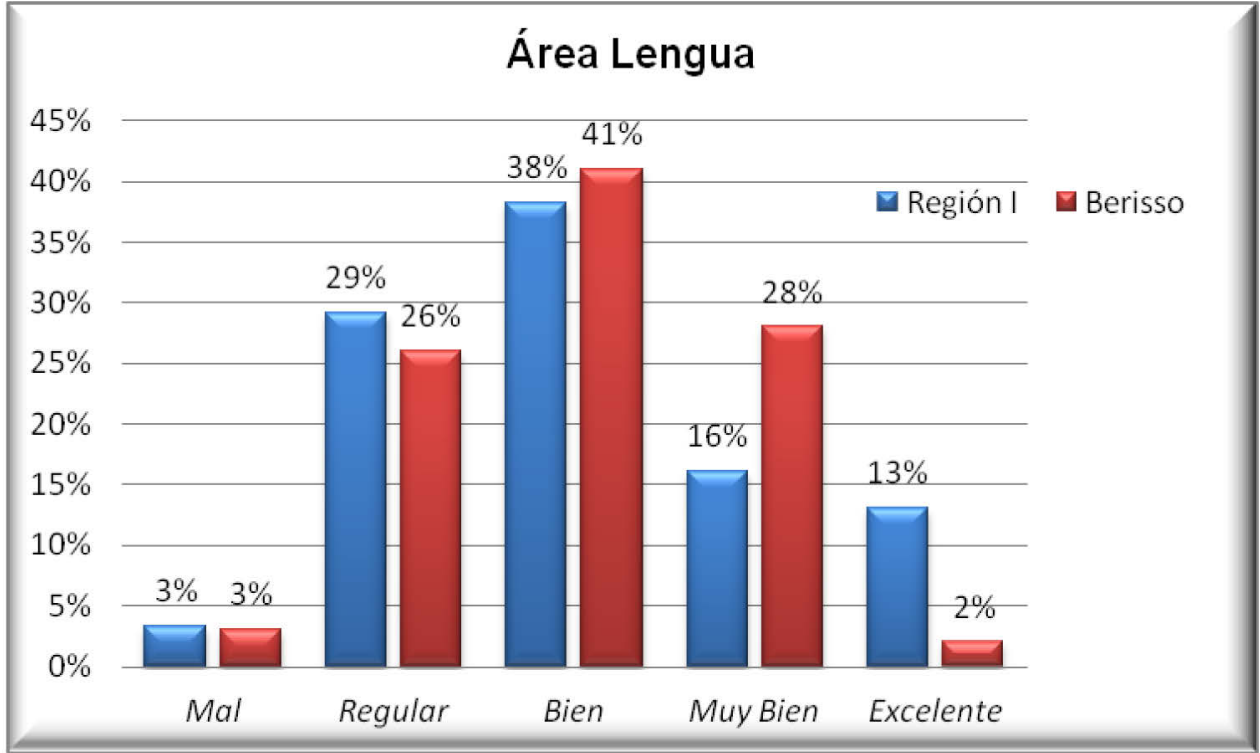

Fuente: Elaboración propia

En Lengua, se aprecian diferencias mayores a favor de Berisso con respecto a la Región I en las calificaciones Bien y Muy Bien, este úlimo con una diferencia del $12 \%$ a favor de Berisso. En los demás puntos la Región I se encuentra por encima de Berisso, salvo en la calificación Mal donde ambos porcentajes son iguales. 


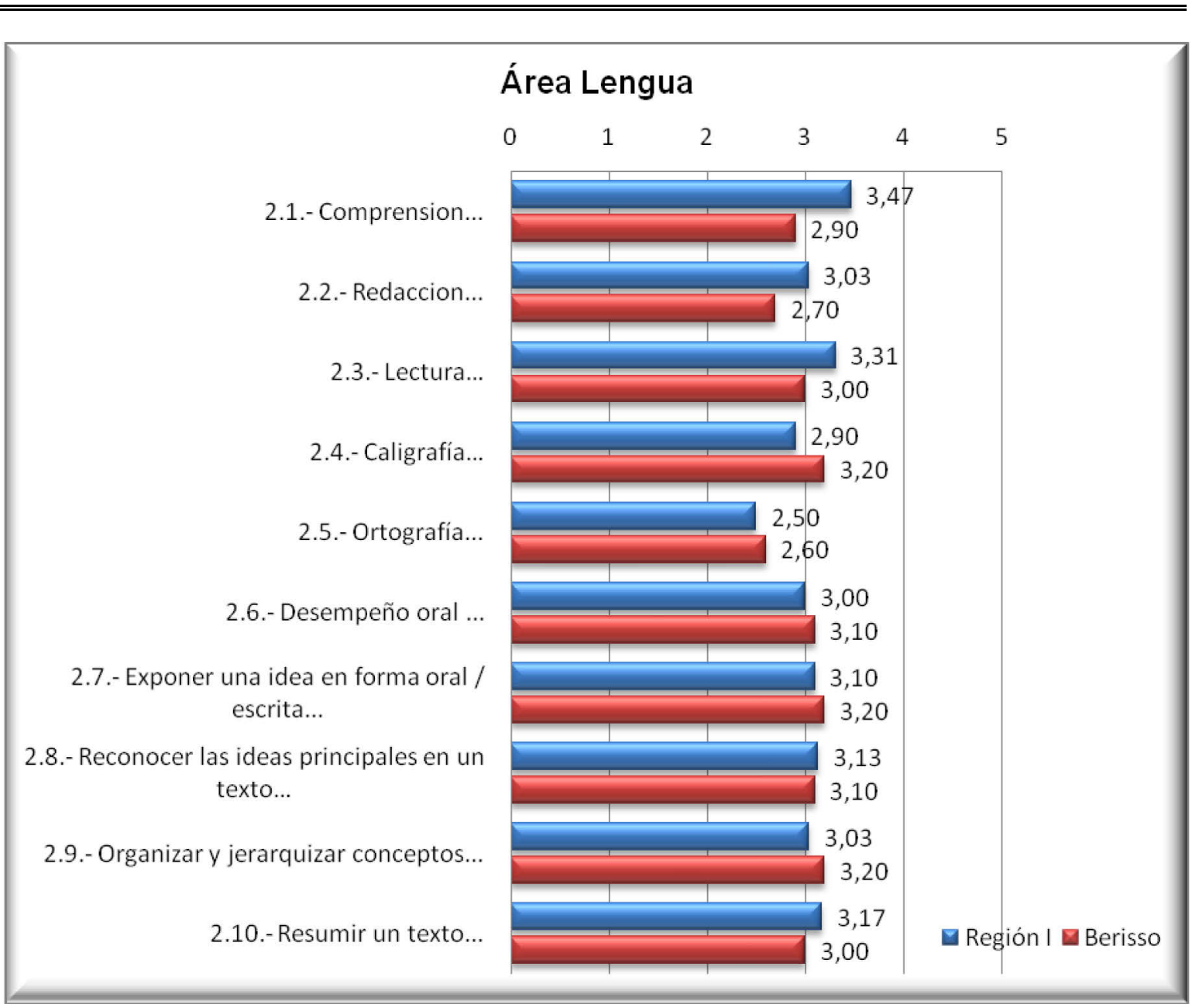

Fuente: Elaboración propia

En el gráfico anterior detalla los puntos evaluados en la encuesta, observandose que Berisso presenta mejor nivel que la Región I en los puntos: "Caligrafía...", "Ortografía...", "Desempeño oral...", "Exponer una idea en forma oral / escrita..." y "Organizar y jerarquizar conceptos...", en las demás respuestas se observa que Berisso se encuentra por debajo de los resultados de la Región I. 


\section{$\underline{\text { Área Ciencias }}$}

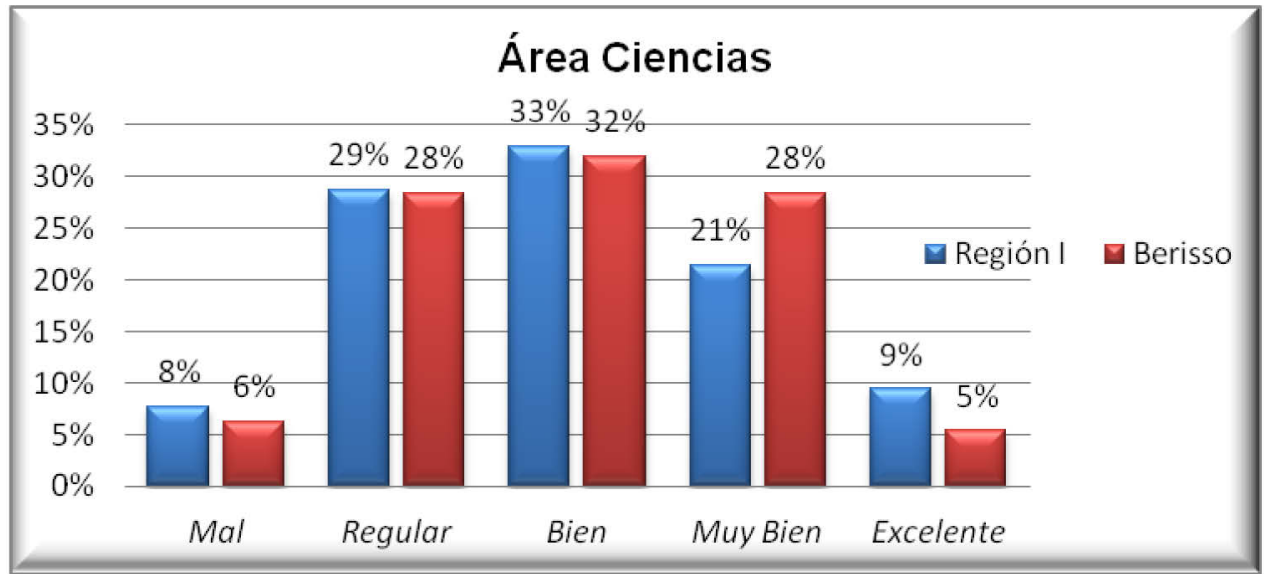

Fuente: Elaboración propia

En este caso, la única respuesta que presenta mayor porcentaje en comparación a la Región I es Muy Bien con una diferencia del 7\% a favor de Berisso, las demás respuestas la Región se encuentra por encima de Berisso. 


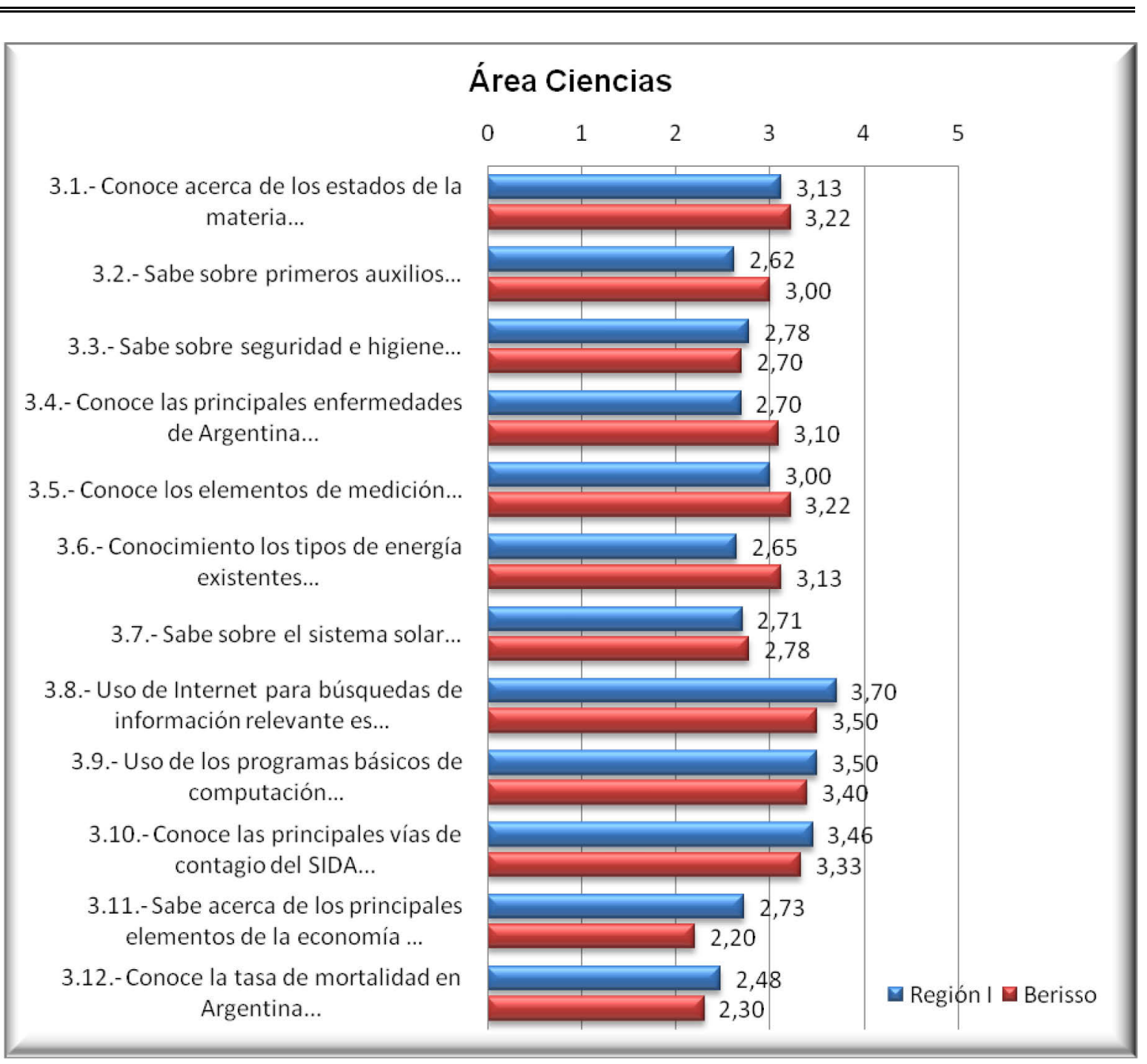

Fuente: Elaboración propia

Al evaluar el saldo de respuesta nos encontramos que en varios puntos son los resultados a favor de Berisso con respecto de la Región I, como ser: "Conoce acerca de los estados de la materia...", "Sabe sobre primeros auxilios...", "Conoce las principales enfermedades de Argentina...", "Conoce los elementos de medición...", "Conocimiento los tipos de energía existentes..." y "Sabe sobre el sistema solar...", en las demás respuestas la Región I se encuentra por encima de Berisso. 


\section{Aptitudes Personales}

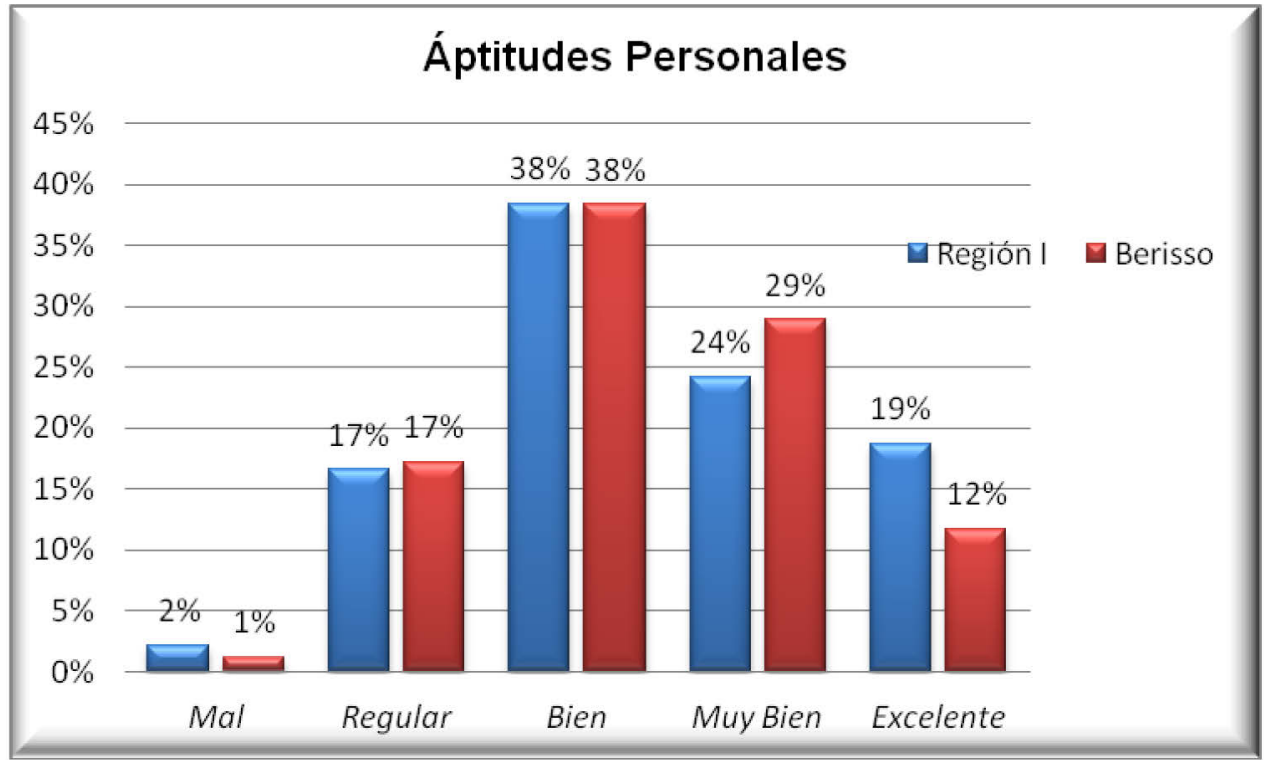

Fuente: Elaboración propia

En Aptitudes Personales, se encuentra una paridad en las calificaciones Bien y Regular, en cambio en Muy Bien Berisso se encuentra por encima de la Región I y en Mal y Excelente la Región I se impone sobre Berisso. 


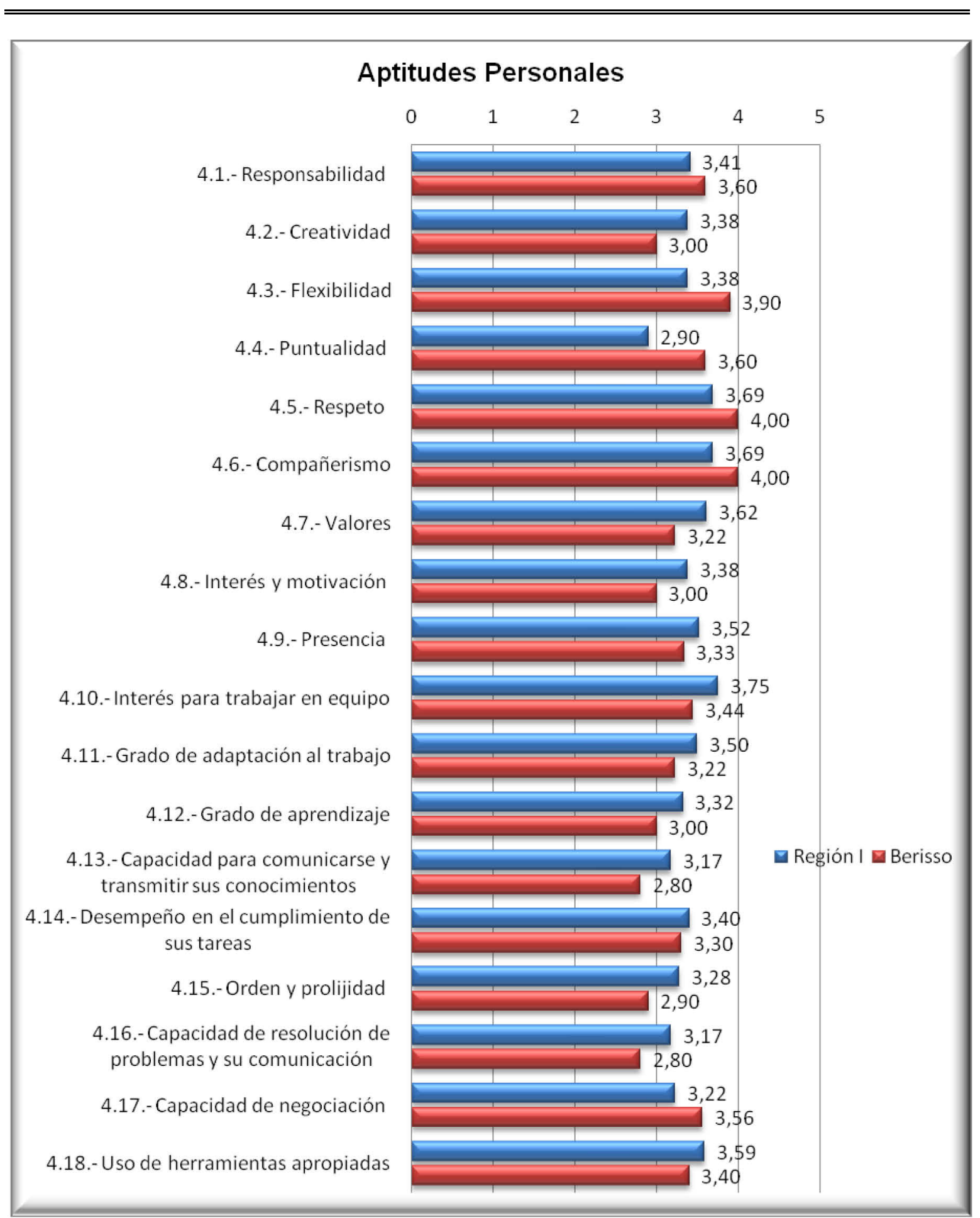

Fuente: Elaboración propia 
En el gráfico anterior (saldo de respuesta), solo en algunos puntos se da que Berisso supera a la Región I, y es los casos: "Responsabilidad...", "Flexibilidad...", "Puntualidad...", "Respeto...", "Compañerismo..." у "Capacidad de negociación...", en el resto de las respuestas Berisso se encuentra superada por la Región I.

\section{Comparación Regional respuestas de Docentes Global}

En esta comparación se observan los resultados globales docentes, y la diferencia que presenta la sumatoria de los resultados de Berisso con el de la región I.

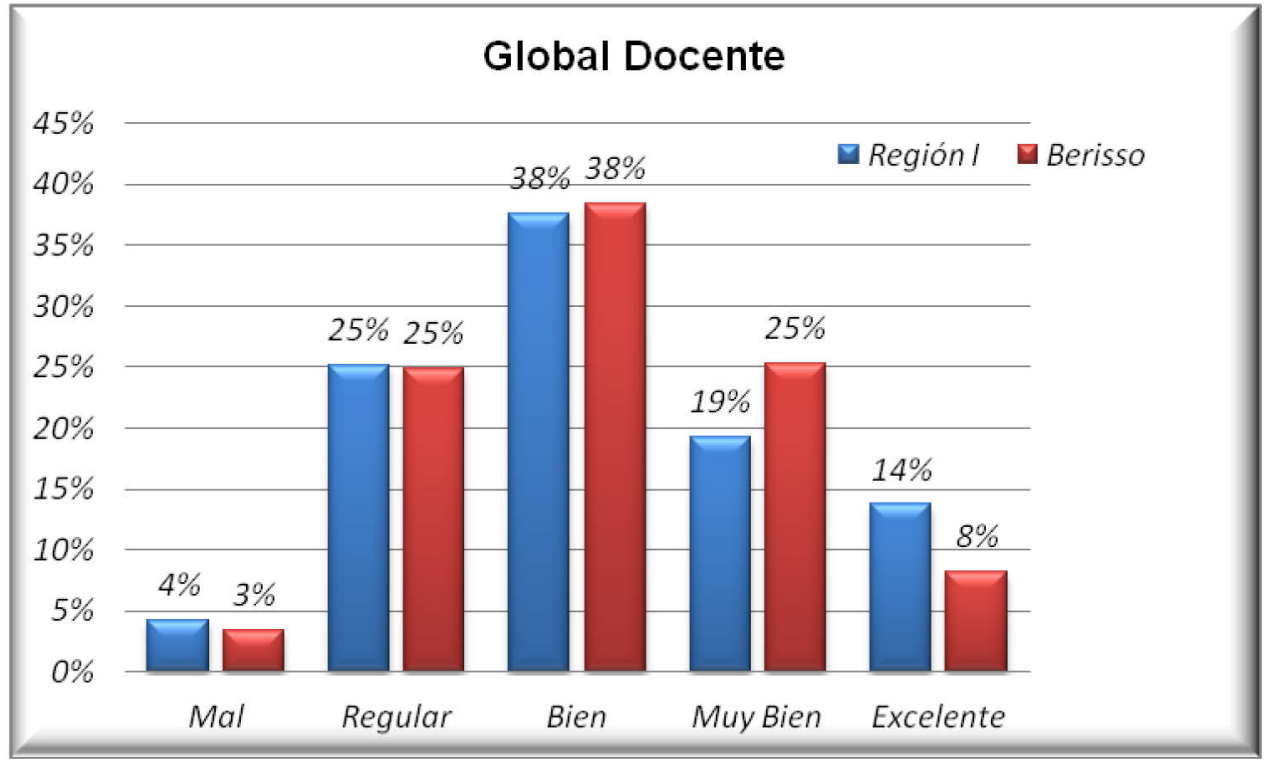

Fuente: Elaboración propia

Como se ve en el gráfico anterior existe una paridad en las calificaciones Mal, Regular y Bien, mientras que Berisso se impone con diferencia positiva en la calificación Muy Bien con $6 \%$ por encima de la región I. En el caso donde la Región I tiene diferencia a favor sobre Berisso es en la calificación Excelente con $6 \%$. 


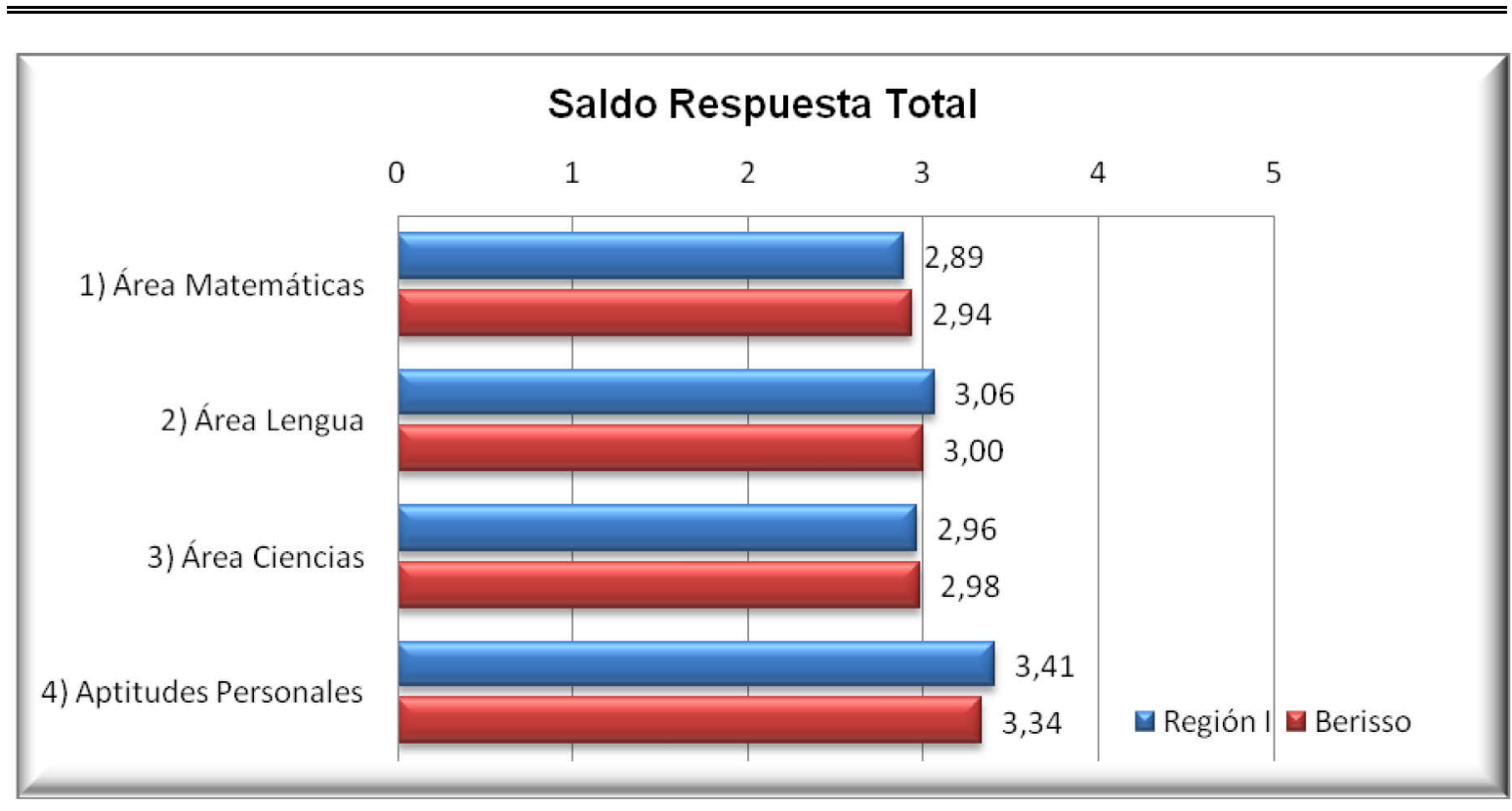

Fuente: Elaboración propia

En el saldo de respuesta total la comparación entre las áreas son parejas existiendo muy poca diferencia entre la Región I y Berisso. Solo se impone Berisso en las áreas Matemáticas y Ciencias, mientras que en las demás la Región I se encuentra por encima.

\subsubsection{Comparación regional respuestas de empresarios}

En esta sección, se presenta la comparación entre los resultados de Berisso y los de la región I, que está comprendida por los partidos de La Plata, Berisso y Ensenada. A continuación se presentaran los resultados del nivel de calidad del secundario, según el panel de expertos compuesto por empresarios. 


\section{Área Matemáticas}

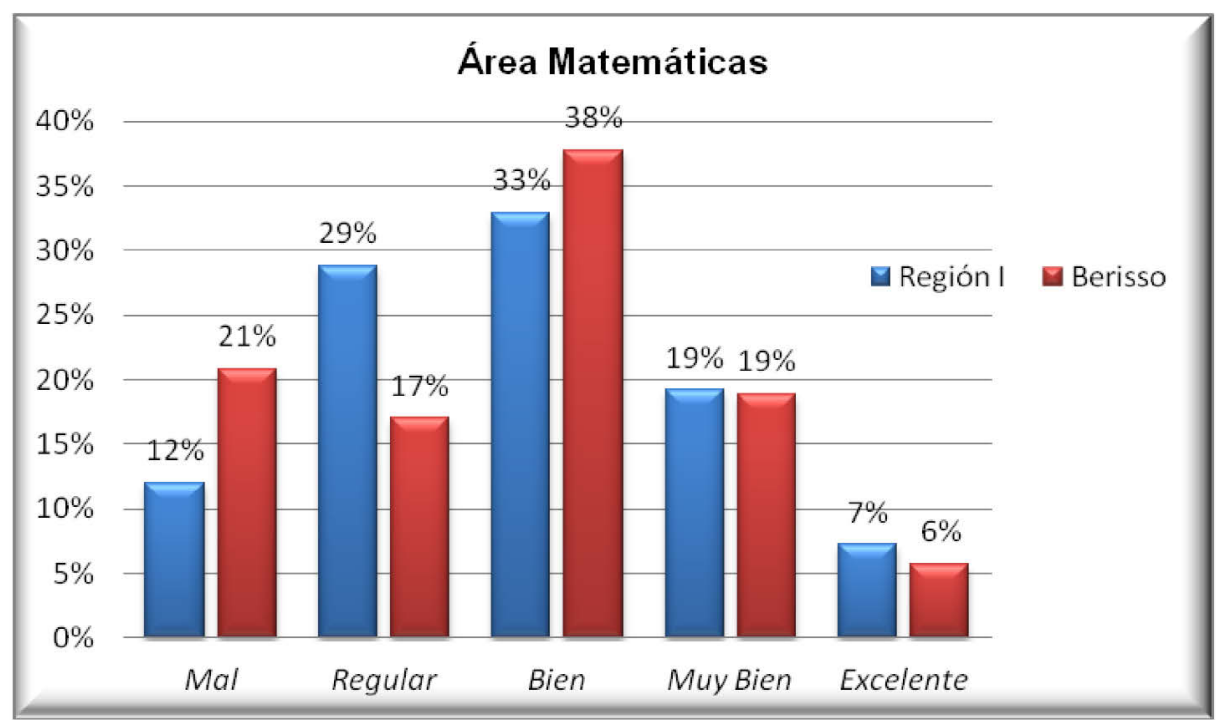

Fuente: Elaboración propia

En matemáticas, se ve reflejado que, tanto la calificación Bien como Mal se encuentran por encima de los resultados de todas las calificaciones de la Región I. Por el contrario en la calificación Regular el resultado de la Región I se encuentra por encima al obtenido por los expertos empresarios. También se aprecia que existe una paridad en las calificaciones Muy Bien y Excelente.

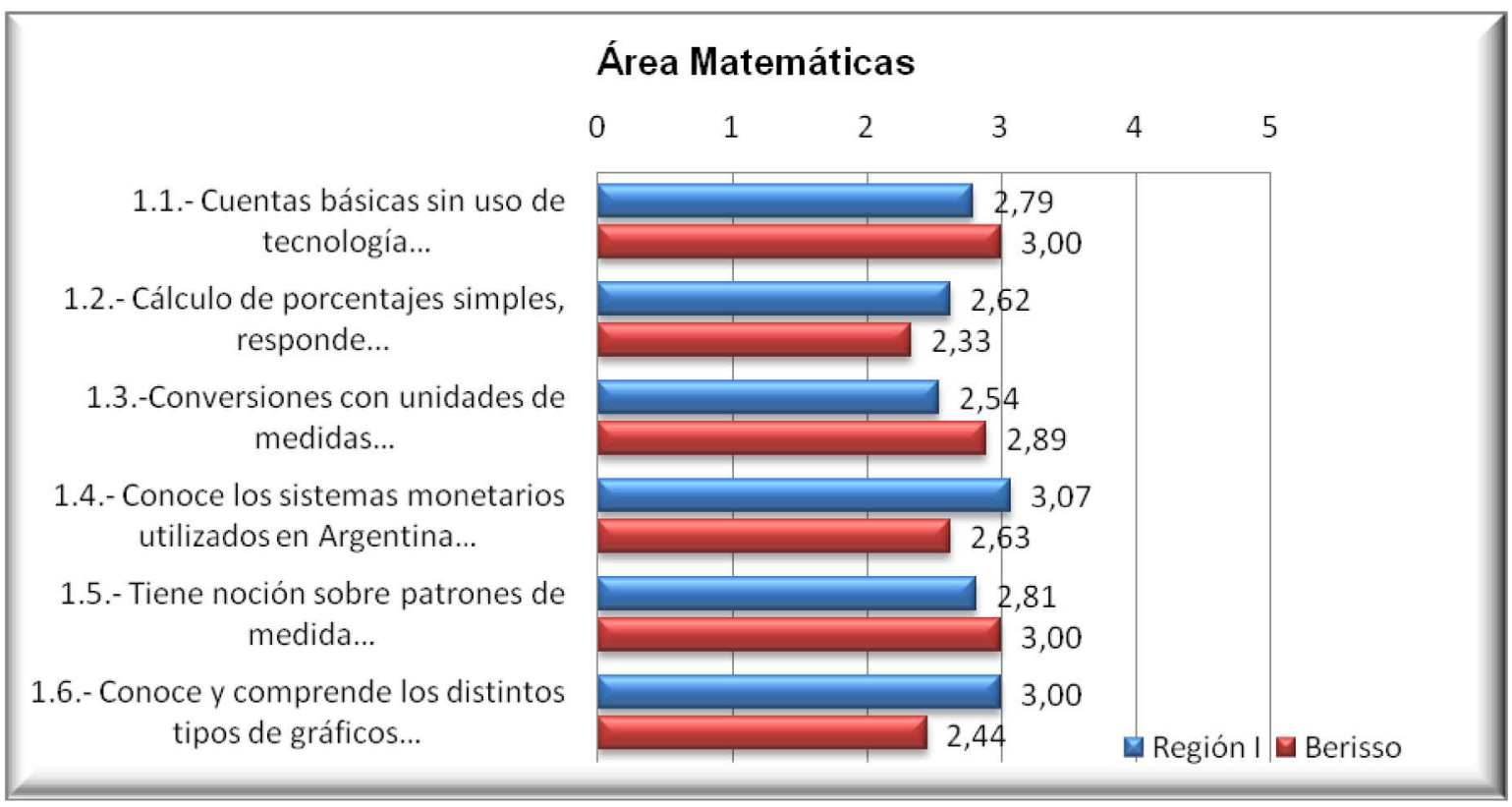

Fuente: Elaboración propia

Autor: Ing. Lucas F. Gambino

Director: Dr. Aldo H. Alonso 
En el gráfico que representa el saldo de respuesta de cada una de las preguntas evaluadas, se aprecia que en las preguntas: "Cuentas básicas sin uso de tecnología...", "Conversiones con unidades de medidas..." y "Tiene noción sobre patrones de medida..." según los resultados de los empresarios, el nivel educativo de Berisso es mayor en comparación con la región I. Por el contrario con el resto de las preguntas donde a criterio de los empresarios el nivel educativo de Berisso es menor que el de la Región I.

\section{Área Lengua}

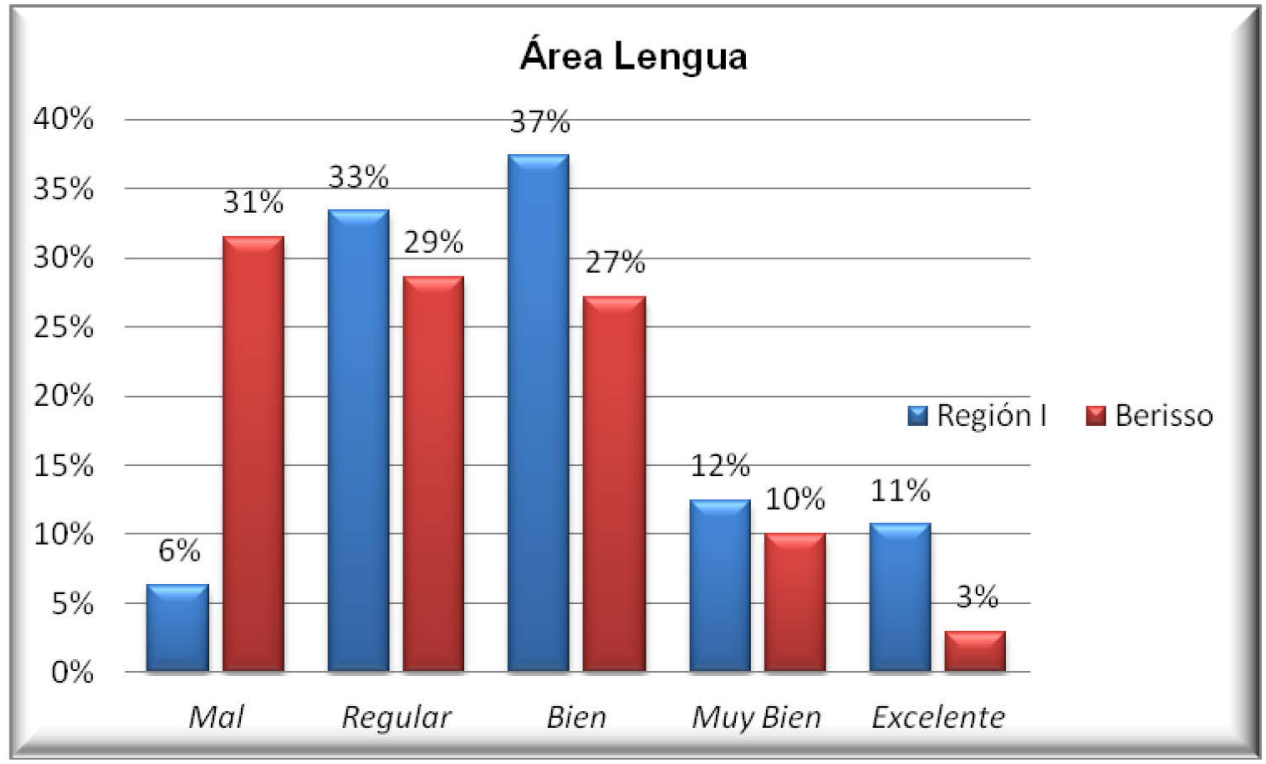

Fuente: Elaboración propia

En el gráfico anterior se refleja que el punto de Berisso con mayor porcentaje es Mal con 25\% de diferencia con respecto a la Región I. En cambio, las demás respuestas Berisso tiene menor porcentaje que la Región I. 


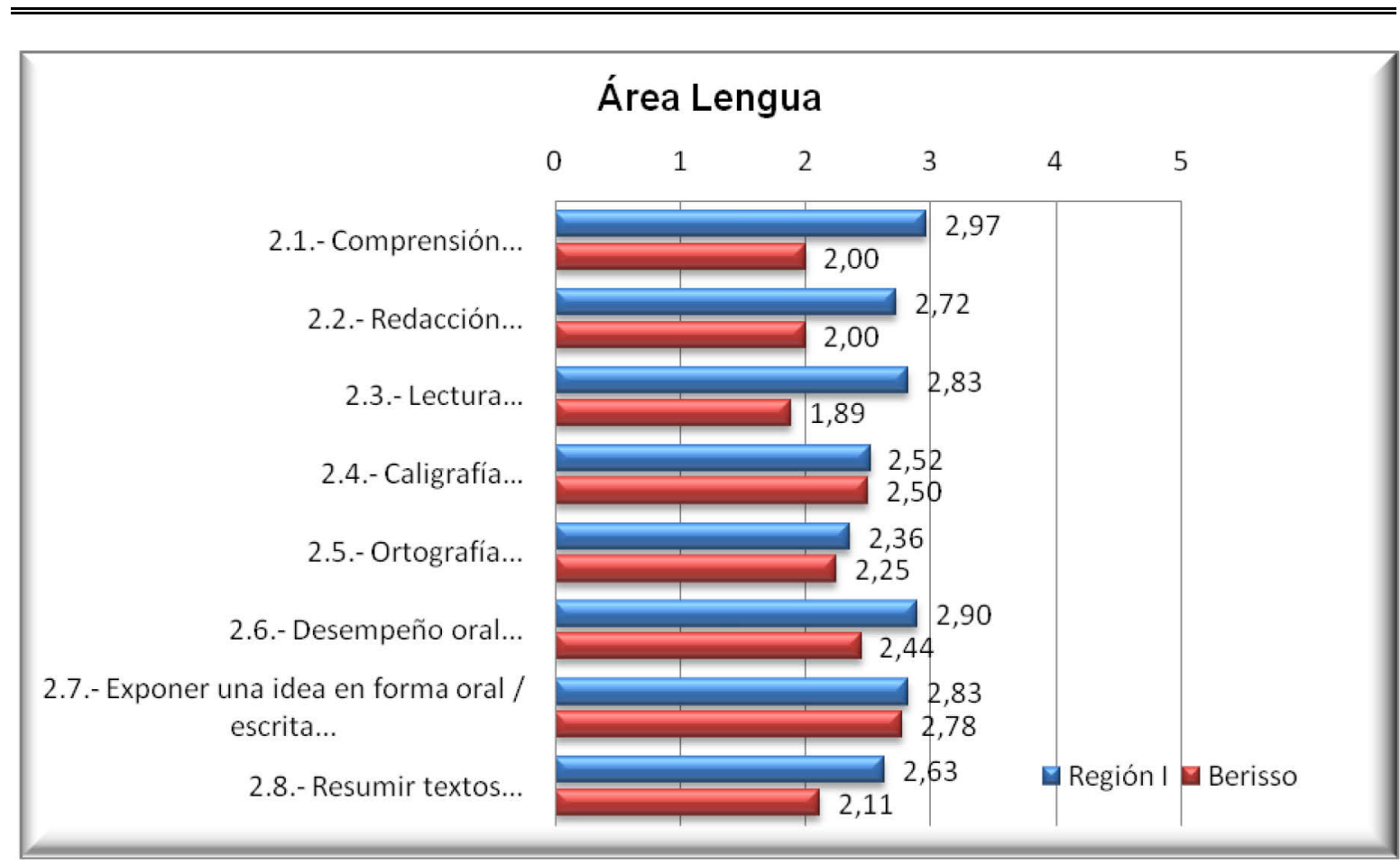

Fuente: Elaboración propia

En el gráfico del saldo de respuesta se observa que en todas las preguntas, los resultados de Berisso son menores que los de la región I.

\section{Área Ciencias}

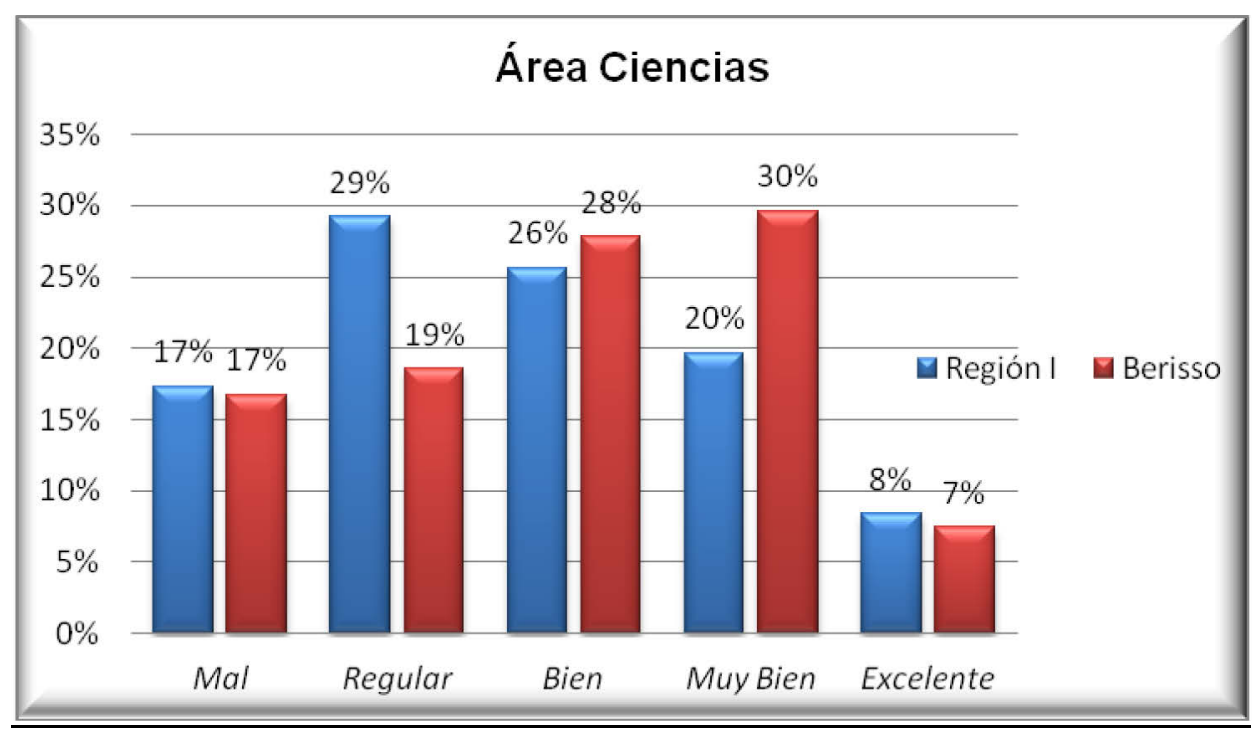

Fuente: Elaboración propia 
En ciencias, según las respuestas de los empresarios del partido de Berisso, las respuestas que tienen un porcentaje por encima de la región I son Bien y Muy Bien, con diferencias de $2 \%$ y $10 \%$ respectivamente.

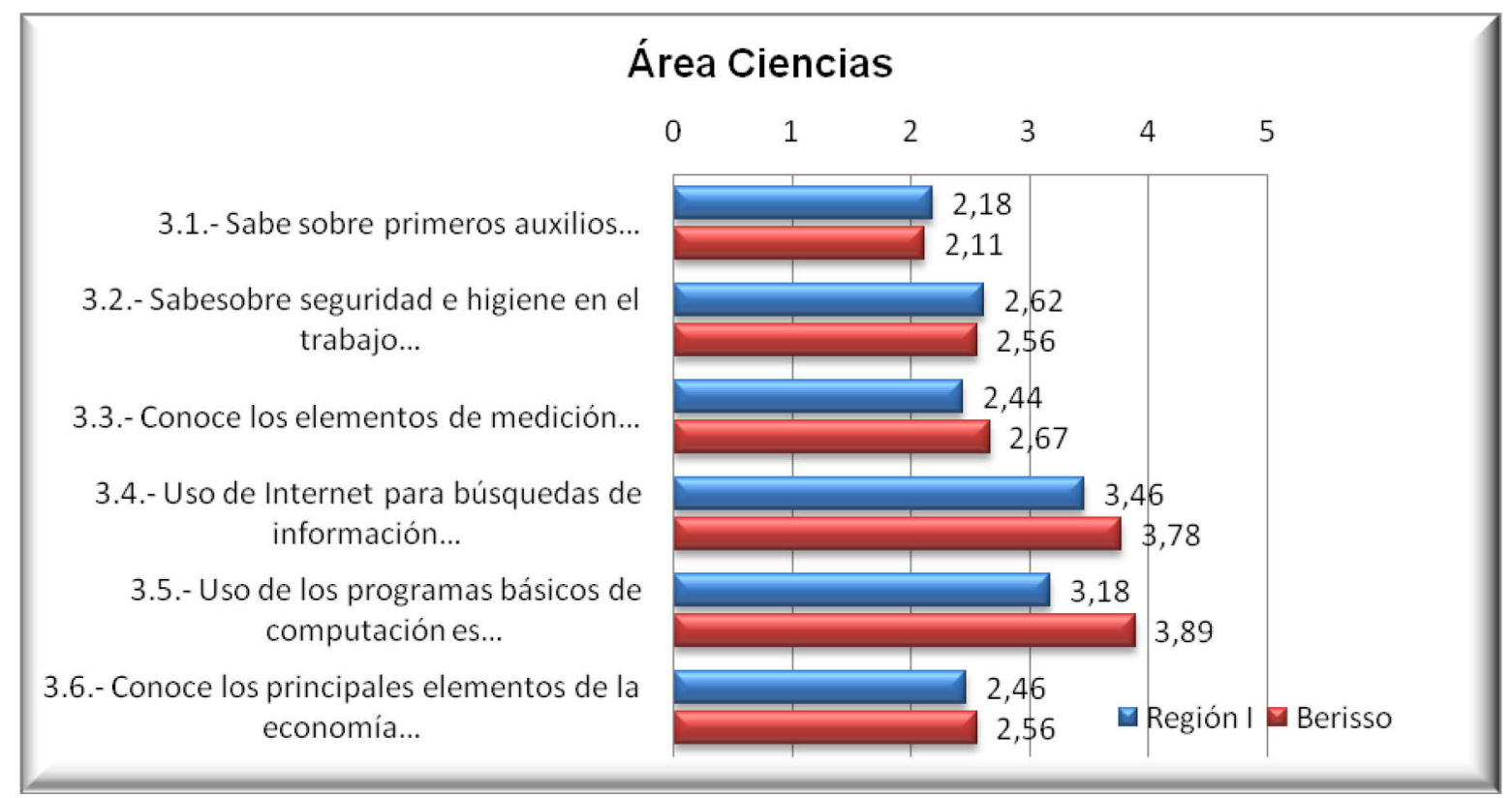

Fuente: Elaboración propia

En el gráfico anterior, se puede observar que existen respuestas de Berisso por encima del nivel de la región I, estan son: "Uso de Internet para búsquedas de información...", "Uso de los programas básicos de computación es..." y "Conoce los principales elementos de la economía...". 


\section{Aptitudes personales}

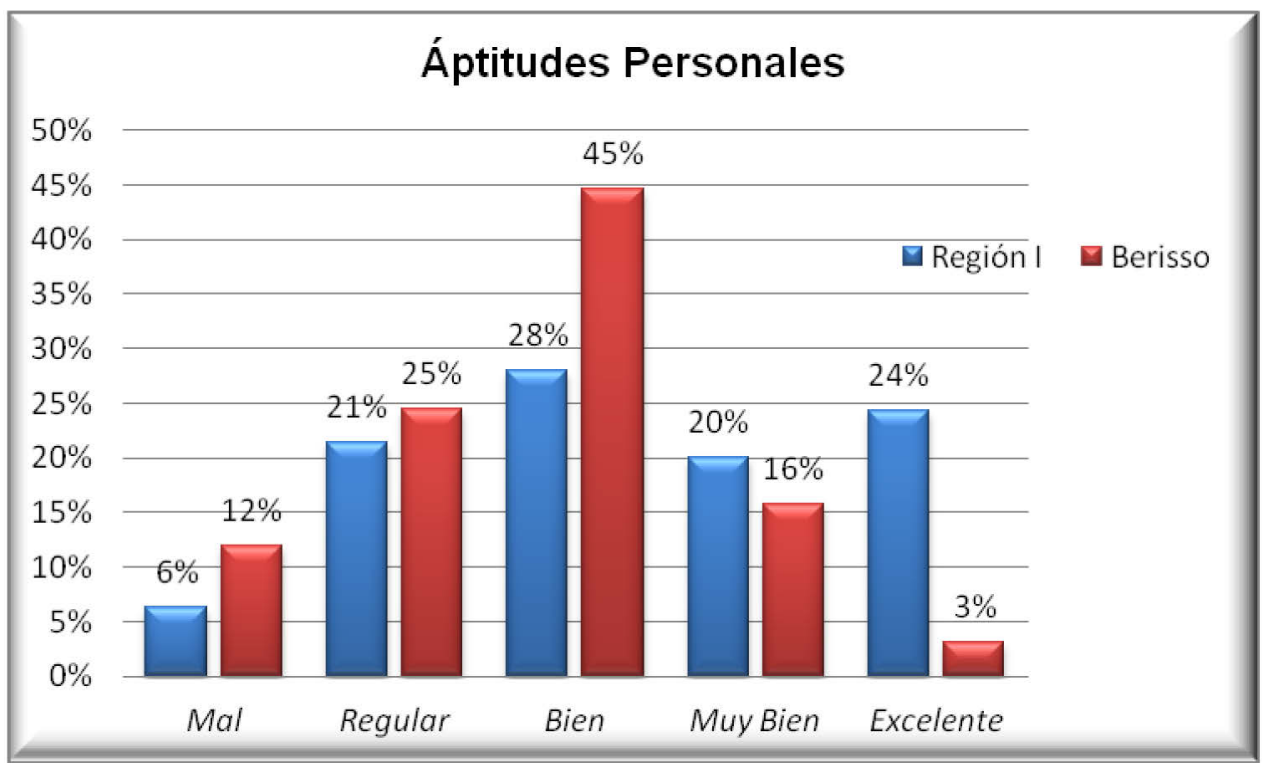

Fuente: Elaboración propia

En el área de las aptitudes personales, se puede observar que las respuestas del partido de Berisso con mayor porcentaje, en relación con la región I, son Bien, con $17 \%$, Regular, con $4 \%$, y Mal con $6 \%$ por encima de la región I. En cambio, Muy bien se ubica debajo por $4 \%$ y Excelente presenta una marcada diferencia, con un $21 \%$ menos en Berisso. 

Aptitudes Personales

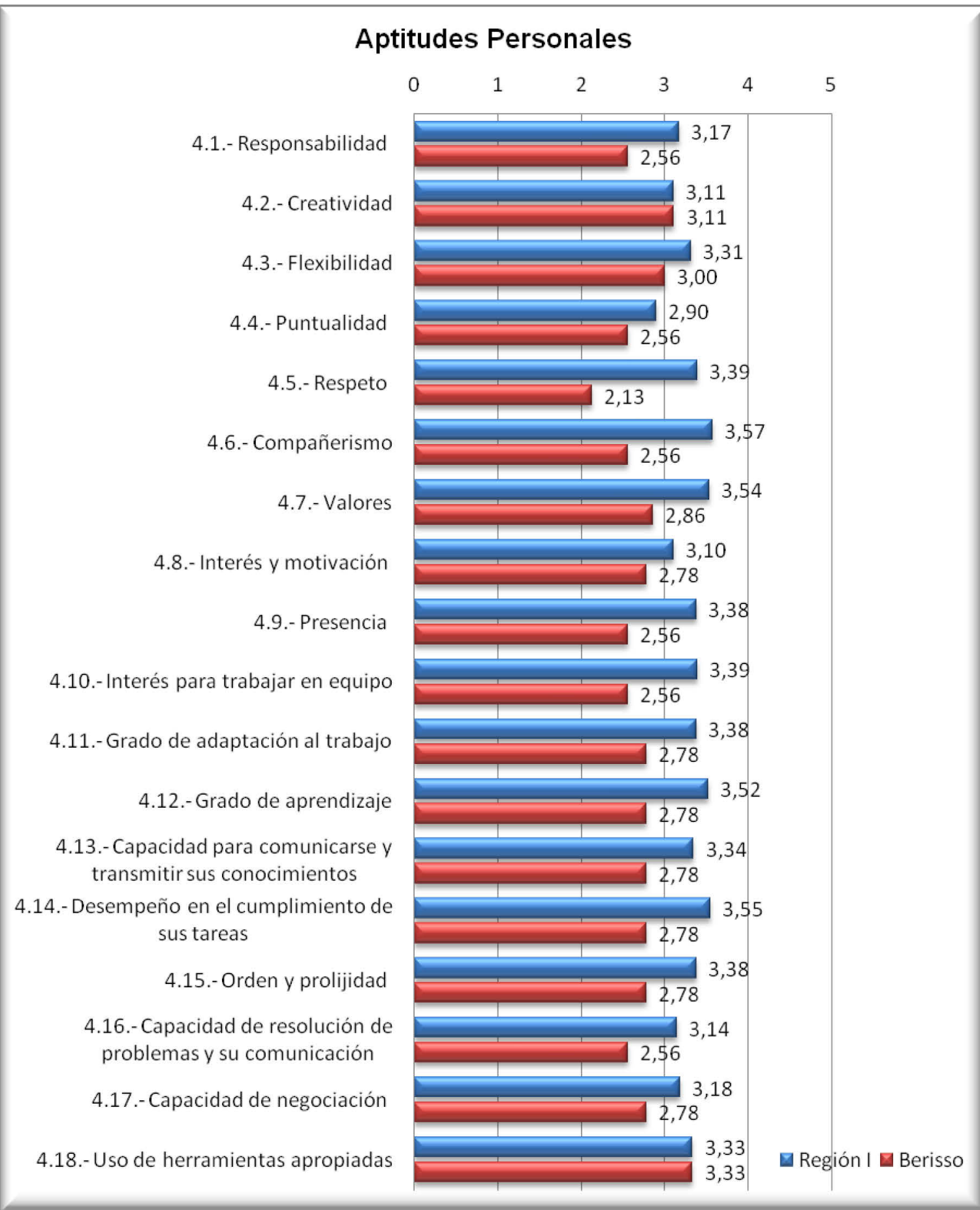

Fuente: Elaboración propia

En el gráfico anterior (saldos de respuesta) de cada pregunta del área Aptitudes, se aprecia que en todos los resultados los egresados de Berisso son inferiores a los de la región I. 
En algunos puntos en particular, la diferencia que hay entre Berisso y la región I es mayor a las demás, como sucede en el caso del "Respeto" y "Compañerismo". En los puntos "Creatividad" y "Uso de herramientas apropiadas" existe una paridad en cuanto a sus resultados.

\section{Comparación Regional respuestas de Empresarios Global}

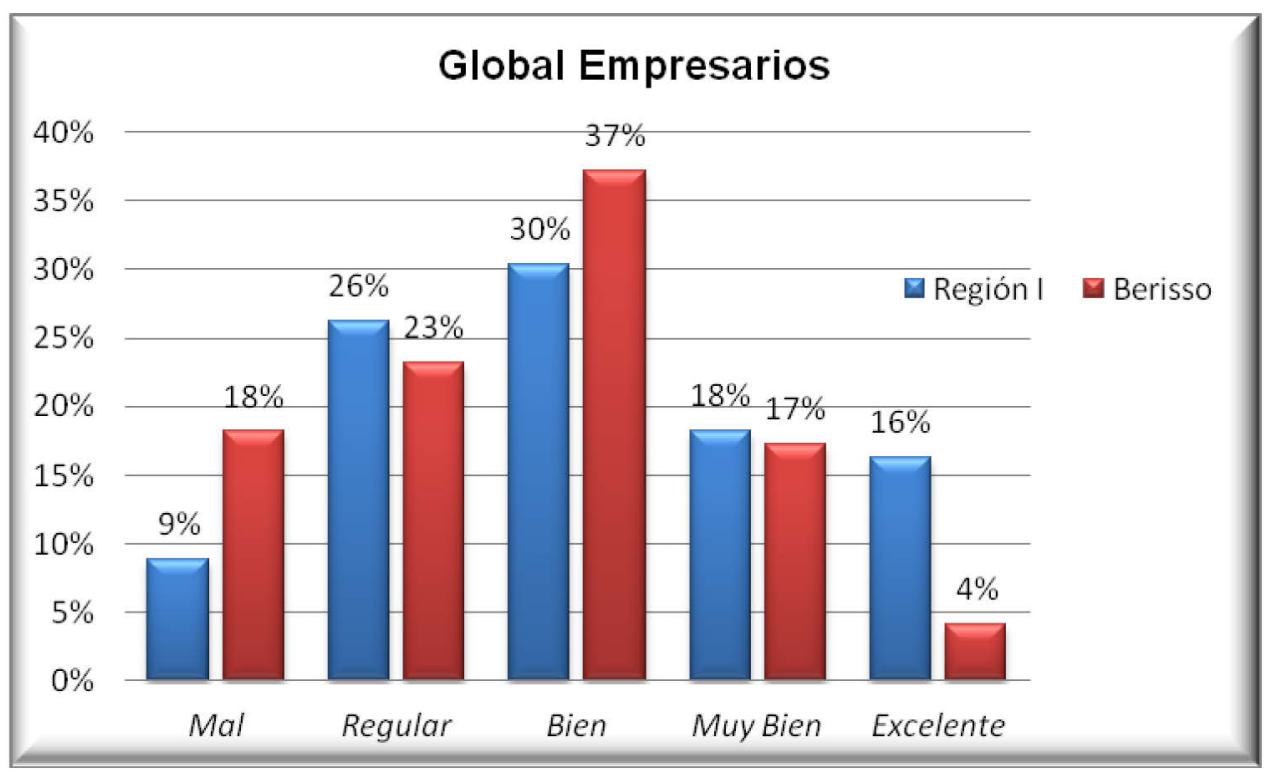

Fuente: Elaboración propia

En este punto, se puede apreciar los resultados globales de los empresarios, y su respectiva comparación con la región I. Se puede observar que el panel de expertos empresarios de Berisso tiene una mejor evaluación en Mal y Bien, mientras que la región I tiene mejor calificación en Regular y Excelente, mientras que existe una calificación similar entre ambos en Muy bien. 


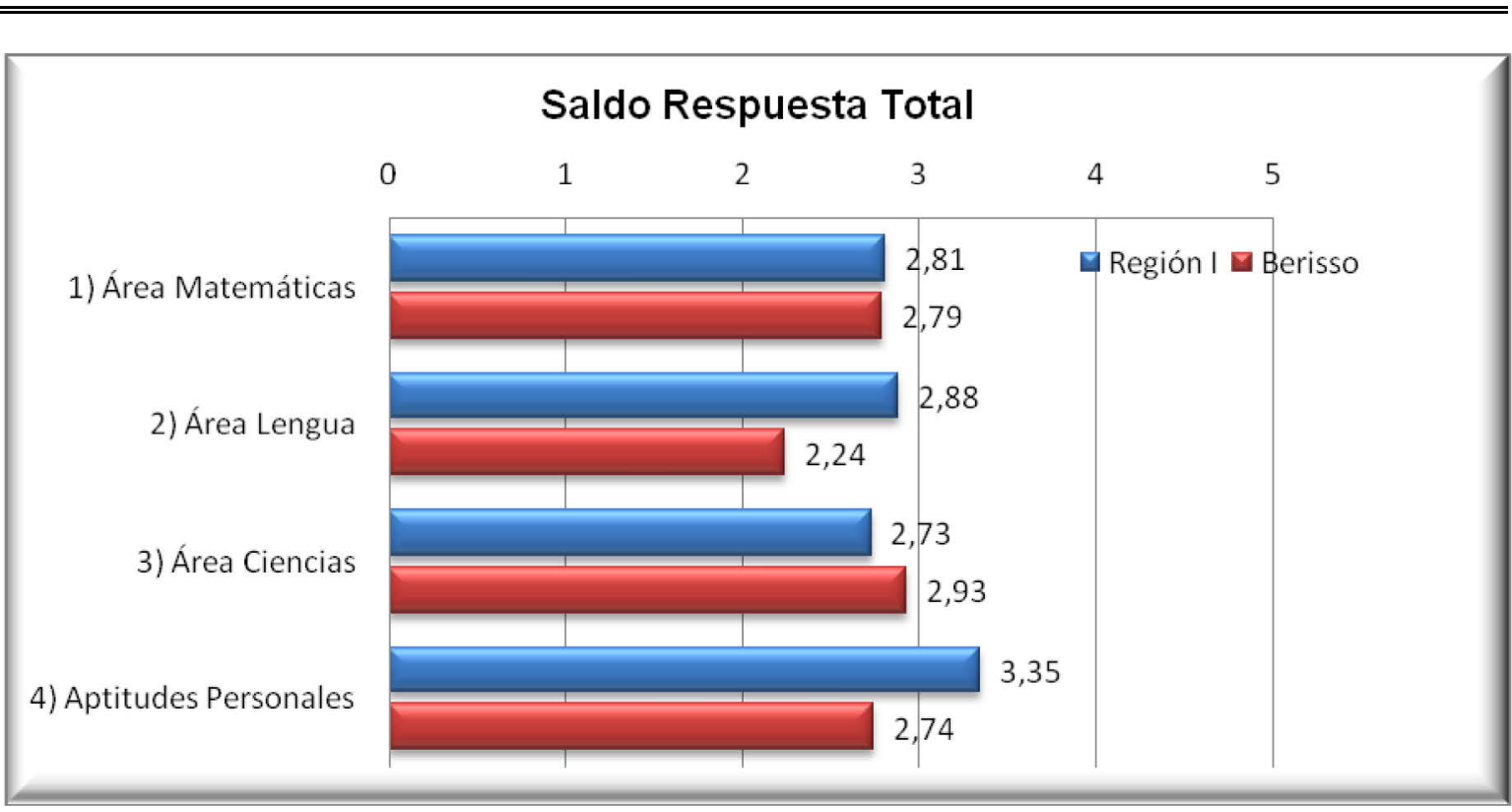

Fuente: Elaboración propia

En el gráfico de saldo de respuesta se puede observar que el panel de expertos empresarios de la región I tiene una mejor calificación en la mayoría de las materias respecto a Berisso, salvo en el área de Ciencias donde se ve mejor calificado a Berisso.

\subsubsection{Total regional}

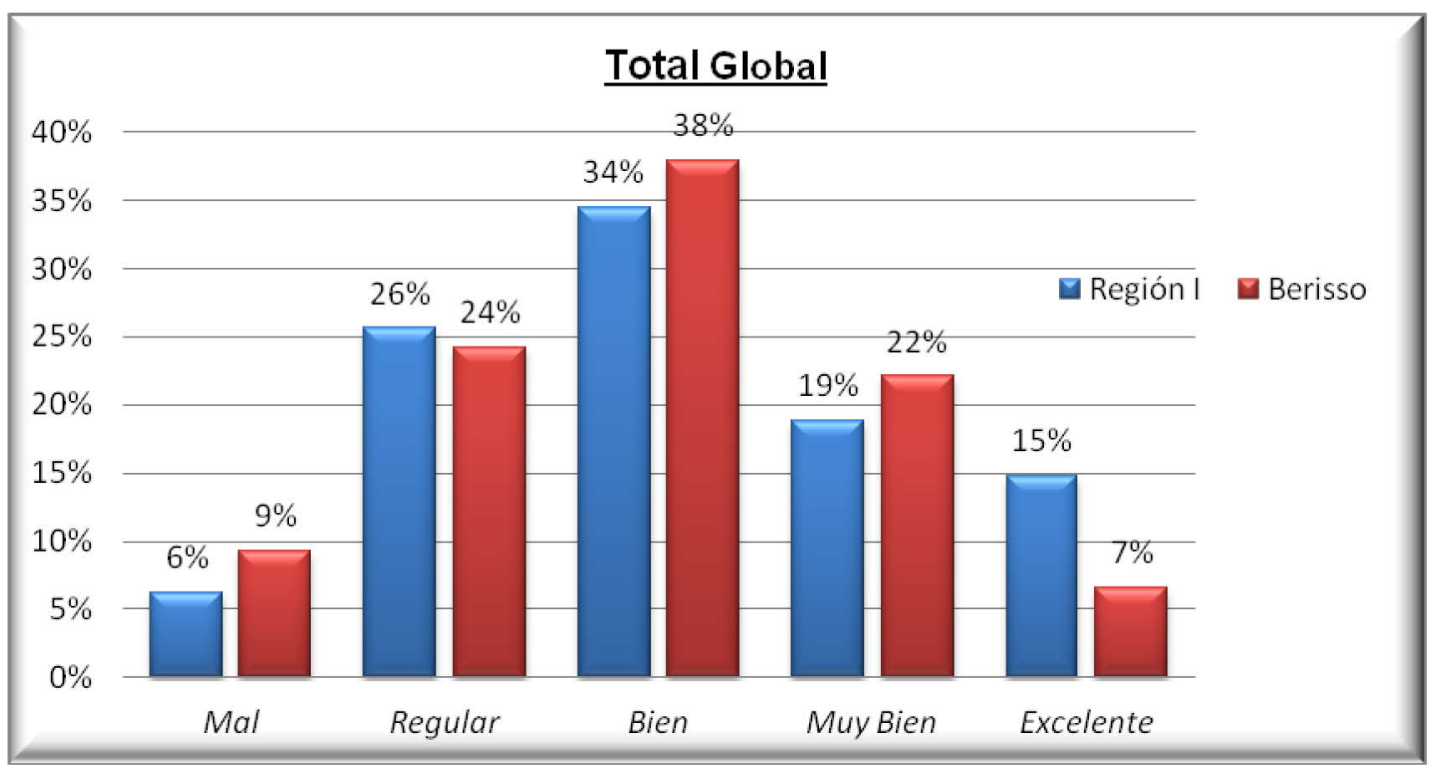

Fuente: Elaboración propia 
El total regional refleja la sumatoria de todos los resultados obtenidos en las encuestas, es decir, los del panel de expertos de docentes, y el de los empresarios. A su vez, se puede observar en los siguientes gráficos la diferencia que hay entre estos resultados y los de la región, la cual está compuesta por los partidos de La Plata, Berisso y Ensenada.

En el gráfico donde se muestran las distintas opciones de respuestas de la encuesta, se puede ver que los resultados del partido de Berisso tienen mayor porcentaje en las respuestas Bien, con 4\%, Muy Bien y Mal, con 3\% por encima de la región I. En cambio, Regular, con 2\% y Excelente con un $8 \%$ por debajo de la región I.

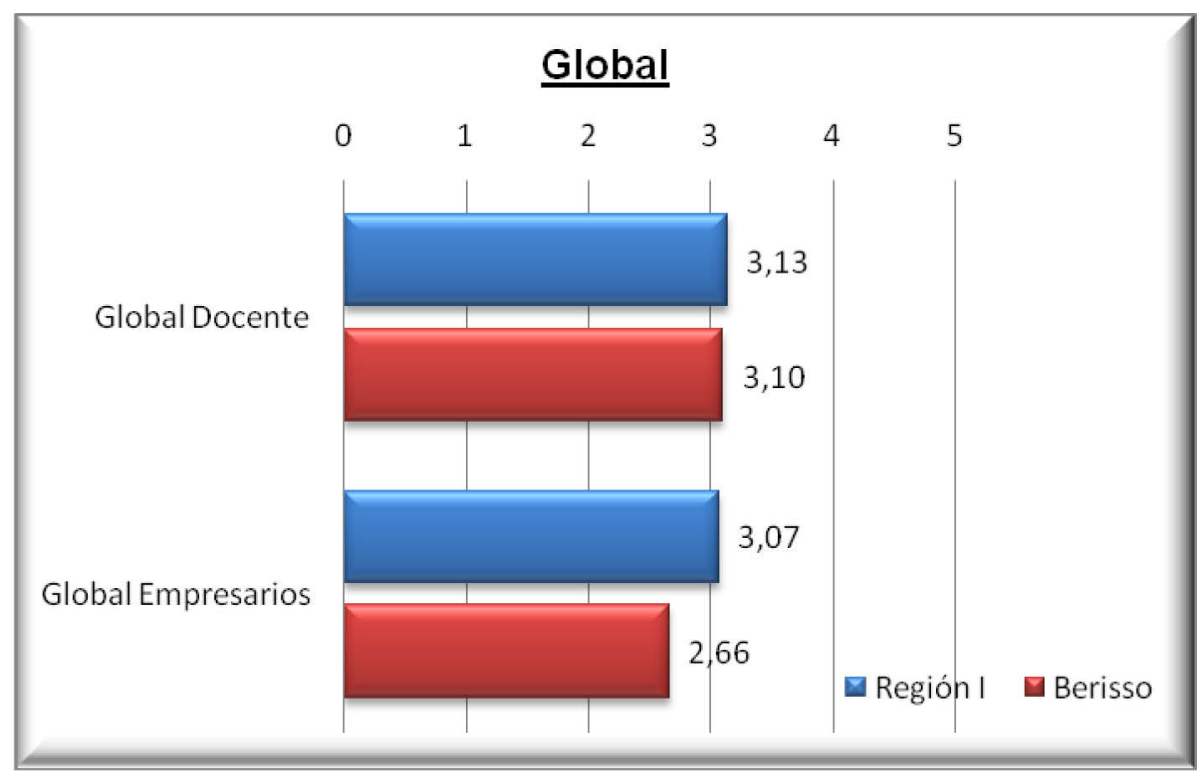

Fuente: Elaboración propia

En el gráfico global, que es el que representa los saldos respuestas totales de los docentes y los empresarios, comparados con la región I, se puede ver que en ambos casos, los resultados obtenidos en Berisso están por debajo de la región I. 


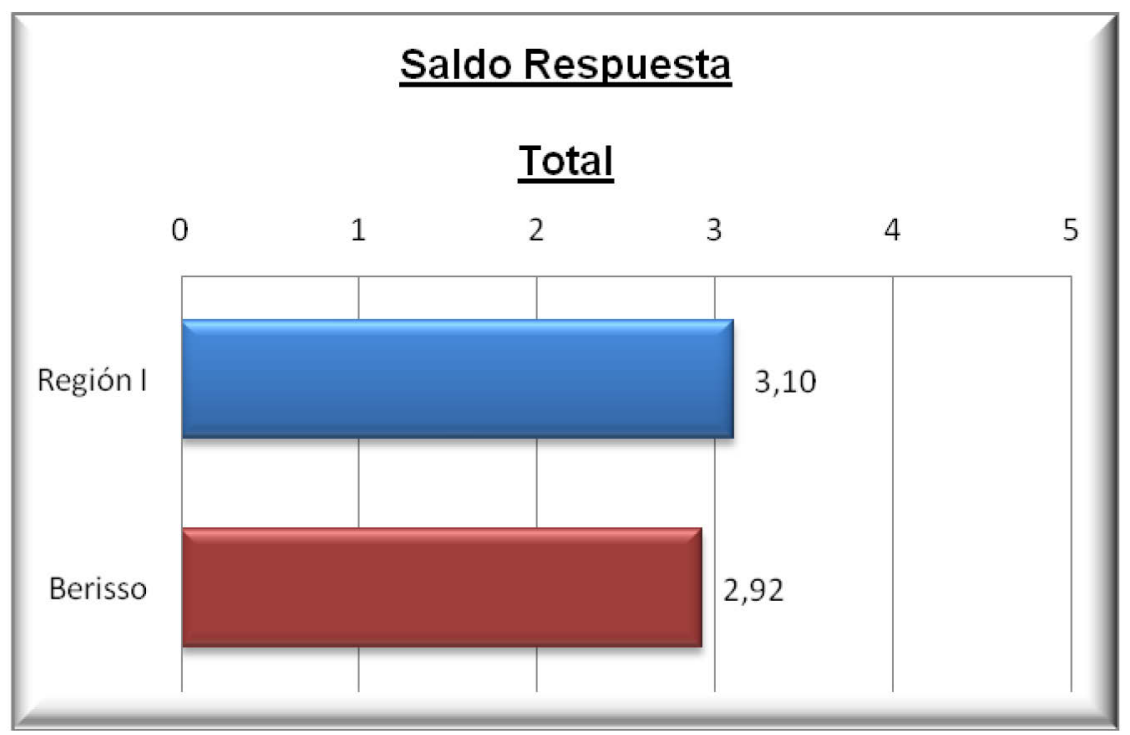

Fuente: Elaboración propia

Por último, el saldo de respuesta total, que hace referencia a todas las respuestas de las áreas evaluadas, tanto de empresarios como docentes. En este caso se observa que, como resumen de los gráficos anteriores, el partido de Berisso tiene un menor nivel educativo, comparado con la región I, con una diferencia de 0,18.

\subsubsection{Comparación internacional}

El resumen de las calificaciones para Berisso por áreas es:

\begin{tabular}{|l|r|r|r|}
\hline & Matemáticas & Lengua & Ciencias \\
\hline Berisso (Docentes) & 2,94 & 3,00 & 2,98 \\
\hline Berisso (Empresarios) & 2,72 & 2,24 & 2,93 \\
\hline Total Berisso $\left(^{*}\right)$ & 2,83 & 2,62 & 2,96 \\
\hline
\end{tabular}

$\left.{ }^{*}\right)$ Promedio ponderado de las calificaciones de Docentes y Empresarios

Su transformación a la escala de PISA, acorde con la ecuación de transformación determinada en el punto 6.4 es:

\begin{tabular}{|l|r|r|r|}
\hline & Matemáticas & Lengua & Ciencias \\
\hline Berisso (Docentes) & 388 & 400 & 396 \\
\hline Berisso (Empresarios) & 344 & 248 & 386 \\
\hline Total Berisso $\left(^{*}\right)$ & 366 & 324 & 391 \\
\hline
\end{tabular}


A continuación se muestran las tablas jerárquicas del informe PISA 2009 a las que se les añadió la ubicación en ellas de Berisso:

Matemáticas

\begin{tabular}{|c|c|c|c|}
\hline Nivel & Jerarquía & Países & Media \\
\hline \multirow{4}{*}{4} & 1 & Shanghái - China & 600 \\
\hline & 2 & Singapur & 562 \\
\hline & 3 & Hong Kong - China & 555 \\
\hline & 4 & Corea del Sur & 546 \\
\hline \multirow{27}{*}{3} & 5 & Taipéi - China & 543 \\
\hline & 6 & Finlandia & 541 \\
\hline & 7 & Liechtenstein & 536 \\
\hline & 8 & Suiza & 534 \\
\hline & 9 & Japón & 529 \\
\hline & 10 & Canadá & 527 \\
\hline & 11 & Países Bajos & 526 \\
\hline & 12 & Macao - China & 525 \\
\hline & 13 & Nueva Zelanda & 519 \\
\hline & 14 & Bélgica & 515 \\
\hline & 15 & Australia & 514 \\
\hline & 16 & Alemania & 513 \\
\hline & 17 & Estonia & 512 \\
\hline & 18 & Islandia & 507 \\
\hline & 19 & Dinamarca & 503 \\
\hline & 20 & Eslovenia & 501 \\
\hline & 21 & Noruega & 498 \\
\hline & 22 & Francia & 497 \\
\hline & 23 & $\begin{array}{l}\text { República } \\
\text { Eslovaca }\end{array}$ & 497 \\
\hline & 24 & Austria & 496 \\
\hline & 25 & Polonia & 495 \\
\hline & 26 & Suecia & 494 \\
\hline & 27 & República Checa & 493 \\
\hline & 28 & Reino Unido & 492 \\
\hline & 29 & Hungría & 490 \\
\hline & 30 & Luxemburgo & 489 \\
\hline & 31 & Estados Unidos & 487 \\
\hline
\end{tabular}


Calidad Educativa del Nivel Secundario de Berisso

\begin{tabular}{|c|c|c|c|}
\hline & 32 & Irlanda & 487 \\
\hline & 33 & Portugal & 487 \\
\hline & 34 & España & 483 \\
\hline & 35 & Italia & 483 \\
\hline & 36 & Letonia & 482 \\
\hline \multirow{13}{*}{2} & 37 & Lituania & 477 \\
\hline & 38 & Federación Rusa & 468 \\
\hline & 39 & Grecia & 466 \\
\hline & 40 & Croacia & 460 \\
\hline & 41 & Dubái (EAU) & 453 \\
\hline & 42 & Israel & 447 \\
\hline & 43 & Turquía & 445 \\
\hline & 44 & Serbia & 442 \\
\hline & 45 & Azerbaiyán & 431 \\
\hline & 46 & Bulgaria & 428 \\
\hline & 47 & Rumania & 427 \\
\hline & 48 & Uruguay & 427 \\
\hline & 49 & Chile & 421 \\
\hline \multirow{17}{*}{1} & 50 & Tailandia & 419 \\
\hline & 51 & México & 419 \\
\hline & 52 & Trinidad y Tobago & 414 \\
\hline & 53 & Kazajistán & 405 \\
\hline & 54 & Montenegro & 403 \\
\hline & 55 & Argentina & 388 \\
\hline & 56 & Jordania & 387 \\
\hline & 57 & Brasil & 386 \\
\hline & 58 & Colombia & 381 \\
\hline & 59 & Albania & 377 \\
\hline & 60 & Túnez & 371 \\
\hline & 61 & Indonesia & 371 \\
\hline & 62 & La Plata & 370 \\
\hline & 63 & Qatar & 368 \\
\hline & 64 & Berisso & 366 \\
\hline & 65 & Perú & 365 \\
\hline & 66 & Panamá & 360 \\
\hline-1 & 67 & Ensenada & 332 \\
\hline
\end{tabular}




\begin{tabular}{|c|c|c|c|} 
& 68 & Kirguistán & 331 \\
\hline & & Promedio OCDE & 496 \\
\hline
\end{tabular}

Fuente: PISA 2009

\section{Lengua}

\begin{tabular}{|c|c|c|c|}
\hline Nivel & Jerarquía & Países & Media \\
\hline 4 & 1 & Shanghái - China & 556 \\
\hline \multirow{30}{*}{3} & 2 & Corea del Sur & 539 \\
\hline & 3 & Finlandia & 536 \\
\hline & 4 & Hong Kong - China & 533 \\
\hline & 5 & Singapur & 526 \\
\hline & 6 & Canadá & 524 \\
\hline & 7 & Nueva Zelanda & 521 \\
\hline & 8 & Japón & 520 \\
\hline & 9 & Australia & 515 \\
\hline & 10 & Países Bajos & 508 \\
\hline & 11 & Bélgica & 506 \\
\hline & 12 & Noruega & 503 \\
\hline & 13 & Estonia & 501 \\
\hline & 14 & Suiza & 501 \\
\hline & 15 & Polonia & 500 \\
\hline & 16 & Islandia & 500 \\
\hline & 17 & Estados Unidos & 500 \\
\hline & 18 & Liechtenstein & 499 \\
\hline & 19 & Suecia & 497 \\
\hline & 20 & Alemania & 497 \\
\hline & 21 & Irlanda & 496 \\
\hline & 22 & Francia & 496 \\
\hline & 23 & Taipéi - China & 495 \\
\hline & 24 & Dinamarca & 495 \\
\hline & 25 & Reino Unido & 494 \\
\hline & 26 & Hungría & 494 \\
\hline & 27 & Portugal & 489 \\
\hline & 28 & Macao - China & 487 \\
\hline & 29 & Italia & 486 \\
\hline & 30 & Letonia & 484 \\
\hline & 31 & Eslovenia & 483 \\
\hline
\end{tabular}


Calidad Educativa del Nivel Secundario de Berisso

\begin{tabular}{|c|c|c|c|}
\hline & 32 & Grecia & 483 \\
\hline & 33 & España & 481 \\
\hline \multirow{21}{*}{2} & 34 & República Checa & 478 \\
\hline & 35 & $\begin{array}{l}\text { República } \\
\text { Eslovaca }\end{array}$ & 477 \\
\hline & 36 & Croacia & 476 \\
\hline & 37 & Israel & 474 \\
\hline & 38 & Luxemburgo & 472 \\
\hline & 39 & Austria & 470 \\
\hline & 40 & Lituania & 468 \\
\hline & 41 & Turquía & 464 \\
\hline & 42 & Dubái (EAU) & 459 \\
\hline & 43 & Federación Rusa & 459 \\
\hline & 44 & Chile & 449 \\
\hline & 45 & Serbia & 442 \\
\hline & 46 & Bulgaria & 429 \\
\hline & 47 & Uruguay & 426 \\
\hline & 48 & México & 425 \\
\hline & 49 & Rumania & 424 \\
\hline & 50 & Tailandia & 421 \\
\hline & 51 & Trinidad y Tobago & 416 \\
\hline & 52 & Colombia & 413 \\
\hline & 53 & Brasil & 412 \\
\hline & 54 & Montenegro & 408 \\
\hline \multirow{11}{*}{$1 a$} & 55 & Jordania & 405 \\
\hline & 56 & Túnez & 404 \\
\hline & 57 & Indonesia & 402 \\
\hline & 58 & La Plata & 402 \\
\hline & 59 & Argentina & 398 \\
\hline & 60 & Kazajistán & 390 \\
\hline & 61 & Albania & 385 \\
\hline & 62 & Qatar & 372 \\
\hline & 63 & Panamá & 371 \\
\hline & 64 & Perú & 370 \\
\hline & 65 & Azerbaiyán & 362 \\
\hline \multirow{2}{*}{$1 b$} & 66 & Berisso & 324 \\
\hline & 67 & Kirguistán & 314 \\
\hline
\end{tabular}


Calidad Educativa del Nivel Secundario de Berisso

\begin{tabular}{|c|c|c|c|}
\hline & 68 & Ensenada & 300 \\
\hline & & Promedio OCDE & 493 \\
\hline
\end{tabular}

Fuente: PISA 2009

\section{Ciencias}

\begin{tabular}{|c|c|c|c|}
\hline Nivel & Jerarquia & Países & Media \\
\hline 4 & 1 & Shanghái - China & 575 \\
\hline \multirow{30}{*}{3} & 2 & Finlandia & 554 \\
\hline & 3 & Hong Kong - China & 549 \\
\hline & 4 & Singapur & 542 \\
\hline & 5 & Japón & 539 \\
\hline & 6 & Corea del Sur & 538 \\
\hline & 7 & Nueva Zelanda & 532 \\
\hline & 8 & Canadá & 529 \\
\hline & 9 & Estonia & 528 \\
\hline & 10 & Australia & 527 \\
\hline & 11 & Países Bajos & 522 \\
\hline & 12 & Taipéi - China & 520 \\
\hline & 13 & Alemania & 520 \\
\hline & 14 & Liechtenstein & 520 \\
\hline & 15 & Suiza & 517 \\
\hline & 16 & Reino Unido & 514 \\
\hline & 17 & Eslovenia & 512 \\
\hline & 18 & Macao - China & 511 \\
\hline & 19 & Polonia & 508 \\
\hline & 20 & Irlanda & 508 \\
\hline & 21 & Bélgica & 507 \\
\hline & 22 & Hungría & 503 \\
\hline & 23 & Estados Unidos & 502 \\
\hline & 24 & República Checa & 500 \\
\hline & 25 & Noruega & 500 \\
\hline & 26 & Dinamarca & 499 \\
\hline & 27 & Francia & 498 \\
\hline & 28 & Islandia & 496 \\
\hline & 29 & Suecia & 495 \\
\hline & 30 & Austria & 494 \\
\hline & 31 & Letonia & 494 \\
\hline
\end{tabular}


Calidad Educativa del Nivel Secundario de Berisso

\begin{tabular}{|c|c|c|c|}
\hline & 32 & Portugal & 493 \\
\hline & 33 & Lituania & 491 \\
\hline & 34 & $\begin{array}{c}\text { República } \\
\text { Eslovaca }\end{array}$ & 490 \\
\hline & 35 & Italia & 489 \\
\hline & 36 & España & 488 \\
\hline & 37 & Croacia & 486 \\
\hline & 38 & Luxemburgo & 484 \\
\hline \multirow{14}{*}{2} & 39 & Federación Rusa & 478 \\
\hline & 40 & Grecia & 470 \\
\hline & 41 & Dubái (EAU) & 466 \\
\hline & 42 & Israel & 455 \\
\hline & 43 & Turquía & 454 \\
\hline & 44 & Chile & 447 \\
\hline & 45 & Serbia & 443 \\
\hline & 46 & Bulgaria & 439 \\
\hline & 47 & Rumania & 428 \\
\hline & 48 & Uruguay & 427 \\
\hline & 49 & Tailandia & 425 \\
\hline & 50 & México & 416 \\
\hline & 51 & Jordania & 415 \\
\hline & 52 & Trinidad y Tobago & 410 \\
\hline \multirow{14}{*}{1} & 53 & Brasil & 405 \\
\hline & 54 & Colombia & 402 \\
\hline & 55 & Montenegro & 401 \\
\hline & 56 & Argentina & 401 \\
\hline & 57 & Túnez & 401 \\
\hline & 58 & Kazajistán & 400 \\
\hline & 59 & La Plata & 394 \\
\hline & 60 & Berisso & 391 \\
\hline & 61 & Albania & 391 \\
\hline & 62 & Indonesia & 383 \\
\hline & 63 & Qatar & 379 \\
\hline & 64 & Panamá & 376 \\
\hline & 65 & Azerbaiyán & 373 \\
\hline & 66 & Perú & 369 \\
\hline-1 & 67 & Kirguistán & 330 \\
\hline
\end{tabular}




\begin{tabular}{|l|c|c|c|} 
& $\mathbf{6 8}$ & Ensenada & $\mathbf{3 0 4}$ \\
\hline & & Promedio OCDE & 496 \\
\hline
\end{tabular}

\section{Conclusiones}

Analizando los datos obtenidos es posible afirmar lo siguiente:

> Se observa que en todos los casos evaluados, los egresados presentan un desempeño que fluctúa entre Regular y Bien, y un menor porcentaje en Muy Bien.

D El panel de expertos de los empresarios tiene una mirada más crítica acerca de los conocimientos y aptitudes de los egresados, debido a que en las encuestas se puede observar que su valoración al respecto es menor que la de los docentes. Esto puede estar influido por el hecho de que el empresario es el usuario de los servicios del alumno al momento de trabajar y no tiene ningún tipo de responsabilidad sobre sus conocimientos.

$>\quad$ Tanto los docentes como los empresarios de la región tienen un mejor saldo de respuesta que los docentes y empresarios de Berisso.

$>\quad$ Según el panel de expertos docentes, los saldos de respuestas en todas las áreas los egresados tienen mayor calificación que los obtenidos por el panel de expertos empresarios.

$>\quad$ En el panel de expertos docentes el área con mayor saldo de respuesta es el referido a las aptitudes personales, mientras que para el panel de expertos compuesto por empresarios es el área de Ciencias.

$>\quad$ Berisso, en comparación con la Región I, muestra mayor nivel en la calidad educativa del secundario, ya que en ambos paneles de expertos el porcentaje en Regular fue de $26 \%$ para la Región I y $24 \%$ para Berisso, en cambio en Bien Berisso tiene un 38\% respecto a la Región I que tiene un $34 \%$ y en la respuesta Muy Bien los paneles de expertos le dan el $22 \%$ a Berisso y el $19 \%$ a la Región I. 
> El saldo de respuesta global de la Región I en comparación con Berisso tanto los docentes como los empresarios de la Región I le dan mejor saldo de respuesta que los docentes y empresarios de Berisso.

$>\quad$ En referencia a los datos secundarios, Berisso en comparación con la región l, presenta:

$\checkmark$ Mayor tasa de matriculación, en el año 2010 y 2011 que la región I.

$\checkmark$ Menor tasa de sobre-edad en Berisso en el año 2010 y mayor en el año 2011 con respecto a la Región I.

$\checkmark$ Levemente menor tasa de alfabetización con respecto a la Región I en los años 2010 y 2011, es decir, que Berisso presenta mayor grado de analfabetismo que en la Región I.

$>\quad$ Con respecto a los datos obtenidos de la fuente primaria:

$\checkmark$ En lo referido a la comparación internacional, se ha observado que Berisso se ha posicionado por debajo de Argentina en todas sus disciplinas. Cabe destacar que Berisso se encuentra por debajo de La Plata y por encima de Ensenada en todas sus áreas.

$\checkmark$ En matemáticas Argentina se encuentra en el puesto 55 con 388 puntos, La Plata está en la ubicación 62 con 370 puntos, Berisso en la ubicación 64 con 366 puntos y Ensenada en la ubicación 67 con 332 puntos.

$\checkmark$ En Lengua Argentina se encuentra en el puesto 60 con 398 puntos, La Plata se encuentra por encima de la Argentina en el puesto 57 con 402 puntos, Berisso está en el puesto 66 con 324 puntos y Ensenada se encuentra en la ubicación 68 (último lugar) con 300 puntos.

$\checkmark$ En Ciencias la Argentina se encuentra en el puesto 56 con 401 puntos y La Plata se encuentra en el puesto 59 con 394 puntos, Berisso está en el puesto 60 con 391 puntos y Ensenada se encuentra en el último puesto con 304 puntos.

$>$ Es importante tener presente que para PISA «Los estudiantes que alcanzan el nivel 2, tienen las competencias mínimas para desenvolverse en el mundo e integrarse productivamente a la sociedad», en las tres áreas tanto 
Argentina como Berisso se han ubicado por debajo de este nivel. Se encuentran en el nivel 1 con calificaciones muy bajas.

Este trabajo ha tenido por objetivo poner en palabras de quienes transitan las instituciones educativas lo que los grandes números expresan al describir fenómenos complejos frente a los cuales aún, como sociedad, como especialistas, como gobierno, no se ha encontrado solución.

Decir que hay un descenso de la matrícula y una disminución de la retención sin más es mostrar sólo una parte de la realidad.

Hacer diagnósticos desde espacios estatales tiene un correlato inmediato (o debería tenerlo) sobre la posibilidad de tomar decisiones con lo que se visibiliza, con lo que se analiza. No con el sentido de señalar culpas sino de asumir, en conjunto, responsabilidades que son del sistema, de las instituciones y de los actores.

Dicho trabajo de investigación realizado en un Centro de Formación Profesional, dos escuelas estatales de nivel secundario y un Instituto de enseñanza de nivel terciario de la Ciudad de Berisso, permite afirmar que, en la percepción de directivos y docentes la inclusión como política no ha logrado satisfacer los discursos aunque el abandono o las dificultades para mejorar la retención no aparecen connotados como una preocupación. Esto hace que todavía persistan algunas prácticas que distan de incorporar otras dimensiones de la inclusión educativa que impactan en el retraso de los cambios que deben implementarse para promover mejores aprendizajes y prácticas de relevancia social y cultural.

En el diálogo con las instituciones también se ha comprobado que muchas están solas, libradas a su suerte y aún no han encontrado la forma de producir 
otras cosas y que sus esfuerzos o los recursos destinados a través de programas o cargos docentes parecen tener un impacto bajo.

El ingreso de los adolescentes que aún están fuera del sistema educativo, la permanencia en la escuela de los adolescentes provenientes de los sectores socialmente más desfavorecidos, así como lograr que sus trayectorias escolares se adecuen cada vez más a la trayectoria escolar teóricamente estipulada resultan los principales desafíos a los que se enfrenta hoy el sistema educativo de la Provincia de Buenos Aires.

Hay problemas de diferentes grados de dificultad. Todos deben ser abordados, algunos requieren un tratamiento urgente para promover situaciones de justicia educativa. Este trabajo puede contribuir a esta causa, revelando los problemas que persisten y las soluciones que aun se aguardan.

\section{Bibliografía}

- Jacques Delors (1997) "La educación encierra un tesoro". Ed. Santillana

- Ferreyra Horacio Ademar (2012) "Aproximaciones a la Educación Secundaria en la Argentina (2000-2010)". Ed. Comunicarte y Universidad Católica de Córdoba - López Armengol Martín A. y Colombo Ma. de la Paz (Proyecto CESPUALE 2011), Vol. II "Hacia una educación superior de calidad. Una mirada de quienes gestionan las universidades en Argentina, España y México. Ed. EDULP

- Dewey John (2004) "Democracia y educación". Ed. Morata

- Benno Sander (1996) "Gestión educativa en América Latina. Construcción y reconstrucción del conocimiento". Ed. Troquel

- Mariño Navarrete Hernando (1988) "Gerencia de la calidad total". Ed. Tercer mundo editores.

- Tenti Fanfani Emilio (1992) "La escuela vacía. Deberes del estado y responsabilidades de la sociedad". Ed. Losada

- Hallak Jacques (1991) "Invertir en el futuro. Definir las prioridades educacionales en el mundo en desarrollo". Ed. Tecnos/UNESCO. 
- Braslavsky Cecilia (1993) "Propuesta para el debate en torno a un propósito formativo organizador de nuevos diseños curriculares, desde la educación inicial hasta la polimodal: la formación de competencias". Ed. Novedades Educativas

- Coll Cesar y otros (1994) "Los contenidos en la reforma. Enseñanza y aprendizaje de conceptos, procedimientos y actitudes". Ed. Santillana.

- Edwards Verónica (1991) "El concepto de calidad de la educación". Publicado por la Oficina Regional de Educación de la UNESCO para América Latina y el Caribe (OREALC).

- Tedesco Juan Carlos (1995) "El nuevo pacto educativo: Educación, competitividad y ciudadanía en la sociedad moderna". Ed. Published

- Braslavsky Cecilia y Filmus Daniel (1988) "Respuesta a la crisis educativa. Primer año del colegio secundario". Ed. Cántaro/FLACSO

- Puiggrós Adriana (1997) "La otra reforma. Desde la educación menemista al fin de siglo". Ed. Galerna

- Frattari Vilma (1998) "La Obra. Revista de educación N 920". Artículo: Calidad de la educación pág. 84.

- Jáuregui Silvia y otros (1983) "El sistema educativo argentino. Características y problemas". Cuadernos Fundación Eugenio A. Blanco (Buenos Aires).

- Coler Marisa y otros (2011) "La educación secundaria en la ciudad de Buenos Aires". Dinámica de la matricula y desafíos institucionales para la inclusión. Informe de Investigación de la Dirección de Investigación y Estadística del Ministerio de Educación del GCBA. Informe final.

- Tenti Fanfani Emilio (2009) "La enseñanza media hoy: masificación con exclusión social y cultural". Ed. Manantial.

- Terigi Flavia (2007), "Los desafíos que plantean las trayectorias escolares", Fundación Santillana, III Foro Latinoamericano de Educación. Jóvenes y docentes. La escuela secundaria en el mundo de hoy.

- Terigi Flavia (2010) "Las cronologías de aprendizaje: un concepto para pensar las trayectorias escolares". Ministerio de Cultura y Educación. Gobierno de La Pampa. 


\section{Páginas web consultadas}

- $\quad$ http://www.unesco.org/new/es

- $\quad$ http://www.educar.org/articulos/calidadeneducacion.asp

- $\quad$ http://www.uis.unesco.org/Library/Documents/eiguide09-es.pdf

- $\quad$ http://www.eduteka.org/pdfdir/Pisa2009.pdf

- http://www.idesa.org

- http://www.oecd.org/pisa/pisaenespaol.htm 


\section{Anexos}

\subsection{Encuestas sobre Calidad Educativa del Nivel Secundario}

\subsubsection{Docentes}
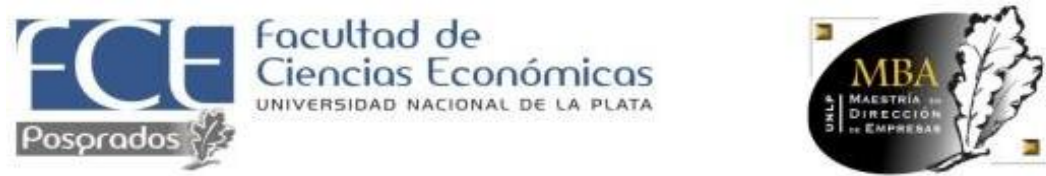

MAESTRIA EN

DIRECCIÓN DE EMPRESAS

Cuestionario para opiniones calificadas (docentes)

\section{Atributos existentes del graduado de escuela media de (Berisso)}

Las siguientes afirmaciones están destinadas a intentar identificar los atributos existentes del graduado objeto de esta encuesta. Por favor marque con una cruz el número de la respuesta que usted crea que representa sus creencias acerca de la afirmación.

\begin{tabular}{|c|c|c|c|c|c|}
\hline $\begin{array}{c}\text { Mal } \\
\text { Mal } \\
\text { (calificación } 0 \\
\text { a 2) }\end{array}$ & $\begin{array}{c}2= \\
\text { Regular } \\
\text { (calificación } \\
\text { más de } 2 \\
\text { hasta 4) }\end{array}$ & $\begin{array}{c}3= \\
\text { Bien } \\
\text { (calificación } \\
\text { más de } 4 \\
\text { hasta 6) }\end{array}$ & $\begin{array}{c}4 \text { = } \\
\text { Muy Bien } \\
\text { (calificación } \\
\text { más de } 6 \\
\text { hasta 8) }\end{array}$ & $\begin{array}{c}5= \\
\text { Excelente } \\
\text { (calificación } \\
\text { más de } 8 \\
\text { hasta 10) }\end{array}$ & $\begin{array}{c}\text { 6= } \\
\text { NS/NC } \\
\text { (No } \\
\text { sabe/ } \\
\text { No } \\
\text { contesta) }\end{array}$ \\
\hline
\end{tabular}

\section{1.- Área Matemáticas}

\begin{tabular}{|c|c|c|c|c|c|c|}
\hline El individuo... & 1 & 2 & 3 & 4 & 5 & 6 \\
\hline $\begin{array}{l}\text { 1.1.- Realiza las cuentas básicas sin uso de } \\
\text { tecnología... }\end{array}$ & & & & & & \\
\hline $\begin{array}{l}\text { 1.2.- Al realizarle una consulta sobre porcentajes } \\
\text { simples, responde... }\end{array}$ & & & & & & \\
\hline $\begin{array}{l}\text { 1.3.- Realiza conversiones con unidades de } \\
\text { medidas... }\end{array}$ & & & & & & \\
\hline 1.4.- Conoce los tipos de triángulos existentes... & & & & & & \\
\hline $\begin{array}{l}\text { 1.5.- Sabe diferenciar los distintos tipos de figuras } \\
\text { geométricas... }\end{array}$ & & & & & & \\
\hline $\begin{array}{l}\text { 1.6.- En caso de fracciones sabe realizar las } \\
\text { operaciones básicas (suma, resta, multiplicación } \\
\text { división)... }\end{array}$ & & & & & & \\
\hline $\begin{array}{l}\text { 1.7.- Sabe realizar el cálculo de la superficie de un } \\
\text { objeto (cuadrado, rectángulo, entre otros)... }\end{array}$ & & & & & & \\
\hline $\begin{array}{l}\text { 1.8.- Sabe realizar el cálculo del volumen de un } \\
\text { cuerpo (cilindro, cubo, entre otros)... }\end{array}$ & & & & & & \\
\hline $\begin{array}{l}\text { 1.9.- Conoce los sistemas monetarios utilizados en } \\
\text { Argentina (tipos de cambio más utilizados y conversión)... }\end{array}$ & & & & & & \\
\hline 1.10.- Tiene noción sobre patrones de medida... & & & & & & \\
\hline $\begin{array}{l}\text { 1.11.- Conoce y comprende los distintos tipos de } \\
\text { gráficos... }\end{array}$ & & & & & & \\
\hline 1.12.- Comprende acerca de datos estadísticos... & & & & & & \\
\hline
\end{tabular}


1.13.- Capacidad para realizar un cálculo

financiero elemental

\section{2.- Área Lengua}

\begin{tabular}{|c|c|c|c|c|c|c|}
\hline El individuo... & 1 & 2 & 3 & 4 & 5 & 6 \\
\hline $\begin{array}{l}\text { 2.1.- Ante una instrucción por escrito, realiza la } \\
\text { tarea... }\end{array}$ & & & & & & \\
\hline $\begin{array}{l}\text { 2.2.- Al leer un texto simple, y ante el requerimiento } \\
\text { de extraer la idea principal, lo hace... }\end{array}$ & & & & & & \\
\hline 2.3.- La capacidad de lectura es... & & & & & & \\
\hline $\begin{array}{l}\text { 2.4.- Al narrar un párrafo manuscrito la ortografía } \\
\text { observada es... }\end{array}$ & & & & & & \\
\hline $\begin{array}{l}\text { 2.5.- Se desempeña oralmente ante sus pares } 0 \\
\text { superiores... }\end{array}$ & & & & & & \\
\hline $\begin{array}{ccccc}\text { 2.6.- } & \text { Posee } & \text { conocimientos } & \text { sobre } & \text { historia } \\
\text { Argentina... }\end{array}$ & & & & & & \\
\hline $\begin{array}{l}\text { 2.7.- El nivel respecto de información sobre la } \\
\text { actualidad es... }\end{array}$ & & & & & & \\
\hline $\begin{array}{l}\text { 2.8.- Conoce como se compone la división de } \\
\text { poderes en Argentina... }\end{array}$ & & & & & & \\
\hline $\begin{array}{l}\text { 2.9.- El grado de responsabilidad cívica (interés por } \\
\text { participar, opinar, etc.) es... }\end{array}$ & & & & & & \\
\hline $\begin{array}{l}\text { 2.10.- Capacidad para comprender catálogos } \\
\text { técnicos y manuales... }\end{array}$ & & & & & & \\
\hline
\end{tabular}

\section{3.- Área Ciencias}

\begin{tabular}{|c|c|c|c|c|c|c|}
\hline \multirow{2}{*}{$\begin{array}{ll} & \text { El individuo... } \\
\text { es... } & \text { 3.1.- El conocimiento de los estados de la materia } \\
\end{array}$} & 1 & 2 & 3 & 4 & 5 & 6 \\
\hline & & & & & & \\
\hline 3.2.- El conocimiento sobre primeros auxilios es... & & & & & & \\
\hline $\begin{array}{l}\text { 3.3.- El conocimiento sobre seguridad e higiene en } \\
\text { el trabajo es... }\end{array}$ & & & & & & \\
\hline $\begin{array}{l}\text { 3.4.- } \mathrm{El} \text { conocimiento sobre las principales } \\
\text { enfermedades de Argentina... }\end{array}$ & & & & & & \\
\hline $\begin{array}{l}\text { 3.5.- El conocimiento sobre los elementos de } \\
\text { medición es... }\end{array}$ & & & & & & \\
\hline 3.6.- Conoce al menos cinco tipos de energía... & & & & & & \\
\hline 3.7.- El nivel de conocimiento sobre el sistema solar & & & & & & \\
\hline $\begin{array}{l}\text { 3.8.- El conocimiento sobre el uso de Internet para } \\
\text { búsquedas de información relevante es... }\end{array}$ & & & & & & \\
\hline $\begin{array}{l}\text { 3.9.- El uso de los programas básicos de } \\
\text { computación es... }\end{array}$ & & & & & & \\
\hline $\begin{array}{l}\text { 3.9.- El conocimiento sobre las consecuencias que } \\
\text { conlleva el consumo del agua no potabilizada es... }\end{array}$ & & & & & & \\
\hline $\begin{array}{l}\text { 3.10.- El conocimiento sobre las principales vías de } \\
\text { contagio del SIDA es... }\end{array}$ & & & & & & \\
\hline
\end{tabular}




\begin{tabular}{|c|c|c|c|c|c|c|}
\hline El Individuo... & 1 & 2 & 3 & 4 & 5 & 6 \\
\hline $\begin{array}{l}\text { 3.11.- El conocimiento acerca de los principales } \\
\text { elementos de la economía (inflación, tasas de interés, } \\
\text { sistema cambiario, canasta básica) es... }\end{array}$ & & & & & & \\
\hline $\begin{array}{l}\text { 3.12.- El conocimiento acerca de la tasa de } \\
\text { mortalidad (edad promedio en argentina) es... }\end{array}$ & & & & & & \\
\hline
\end{tabular}

\section{4.- Aptitudes Personales}

\begin{tabular}{|c|c|c|c|c|c|c|}
\hline El individuo... & 1 & 2 & 3 & 4 & 5 & 6 \\
\hline 4.1.- Responsabilidad en la tarea & & & & & & \\
\hline 4.2.- Creatividad & & & & & & \\
\hline 4.3.- Flexibilidad & & & & & & \\
\hline 4.4.- Puntualidad en el trabajo & & & & & & \\
\hline 4.5.- Respeto por su trabajo y las perso & & & & & & \\
\hline 4.6.- Compañerismo & & & & & & \\
\hline 4.7.- Conocimiento sobre sus propios $\mathrm{v}$ & & & & & & \\
\hline 4.8.- Demuestra Interés y motivación $p c$ & & & & & & \\
\hline 4.9.- Buena presencia & & & & & & \\
\hline 4.10.- Le interesa trabajar en equipo & & & & & & \\
\hline 4.11.- Grado de adaptación a la tarea & & & & & & \\
\hline 4.12.- Grado de aprendizaje & & & & & & \\
\hline $\begin{array}{cccc}\text { 4.13.- } & \text { Capacidad para comunica } \\
\text { conocimientos }\end{array}$ & & & & & & \\
\hline 4.14.- Desempeño en el cumplimiento $c$ & & & & & & \\
\hline 4.15.- Orden y prolijidad en la tarea & & & & & & \\
\hline $\begin{array}{l}\text { 4.16.- Capacidad de resolución de pr } \\
\text { del mismo }\end{array}$ & & & & & & \\
\hline 4.17.-Poder de negociación & & & & & & \\
\hline 4.18.- Uso de herramientas apropiadas & & & & & & \\
\hline
\end{tabular}




\subsubsection{Empresarios}

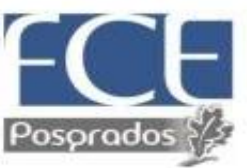

\section{Facultad de}

Ciencias Económicas

UNIVERSIDAD NACIONAL DE LA PLATA

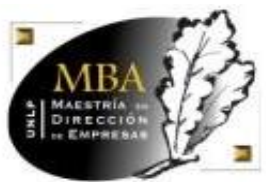

MAESTRIA EN

DIRECCIÓN DE EMPRESAS

Cuestionario para opiniones calificadas (empresarios)

Atributos existentes del graduado de escuela media de (Berisso)

Las siguientes afirmaciones están destinadas a intentar identificar los atributos existentes del graduado objeto de esta encuesta. Por favor marque con una cruz el número de la respuesta que usted crea que representa sus creencias acerca de la afirmación.

\begin{tabular}{|c|c|c|c|c|c|}
\hline $\begin{array}{c}\text { Mal } \\
\text { (calificación } 0 \\
\text { a 2) }\end{array}$ & $\begin{array}{c}2= \\
\text { Regular } \\
\text { (calificación } \\
\text { más de } 2 \\
\text { hasta 4) }\end{array}$ & $\begin{array}{c}3= \\
\text { Bien } \\
\text { (calificación } \\
\text { más de } 4 \\
\text { hasta 6) }\end{array}$ & $\begin{array}{c}4= \\
\text { Muy Bien } \\
\text { (calificación } \\
\text { más de } 6 \\
\text { hasta 8) }\end{array}$ & $\begin{array}{c}5= \\
\text { Excelente } \\
\text { (calificación } \\
\text { más de } 8 \\
\text { hasta 10) }\end{array}$ & $\begin{array}{c}\mathbf{6 =} \\
\text { NS/NC } \\
\text { (No } \\
\text { sabe/ } \\
\text { No } \\
\text { contesta) }\end{array}$ \\
\hline
\end{tabular}

\section{1.- Área Matemáticas}

\begin{tabular}{|c|c|c|c|c|c|c|}
\hline El individuo... & 1 & 2 & 3 & 4 & 5 & 6 \\
\hline $\begin{array}{l}\text { 1.1.- Realización de cuentas básicas sin uso de } \\
\text { tecnología... }\end{array}$ & & & & & & \\
\hline $\begin{array}{l}\text { 1.2.- Ante un cálculo de porcentajes simples, } \\
\text { responde... }\end{array}$ & & & & & & \\
\hline $\begin{array}{l}\text { 1.3.- Realiza conversiones con unidades de } \\
\text { medidas... }\end{array}$ & & & & & & \\
\hline $\begin{array}{l}\text { 1.4.- Distingue los distintos tipos de figuras } \\
\text { geométricas... }\end{array}$ & & & & & & \\
\hline $\begin{array}{l}\text { 1.5.- En caso de fracciones, realiza las } \\
\text { operaciones básicas... }\end{array}$ & & & & & & \\
\hline $\begin{array}{l}\text { 1.6.- Conocimiento acerca de los sistemas } \\
\text { monetarios utilizados en Argentina (tipos de cambio } \\
\text { más utilizados y conversión)... }\end{array}$ & & & & & & \\
\hline 1.7.- Tiene noción sobre patrones de medida... & & & & & & \\
\hline $\begin{array}{l}\text { 1.8.- Conoce y comprende los distintos tipos de } \\
\text { gráficos... }\end{array}$ & & & & & & \\
\hline 1.9.- Comprende datos estadísticos... & & & & & & \\
\hline $\begin{array}{l}\text { 1.10.- Capacidad para realizar un cálculo } \\
\text { financiero elemental... }\end{array}$ & & & & & & \\
\hline
\end{tabular}

\section{2.- Área Lengua}

\begin{tabular}{|l|l|l|l|l|l|l|}
\hline El individuo... & $\mathbf{1}$ & $\mathbf{2}$ & $\mathbf{3}$ & $\mathbf{4}$ & $\mathbf{5}$ & $\mathbf{6}$ \\
\hline 2.1.- La comprensión de textos es... & & & & & & \\
\hline 2.2.- La redacción de textos es... & & & & & & \\
\hline 2.3.- La capacidad de lectura es... & & & & & & \\
\hline 2.4.- La caligrafía es... & & & & & & \\
\hline 2.5.- La ortografía es... & & & & & & \\
\hline
\end{tabular}


2.6.- El desempeño oral es...

2.7.- El nivel de información sobre la actualidad es...

2.8.- Capacidad para comprender catálogos técnicos y manuales...

\section{3.- Área Ciencias}

\begin{tabular}{|c|c|c|c|c|c|c|}
\hline El individuo... & 1 & 2 & 3 & 4 & 5 & 6 \\
\hline 3.1.- Conocimiento sobre primeros auxilios... & & & & & & \\
\hline 3.2.- Conocimiento sobre seguridad e higiene en el trabajo... & & & & & & \\
\hline 3.3.- Conocimiento sobre los elementos de medición... & & & & & & \\
\hline $\begin{array}{l}\text { 3.4.- Conocimiento sobre el uso de Internet para búsquedas de } \\
\text { información relevante es... }\end{array}$ & & & & & & \\
\hline 3.5.- El uso de los programas básicos de computación es... & & & & & & \\
\hline $\begin{array}{l}\text { 3.6.- Conocimiento acerca de los principales elementos de la } \\
\text { economía (inflación, tasas de interés, sistema cambiario, canasta } \\
\text { básica)... }\end{array}$ & & & & & & \\
\hline
\end{tabular}

\section{4.- Aptitudes Personales}

\begin{tabular}{|c|c|c|c|c|c|c|}
\hline El individuo... & 1 & 2 & 3 & 4 & 5 & 6 \\
\hline 4.1.- Responsabilidad & & & & & & \\
\hline 4.2.- Creatividad & & & & & & \\
\hline 4.3.- Flexibilidad & & & & & & \\
\hline 4.4.- Puntualidad & & & & & & \\
\hline 4.5.- Respeto & & & & & & \\
\hline 4.6.- Compañerismo & & & & & & \\
\hline 4.7.- Valores & & & & & & \\
\hline 4.8.- Interés y motivación & & & & & & \\
\hline 4.9.- Presencia & & & & & & \\
\hline 4.10.- Le interesa trabajar en equipo & & & & & & \\
\hline 4.11.- Grado de adaptación al trabajo & & & & & & \\
\hline 4.12.- Grado de aprendizaje & & & & & & \\
\hline $\begin{array}{cccccc}\begin{array}{l}\text { 4.13.- } \\
\text { conocimientos }\end{array} & \text { Capacidad para comunicarse } & \text { y } & \text { transmitir } & \text { sus }\end{array}$ & & & & & & \\
\hline 4.14.- Desempeño en el cumplimiento de sus tareas & & & & & & \\
\hline 4.15.- Orden y prolijidad & & & & & & \\
\hline $\begin{array}{l}\text { 4.16.- Capacidad de resolución de problemas y comunicación } \\
\text { del mismo }\end{array}$ & & & & & & \\
\hline 4.17.- Capacidad de negociación & & & & & & \\
\hline 4.18.- Uso de herramientas apropiadas & & & & & & \\
\hline
\end{tabular}




\section{Datos de Fuente Secundaria}

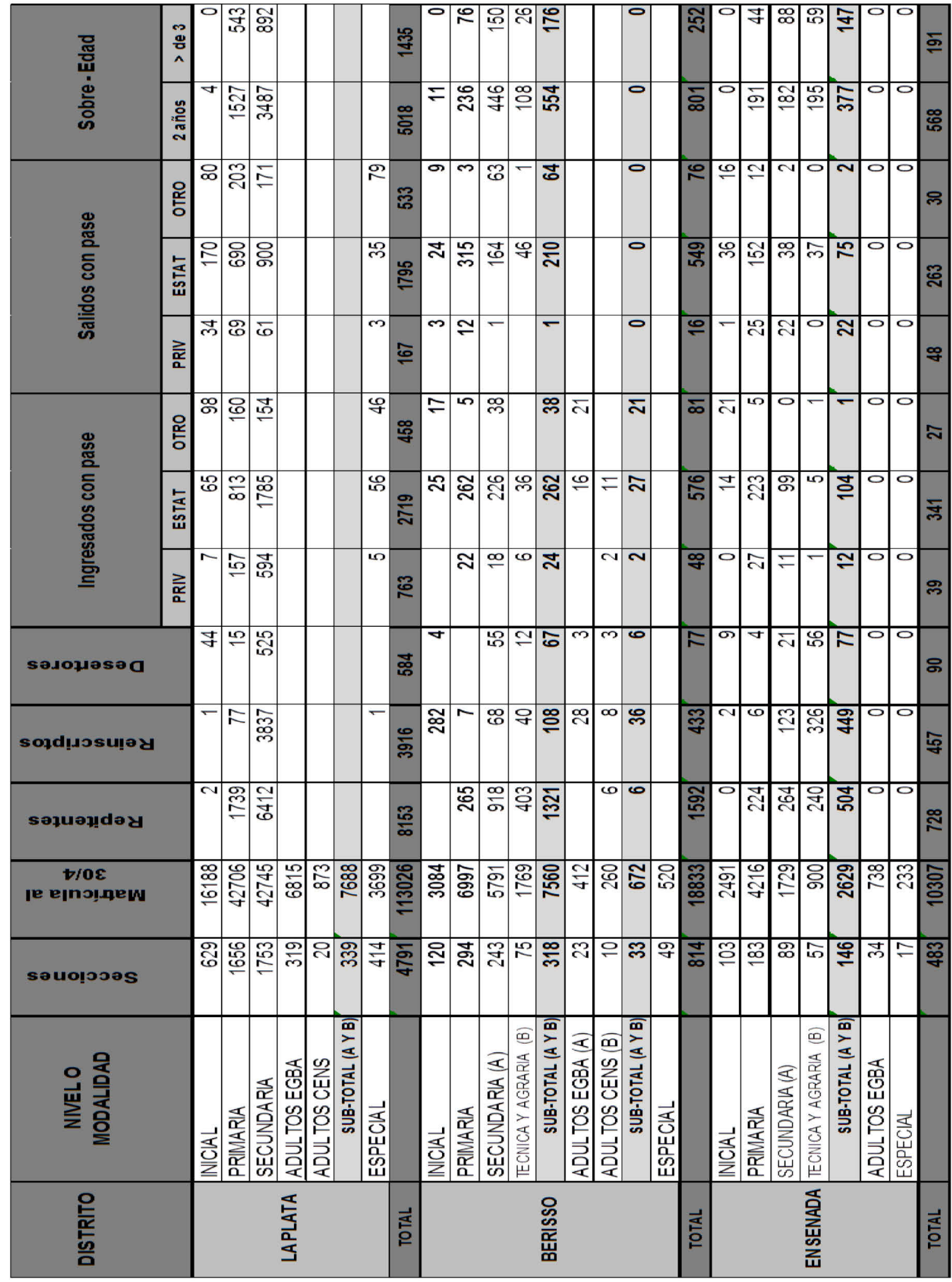

Autor: Ing. Lucas F. Gambino 


\section{Población}

\begin{tabular}{|l|l|l|l|}
\hline LA PLATA & Chicos entre 12 y 18 años & 67930 & Año 2010 \\
\cline { 2 - 4 } & Chicos entre 11 y 17 años & 66092 & Año 2011 \\
\hline
\end{tabular}

\begin{tabular}{|l|l|l|l|}
\hline BERISSO & Chicos entre 12 y 18 años & 10366 & Año 2010 \\
\cline { 2 - 4 } & Chicos entre 11 y 17 años & 10313 & Año 2011 \\
\hline
\end{tabular}

\begin{tabular}{|l|l|l|l|}
\hline ENSENADA & Chicos entre 12 y 18 años & 6590 & Año 2010 \\
\cline { 2 - 4 } & Chicos entre 11 y 17 años & 6517 & Año 2011 \\
\hline
\end{tabular}

Nota: la población total incluye a las personas viviendo en situación de calle.

El índice de masculinidad indica la cantidad de varones por cada 100 mujeres.

Fuente: INDEC. Censo Nacional de Población, Hogares y Viviendas 2010.

\section{Cantidad de personas que reportan leer y escribir}

\begin{tabular}{|c|c|c|}
\hline \multicolumn{3}{|c|}{2011} \\
\hline LA PLATA & BERISSO & ENSENADA \\
\hline 65302 & 10186 & 6435 \\
\hline
\end{tabular}

Datos suministrados por la Dirección de Información y Estadística de la Dirección Provincial de Planeamiento de la DGCyE

\section{Artículos periodísticos:}

\section{Más resultados adversos en la universidad platense}

Aspirantes a Medicina reprobaron un examen de nivel primario.

\section{La Nación 1998}

LA PLATA.- Un grupo de aspirantes a incorporarse en la Facultad de Ciencias Médicas de la Universidad Nacional de La Plata (UNLP), recientemente reprobados en una prueba de ingreso, no logró superar un examen de matemática elaborado sobre la base de conocimientos que se imparten en la escuela primaria. 
A esta prueba optativa, la misma que se utiliza para evaluar a los alumnos de séptimo grado que desean ingresar en los colegios secundarios de la UNLP, se presentaron 217 jóvenes. El $89 \%$ de ellos fue aplazado.

Estos resultados ahondan la preocupación por la deficiente preparación que los estudiantes obtienen en la enseñanza media. Como se recordará, 1727 aspirantes a estudiar la carrera de Medicina en la UNLP fueron reprobados en la evaluación diagnóstica que los hubiera eximido de realizar un curso introductorio a la carrera.

Ninguno de los que rindió la evaluación optativa logró responder correctamente la totalidad de las preguntas. Únicamente el $11 \%$ de ellos pudo aprobar.

Uno solo logró dar adecuada resolución a cinco de los seis ejercicios sobre matemática que integraban la prueba. Once lograron presentar cuatro bien resueltos; 46 hicieron correctamente dos o tres; 26 , solamente uno, y 16, ninguno.

El examen constaba de tres problemas geométricos y tres aritméticos. Entre los primeros, los estudiantes debieron resolver, sin la ayuda de la calculadora, problemas de superficies y perímetros.

Uno de los ejercicios aritméticos interrogaba: "¿Cuántas decenas tiene el mayor número natural de tres cifras distintas?" Otro, de carácter incierto y gastronómico, enunciaba: "Paula va a preparar un sándwich y puede elegir entre tres tipos de pan (negro, lactal, francés) y cuatro de fiambre (jamón, salame, matambre y lomito). Si prepara el sándwich con un solo tipo de fiambre y un solo tipo de pan, ¿de cuántas maneras puede hacerlo?"

\section{Más resultados adversos}

La inquietud desatada por los resultados de la evaluación de los aspirantes a estudiar en la Facultad de Ciencias Médicas de esta ciudad fue incentivada por otros resultados adversos registrados en diferentes unidades académicas.

En la Facultad de Ciencias Jurídicas y Sociales de la UNLP, el examen diagnóstico fue aprobado solamente por el 33\% de los aspirantes, es decir, 600 alumnos sobre un total de 1800 . 
Mucho peor fue el resultado obtenido en la sede de Ciencias Veterinarias, en la que se inscribieron 1700 estudiantes, de los cuales 540 (el 32\%) se presentaron a la prueba diagnóstica.

Cada alumno rindió tres exámenes y, del total de 1620 pruebas, fueron aprobadas solamente 125 , es decir, menos del $10 \%$ de los ejercicios presentados. Sólo cuatro alumnos completaron bien los tres cuestionarios.

No obstante, los reprobados tienen la oportunidad de realizar el curso de nivelación. Con el $80 \%$ de asistencia a las clases y aprobando un examen final, podrán finalmente ingresar a la carrera.

El decano de esa casa de altos estudios, doctor Eduardo Pons, comentó que esos resultados no son sorprendentes y admitió que las pruebas eran realmente complejas.

En Ciencias Exactas, el examen diagnóstico fue superado solamente por el $30 \%$ de los inscriptos, pero los aplazados gozarán también de otra oportunidad para ingresar a través del curso de nivelación.

La situación fue más alentadora en la Facultad de Odontología, donde aprobó alrededor del $70 \%$ de los inscriptos, que, de todas maneras, deberá realizar un curso teórico-práctico obligatorio.

En el resto de las unidades académicas los ingresantes deben efectuar cursos introductorios sin la opción de una prueba diagnóstica para eludirlo.

Consultado por La Nación, Horacio Sanguinetti, ex secretario de Educación porteño y, desde ayer, nuevamente rector del Colegio Nacional de Buenos Aires, opinó que las dificultades de los estudiantes secundarios para aprobar los exámenes de ingreso en la educación superior no es un fenómeno nuevo, aunque se ha acentuado en los últimos años.

"La enseñanza media vive una situación crítica y caótica desde hace 30 años -comentó-. Pero, en la actualidad, la situación se agrava por la deserción de la familia en la faz educativa y, también, por la falta de lectura y de dominio del lenguaje de los jóvenes.".

Víctor J. Gil 


\section{Preocupación de Ferreira}

La Nación 2002

Consultado por La Nación, el decano de Medicina de la Universidad de Buenos Aires (UBA), Luis Ferreira, expresó su preocupación por el magro resultado de las pruebas.

Ferreira impulsa en la UBA una selección rigurosa de los aspirantes a Medicina, por medio del Curso Preuniversitario de Ingreso (CPI).

De los 12.000 estudiantes que en octubre último se inscribieron en el CPI para ingresar en 2002 en la UBA, sólo unos 1200 aprobaron el primero de los tres módulos en que se divide el curso, confirmó ayer el decano.

Frente a los 1727 alumnos reprobados en la Universidad de La Plata, Ferreira estimó que se trata de "una cifra alarmante y nos lleva a pensar sobre cómo vienen preparados los alumnos del secundario para entrar en la Universidad".

\section{> Nuevos aplazos masivos en el ingreso a Ingeniería}

El $75 \%$ de los aspirantes reprobó el examen en la Universidad de La Plata

La Nación 2002

LA PLATA.- El examen de ingreso, que ayer desaprobó el $75 \%$ de los aspirantes que pretenden estudiar en la Facultad de Ingeniería de la Universidad Nacional de La Plata (UNLP), volvió a generar duras críticas al polimodal, el ciclo que reúne a los últimos tres años del ex secundario.

Sobre un total de 1000 inscriptos habilitados para rendir el examen de ingreso que los podía eximir del curso de admisión que se prolongará por cuatro semanas, sólo se presentaron a rendir 335. De éstos, sólo 81 pudieron superar el examen, confirmó a LA NACION el decano de Ingeniería, Alberto Giovanbattista.

$\mathrm{Al}$ analizar las causas del mal desempeño, las autoridades de la facultad advirtieron que los alumnos no llegan bien formados a la Universidad debido a que en el último año del polimodal no se dicta la asignatura matemática. 
La falla fue admitida por las autoridades educativas. Al ser consultado por LA NACION, el subsecretario de Enseñanza Media del gobierno bonaerense, Alberto Sileoni, reconoció que "no dictar matemática en el último año del polimodal es un error. Estamos trabajando para incluir la asignatura".

Al respecto, agregó: "Quizás este año podremos dictarla en forma experimental y evaluar luego la evolución de los alumnos".

El decano de Ingeniería explicó que "de los 335 alumnos que creían que estaban capacitados para rendir la evaluación, unos 40 no pudieron responder ni un solo problema, por lo que su calificación fue cero".

El planteo de Giovanbattista sobre la deficiente preparación con que los alumnos llegan a la Universidad es compartido por los titulares de las facultades de Medicina y de Ciencias Jurídicas, que habían realizado similares descargos ante los reiterados aplazos en las pruebas de ingreso que se tomaron en los últimos tres años.

Pero el cuestionamiento del decano va más allá de la retórica. "La Facultad de Ingeniería prepara un curso a distancia que será emitido por el canal de la UNLP para que los alumnos del último año del polimodal puedan afianzar, en horario extracurricular, los conocimientos básicos de matemática", aseguró Giovanbattista.

Y aclaró: "Nosotros no intentamos reemplazar la educación básica. Sólo queremos que los chicos que estén interesados en estudiar ingeniería puedan tener elementos suficientes para ingresar en la facultad".

La Dirección General de Cultura y Educación afirmó que, efectivamente, en el último año del polimodal no se dicta la asignatura matemática. "Durante el $8^{\circ} \mathrm{y}$ $9^{\circ}$ año de la educación general básica (EGB) y los dos primeros ciclos del polimodal hay una carga horaria equivalente a los cinco años de la vieja secundaria", explicó Sileoni.

El curso de ingreso a Ingeniería se modificó el año último ante los altos índices de deserción que tenía la unidad académica. "Durante los últimos seis años habíamos planteado un curso nivelatorio con examen final y que no era 
eliminatorio. Pero las estadísticas marcaron que el $90 \%$ de los alumnos que le iba mal en esa prueba después no tenía los suficientes conocimientos como para comenzar a cursar alguna de las asignaturas del primer año", explicó el decano.

Modalidad diferente

Ahora, los aspirantes que pretenden ingresar en la carrera tienen que aprobar una evaluación de matemática que se puede rendir en diciembre o en febrero. Precisamente, en diciembre último se habían presentado 340 aspirantes de los 1000 inscriptos y en esa ocasión sólo aprobaron 46.

Entre el examen de diciembre y el que se tomó anteayer sólo ingresaron 127 alumnos que estarán en condiciones de cursar la carrera en marzo próximo. El $90 \%$ de los ingresantes que fue desaprobado o que no se presentó a rendir tendrá que realizar un curso introductorio de cuatro semanas -y un examen finalque comenzará mañana.

\section{Antecedentes}

Ingeniería: en diciembre de 2001, de 1000 inscriptos rindieron sólo 316; de ellos, reprobó el 86 por ciento.

Medicina: en junio último, más del $70 \%$ de los 1600 inscriptos superaron el examen de ingreso y el recuperatorio. La cifra de reprobados en esta facultad superaba siempre el 65 por ciento.

Derecho: hace dos años, más de 2000 ingresantes reprobaron un polémico examen que incluía preguntas básicas de historia argentina.

Jesús A. Cornejo

\section{$>$ Proponen un examen único en Medicina}

El ingreso universitario ante los altos niveles de fracaso

Los decanos de las facultades de todo el país estudian establecer una prueba nacional de ingreso y un cupo de admisión

La Nación 2004 
Preocupados por el alto nivel de fracaso de los aspirantes y el creciente malestar de estudiantes y padres que denuncian la alta exigencia de las pruebas de admisión, los decanos de las facultades de Medicina de todo el país comenzarán a debatir hoy una reforma en el sistema de ingreso, que propone una prueba nacional común para todo el país, un cupo por facultad y un curso preparatorio voluntario que deben dictar las universidades y pagar los estudiantes.

La propuesta, elaborada por Carlos Fernández, médico y vicerrector de la Universidad Nacional de Tucumán (UNT), se presentará en la reunión mensual que realizan todos los primeros viernes de cada mes los integrantes de la Asociación de Facultades de Ciencias Médicas de la República Argentina (Afacimera), que reúne a más de 20 facultades de instituciones públicas y privadas.

El proyecto, al que tuvo acceso LA NACION, propone unificar el sistema de ingreso con un examen de admisión nacional idéntico, que se tome el mismo día y a la misma hora en todo el país. El examen, con contenidos y formato acordados entre las facultades, no tendrá recuperatorio y deberá aprobarse con 7 puntos. La nota se promediará con la calificación promedio alcanzada en la escuela media -lo que servirá para "valorizar los estudios secundarios"- y el resultado de una prueba de capacidad de razonamiento y resolución de problemas, aunque ambas calificaciones tendrán un peso menor.

Con esa nota se elaboraría un listado general de méritos y los estudiantes ingresarían en las carreras hasta completar los cupos determinados en cada facultad, cuya suma establecería el número de postulantes que se pueden aceptar en todo el país.

La novedad es, además, el "cupo regional", que permitiría que si el número de alumnos en condiciones de ingresar supera el cupo en una institución se los pueda derivar a otra que tenga plazas disponibles.

"Tenemos que sincerar los problemas. Las facultades son incapaces de recibir la cantidad de alumnos que se inscriben. Hay que pensar en soluciones más abarcativas, de alcance nacional, y discutir esto con las autoridades de los 
ministerios de Educación y de Salud", dijo Fernández a LA NACION. De hecho, las autoridades de ambas carteras ya recibieron el proyecto y comenzaron a consultar a expertos.

\section{Consenso difícil}

Recientemente, los fracasos masivos de los aspirantes en las facultades de Medicina de Córdoba (90\%), La Plata (80\%) y Rosario (76\%) sacaron a la luz el problema del acceso, que estas carreras, con sus exigencias académicas, de prácticas e infraestructura, enfrentan con particular transparencia.

Para concretarse, la propuesta tiene un largo camino por recorrer: lograr consenso en las universidades es el primero y más difícil. Por ejemplo, la Facultad de Medicina de la UBA no forma parte de Afacimera desde abril de 2001, y, según pudo saber LA NACION, otras facultades no están muy dispuestas a apoyar la instalación de un único examen para todas.

La idea del cupo tiene más aceptación. De hecho, muchas lo tienen establecido y las únicas dos carreras de todo el país que recibieron la máxima acreditación de la CONEAU -por seis años- fueron las de las universidades nacionales de Cuyo y Tucumán, ambas con cupo y examen de ingreso. Según afirman sus autoridades, la relación docente-alumno resulta ideal, lo que hace que el índice de fracaso sea más bajo y los estudiantes se reciban en el tiempo establecido en mayor medida.

El proyecto también prevé que las facultades ofrezcan un curso preparatorio voluntario para la prueba de acceso, de tres a cuatro meses de duración, que sea pago a "un costo razonable" de \$ 30 a \$ 40 mensuales, con un número de becas que puede llegar al $10 \%$ de los inscriptos. Según dijo Fernández, el proyecto está pensado para las universidades públicas, pero "las privadas podrían sumarse".

"Racionalizar el ingreso es imperativo y hay que afrontar este problema abiertamente. Es un tema fundamental para todas, públicas y privadas", dijo Abraham Sonis, de la Universidad Maimónides. 


\section{Nuevos aplazo, nuevas frustraciones}

Diario La Nación: 2008

Son conocidas las dificultades que afrontan los alumnos que concluyen la escuela media y procuran continuar su formación en el tercer nivel. En los últimos días se ha registrado un nuevo capítulo de "bochazos" en dos facultades de la Universidad Nacional de La Plata (UNLP) y en la Universidad Tecnológica Nacional (UTN).

En el primer caso, apenas el $11,2 \%$ de los alumnos -33 sobre un total de 294- aprobó el examen para ingresar en la Facultad de Ingeniería. La prueba, que permitía evitar la instancia del curso nivelatorio, registró un resultado también preocupante: por cada uno de los que aprobaron hubo dos que sacaron cero. Fueron 60 los estudiantes que entregaron la hoja en blanco y obtuvieron la peor calificación. En tanto, hubo 206 inscriptos que ni siquiera se presentaron a rendir.

La de ahora fue la segunda oportunidad que los egresados del secundario tuvieron para ingresar en la facultad, tras el examen de diciembre. En total se inscribieron 956 alumnos; de ellos, 456 rindieron sus exámenes en diciembre y sólo aprobaron 133. En el llamado de enero pasado se presentaron 294 y aprobaron 33. Así, sólo 166 aspirantes llegaron a la nota del seis, el puntaje mínimo para aprobar.

En segundo lugar, los "bochazos" siguieron sucediéndose entre los alumnos de la Facultad de Ciencias Astronómicas y Geofísica de la UNLP, donde sólo uno de los 35 aspirantes logró superar el examen de ingreso y, así, evitar el intensivo curso nivelatorio de admisibilidad. En efecto: una sola persona logró superar el examen de matemática, que consistía en 16 preguntas sobre geometría, logaritmos, trigonometría, polinomios y ecuaciones algebraicas, entre otros temas.

Cabe mencionar, asimismo, que en las evaluaciones de ingreso de la Facultad Regional de Mendoza de la UTN, en el primer examen de matemática, aprobaron sólo 22 de 1100 postulantes, apenas el 2\%. La mayoría de los 
aspirantes había asistido a un taller de orientación que la UTN realizó en noviembre del año último. En diciembre, aprobó el primer examen el $2 \%$ de los 1100, y en un curso de recuperación aprobaron con más de 7 puntos 306 sobre 800. En la tercera oportunidad, a fines de enero, rindieron satisfactoriamente 56 de los 556 estudiantes que se presentaron, es decir, un 10\%.

Durante los últimos años, el número de aplazos en los exámenes de ingreso en distintas universidades del país creció exponencialmente, sin que hasta el momento se haya encontrado la manera de revertir tan preocupante situación. En este sentido, resulta auspiciosa la iniciativa del Ministerio de Educación, que pondrá a disposición de las provincias un curso de apoyo para los alumnos diseñado especialmente para profundizar ejercitaciones intelectuales básicas, como práctica de lectura, expresión, comprensión y razonamiento.

El programa tuvo un primer ensayo, a través de una experiencia piloto, con alumnos de los últimos años de escuelas estatales de la ciudad de Buenos Aires, el conurbano, La Plata y Luján. Un $60 \%$ de los asistentes encontró al curso de apoyo diferente o muy diferente de su experiencia en la secundaria. Para el $72,3 \%$, la mayor utilidad del curso fue reforzar conocimientos, pero más de seis de cada diez afirmaron haber incorporado cosas que no sabían y el $66,3 \%$ dijo que había mejorado su forma de expresión. Las mayores dificultades se encontraron en matemática, donde el $47,1 \%$ admitió tener problemas (contra el $17,3 \%$ en literatura y el $14,3 \%$ en ciencia, cultura y sociedad).

Estos resultados revelan una de las debilidades del sistema educativo y corroboran que los contenidos de los programas de la escuela secundaria y del polimodal son inadecuados e insuficientes en la preparación y formación de los alumnos. Por consiguiente, es de esperar que las autoridades educativas encaren una amplia reformulación de dichos programas y contenidos y que, además, se profundicen los esfuerzos para lograr una mejor articulación entre el nivel medio de enseñanza y la universidad, de manera de poner fin a esta cadena de frustraciones. Cuanto se haga en esa dirección será de inestimable valor para el alumnado. 


\section{Aulas sin clima para aprender $^{8}$}

Por Gustavo Laies

Para LA NACION. (21/06/2008)

Los resultados de la evaluación de la Unesco terminaron con la idea de que tenemos la mejor educación de América latina. En esta materia, nos gastamos "las joyas de la abuela".

Los países que muestran resultados superiores a los nuestros tienen tanto modelos centralizados como descentralizados, financiamiento por oferta como por demanda, dispositivos de evaluación de los docentes como ausencia de los mismos, alto porcentaje de matrícula en la educación privada como nula. En ese sentido, no parece que funcione nuestro razonamiento habitual de ideologizar los problemas para evitar responsabilizarnos. Nuestros problemas principales están en la cotidianidad de las escuelas.

Los países que nos superan comunican los resultados de las evaluaciones en tiempo y forma a las escuelas, estos datos resultan creíbles y están a disposición de la comunidad de un modo transparente. En nuestro país, los resultados de las evaluaciones no son devueltos a las escuelas en tiempo y forma, son comunicados con gran discontinuidad, de modos poco claros y todo eso deteriora su credibilidad y pertinencia. El reporte comparativo nos muestra como el país en el que mayor cantidad de alumnos llegó tarde a la prueba, adultos que interrumpieron la situación de evaluación, chicos que transgredieron la norma de quedarse en el aula hasta que todos terminaran.

Parece haber llegado el momento de abordar el problema. Chicos que lleguen en hora, con hábitos de orden y trabajo, docentes que vayan a la escuela todos los días y lleguen temprano, menor interferencia y desorden en las aulas, edificios en condiciones de limpieza y orden, bibliotecas, padres que apoyen a los docentes y exijan a sus hijos, responsabilidad que cada uno debe asumir por los resultados de su tarea.

\footnotetext{
${ }^{8} \mathrm{http}$ ///www.lanacion.com.ar/1023359-aulas-sin-clima-para-aprender
} 
A nuestra escuela le pasa lo mismo que al país: carece de orden, normas claras y un clima apropiado para producir. Pero esa no puede ser una excusa. Alguna vez fuimos capaces de construir un proyecto educativo que transformó la sociedad y le dio un proyecto a la Nación.

\section{Polémica por bochazos en la UNLP ${ }^{9}$}

Los cursos de ingreso desnudan serios problemas entre los estudiantes que llegan del secundario. (14/02/2010)

Año tras año, con el inicio de los cursos de ingreso a la Universidad llegan las desaprobaciones masivas en las evaluaciones diagnósticas. El 2010 no fue la excepción: un promedio de 2 de cada 10 ingresantes aprobaron los exámenes en Informática, Agronomía y el Observatorio. El tema suscitó una honda preocupación y un debate no exento de posiciones disímiles y hasta antagónicas.

En el Observatorio se dicta un curso de nivelación de Matemática. En las tres primeras evaluaciones, el nivel de aprobación osciló entre el 5 y el $25 \%$. "Es un tema difícil de abordar, porque tendría que criticar fuertemente a la escuela secundaria", dice Daniel Carpintero, quien dicta el cursillo en la facultad del Bosque.

"Pareciera que la Universidad siempre busca los culpables afuera. Pero es necesario hacer una crítica constructiva", afirma, y explica: "hace 19 años que damos este curso, que consta de un repaso de temas de la secundaria, y nos encontramos con que el $30 \%$ nunca vio logaritmos, o que el $50 \%$ no pone los paréntesis en las fórmulas; es como si en Lengua no pusieran los acentos".

El astrónomo señala que "a la pobreza en la enseñanza en la escuela media hay que sumarle dos cuestiones: la modalidad de corrección y la poca expectativa que existe sobre la belleza de la Matemática". En el primer caso, asegura que "la Universidad se convierte en la mala porque corrige cosas que

\footnotetext{
${ }^{9}$ http://www.eldia.com/edis/20100214/educacion0.htm
} 
antes no se corregían, pero alguien tiene que parar la bola de nieve", enfatiza. En cuanto al segundo aspecto, comenta que "en el Polimodal se presentaban problemas de Matemática relacionándolos con temas de la vida cotidiana para hacerla más llevadera. No está mal, pero también existe una Matemática pura, y la belleza radica en razonarla, pensarla, resolverla. Cuando lo entienden, el cambio de actitud es notable, y al final del curso el $90 \%$ ya está en otro nivel", asegura.

Los problemas también se detectan en la lectura y comprensión de textos. De hecho, en Bellas Artes se introdujo una materia con ese nombre para todas las carreras. Egresada de la UNLP y docente en escuelas medias, Leticia Cazorla coincide en un punto con el astrónomo: "en la escuela de los últimos años todo lo que suponía esforzarse se desechaba. Se le exigía al profesor que hiciera propuestas divertidas, que incorporara textos de fácil comprensión, breves, desconociendo que el trabajo intelectual exige esfuerzo, dedicación y concentración. Las consecuencias están a la vista", remarca.

\section{CONTRAPUNTO}

Para el decano de Medicina, Jorge Martínez, los denominados "bochazos" representan "la experiencia que hemos recogido en los últimos 17 años. El déficit de la secundaria es tan grande que en un curso corto se hace imposible nivelar. Además, nivelar sin evaluar no sirve y si la evaluación se desaprueba y el alumno ingresa igual, estamos en problemas. El Estado debe ocuparse de la secundaria y a la Universidad deben entrar quienes lo merecen", opina.

Tras aclarar que en su unidad académica han quitado las evaluaciones diagnósticas y han tomado "el camino de reforzar Matemática y de acompañar al alumno en todo su trayecto académico", el decano de Ciencias Exactas, Carlos Della Védova, opina que "si un chico llegó hasta la facultad es porque es apto para cursar cualquiera de las carreras. La experiencia nos dice que muchos que desaprueban al principio, en 5 o 6 años son investigadores". 


\section{HETEROGENEO}

En Agronomía se toman dos exámenes diagnósticos antes del curso. Uno a finales de diciembre y otro a principios de febrero. Los resultados fueron decididamente malos. "Tenemos una política claramente inclusiva", dice el secretario académico Pablo Yapura, para explicar que "en marzo se toman otras 3 pruebas, y quienes aún deban contenidos, en abril y mayo pueden hacer una nivelación intensiva".

Luciana Garatte, profesora y coordinadora del ingreso, afirma que "no es que no nos preocupe la escuela media, pero la estrategia apunta a atender la diversidad de experiencias, necesidades y perfiles". "(A los alumnos) se les facilita una instancia efectiva, nadie les regala nada, y al final del curso aprueba cerca del $80 \% "$.

\section{"TEMAS QUE NUNCA VI"}

La alumna platense Florencia López Blanco se inscribió en Agronomía y rindió Matemática y Física en diciembre. "Me preparé sola y salí mal -cuenta-, pero en febrero aprobé. Me presenté a esas materias porque tuve un paso previo por Exactas. En cuanto a Química, preferí hacer el curso porque sólo vi algo en $1^{\circ}$ del Polimodal. En La Plata no hay buen nivel; tengo compañeros en otras facultades y todos coinciden en que el salto (a la Universidad) es muy grande".

Distinto es el caso de Matías Jeanneret, oriundo de Roque Pérez y egresado de la Escuela Agrotécnica Salesiana del Valle, en 25 de Mayo. "Todos los contenidos de las tres materias los tuve en el penúltimo año del colegio. Llegué a La Plata poco antes de que comience el curso. Rendí bien Matemática, y a Química y Física no me presenté porque no tenía las carpetas para repasar", asevera.

\section{EL FACTOR SOCIAL}

"El sentido común me hace ver que hace 20 o 30 años llevarse materias a marzo era la excepción; hoy es la regla", dice el secretario académico de Ingeniería, José Scaramutti, para quien "la responsabilidad no sólo es de la 
escuela. Llevarse materias antes provocaba un impacto en el hogar. Hoy los padres no le prestan la misma atención y no tienen la misma rigidez. Entonces, cuando se le quieren poner pautas al chico fuera de la casa, se produce un choque".

Leticia Cazorla coincide: "para el docente es sumamente difícil enseñar cuando está tan cuestionado, tan desprestigiado. Algunos padres objetan calificaciones, medidas disciplinarias, contenidos. Sin su colaboración, sin su respeto, nuestra tarea se hace cada vez más difícil".

¿Un posible camino? "Nosotros no estamos para juzgar a la escuela media, pero podemos marcar falencias para que se corrijan. Son dos mundos muy distintos que hay que empalmar, y para eso hace falta profundizar en políticas de articulación entre los dos niveles", sugiere el decano de Informática, Armando de Giusti.

\section{DISPARIDADES}

"Las disparidades crecieron de una manera alarmante. Hay una distancia enorme entre lo que los alumnos deberían saber para iniciar con éxito una carrera universitaria y los conocimientos con los que realmente cuentan", asegura Leticia Cazorla, profesora de Lengua de escuelas medias y egresada de la UNLP.

\section{EI CBC, un monstruo que no es tan malo}

\section{Siete alumnos cuentan cómo es el temido primer bimestre en la UBA}

Por Raquel San Martín

De la Redacción de LA NACION. Domingo 23 de mayo de 2010

De la escuela a la universidad

Silvina Premat

LA NACION

A dos meses de haber comenzado la universidad, Fabricio De Sa Torres, de 19 años, no se acostumbra: a los exámenes parciales sigue llamándolos "pruebas" y a la universidad misma, "el cole". Lucía Moltrasio, de 18, también intenta adaptarse al cambio más importante que implicó para ella el comienzo del 
Ciclo Básico Común ( $C B C$ ) en la Universidad de Buenos Aires (UBA): tener que viajar todos los días casi una hora en tren.

Sin embargo, como muchos de los cerca de 60.000 jóvenes que cursan el CBC, Fabricio y Lucía están a gusto. Perciben que los primeros pasos en la vida universitaria los invitan a un mayor protagonismo en la toma de decisiones de su propia historia. Y eso los entusiasma.

Después de la primera tanda de exámenes parciales del cuatrimestre, La Nación reunió a siete estudiantes del ciclo de ingreso en la UBA para distintas carreras, que, en estas ocho semanas de clases, confirmaron algunos de los mitos con los que se vincula a esa universidad y desecharon otros.

La masividad que caracteriza los pasillos de la mayoría de las trece facultades de la UBA puede provocar dificultades y retrasos a la hora de hacer un trámite, pero no impide que los alumnos se sientan bien tratados.

Si bien Lucía comparte en Ciudad Universitaria un taller de dibujo proyectual con otros 200 estudiantes, no encuentra dificultades porque, según cuenta, los docentes organizan grupos pequeños en las clases. El resultado es el mismo que percibe Belén Altamirano en los talleres de semiología, en la sede Montes de Oca, del CBC. "No noto que me traten como si fuera un legajo", cuenta Maximiliano Basegotte, de 20 años, y aspirante a ingresar en Arquitectura.

"Si bien los profesores no saben mi nombre, y pedírselo es imposible porque hay algunos que tienen 500 alumnos, estoy bien porque hasta ahora tengo profesores delante de mí que aman dar clase." Y agrega: "Eso está bueno porque no me sirve que los profesores sólo sepan mi nombre y apellido, como me pasó en el secundario, sino que den la clase con vocación y hasta con amor".

Nicolás Correa, de 19 años, no coincide del todo con Maximiliano en cuanto a la calidad de los docentes. El comenzó el CBC a mediados de 2009, cuando cambió de idea sobre la carrera que quería estudiar. Después de haber aprobado tres de las cinco materias del primer cuatrimestre para Contador Público en una universidad privada se pasó a la UBA, para ingresar en Derecho. "Hasta 
ahora tuve profesores buenos y otros que se nota que van sólo para cobrar el sueldo", dice.

Muchos consideran que el CBC es un año perdido, y argumentan la necesidad de reformarlo e incluso de eliminarlo como sistema de ingreso. Quienes lo cursan, al menos los siete estudiantes consultados por La Nación, no piensan igual.

"EI CBC está hecho para introducir al alumno a la vida de una facultad", dijo Ignacio Martínez Basanta, de 18 años, ingresantes de Derecho. "Además, un alumno de la UBA sale con la habilidad de resolver más problemas que cualquier otro porque van apareciendo trabas y se va haciendo difícil", agregó Ignacio.

"Sí, es como dice Ignacio, y esto sirve también para aprender a organizar los tiempos", dijo Pablo Sánchez Rey, de 18 años, que aspira a ser biólogo. "Además, si yo no hubiese tenido el $\mathrm{CBC}$, no podría empezar con química orgánica, me despedazarían. Todo lo que vi en un año de química en el secundario acá lo vimos en una hora y media de clase", cuenta Pablo, quien ahora está "fascinado" con la química, pero que al principio del CBC le costó "horrores".

Quizá tanto como a Pablo con la química a los demás también les está costando adaptarse a un ritmo de estudio bien distinto del que conocían hasta ahora. "En la secundaria yo me preparaba dos días antes de la prueba; en cambio, acá tengo que prepararme con anticipación. Además, después de cada clase tengo que ir leyendo lo que se va dando para que no se me acumule y no llegar al último día con todo por estudiar. Eso me pasó justamente con el parcial que tuve esta mañana", dice Ignacio al referirse a un examen de economía.

¿Hubo algo de todo lo que se suele decir de la UBA que ellos hayan constatado hasta ahora como verídico? "Que hacer trámites es más engorroso", responden varios. Ya sea que se trate de gestionar la libreta como alumno regular, legalizar el título secundario o corregir un error administrativo.

"Cuando me inscribí anotaron mal mi apellido y fue un problema porque no sabía adónde tenía que ir", cuenta Nicolás y continúa: "Si bien me quejé desde el 
primer día recién lo arreglaron dos semanas antes de que terminara el cuatrimestre. Un trámite así en la universidad privada, donde hice algunos meses, me lo arreglaron en cuestión de minutos. De todas formas estoy mejor en la UBA".

¿Qué los sorprendió al comenzar la universidad? "Ser la más chica del grupo", comenta Belén, de 18 años, que tiene compañeros "muy grandes; sobre todo en matemáticas, que curso a la tarde; todos son mayores de 21". En las materias para otras carreras, según los chicos, la edad de los ingresantes se eleva en el turno vespertino y nocturno. "Yo tengo dos compañeros de 40 años", dice Fabricio, y Maximiliano agrega: "Sí, yo he visto hombres grandes, más bien ancianos".

\section{Medicina y Abogacía son las preferidas}

Algo más de 59.000 estudiantes se inscribieron para comenzar el CBC en la UBA este año, un $7 \%$ más que en 2009. Las carreras tradicionales continúan siendo las más elegidas: medicina (5986 inscriptos) y abogacía (4723 inscriptos) encabezan las preferencias. Les siguen en cantidad de alumnos psicología (4251), contador público (3370), administración (2759), arquitectura (2652), diseño gráfico (2115), ciencias de la comunicación (1596), diseño de indumentaria y textil (1523), relaciones del trabajo (1048) y kinesiología (1045). Según cifras de la UBA, un $20 \%$ de estos alumnos abandonará el curso antes de fin de año.

\section{$>$ La educación argentina marcó uno de los mayores retrocesos a nivel mundial $^{10}$}

Así lo reveló el conocido informe PISA que mide la calidad educativa en el mundo. En 10 años, la Argentina cayó de 418 a 398 puntos, mientras que el resto de los países de la región subieron entre 16 y hasta 40 puntos. Chile es el que está mejor ubicado.(8/12/2010)

Argentina y España se encuentran entre los países que más retrocedieron en materia de educación en la última década, al tiempo que Perú, Chile y Brasil

http://www.infobae.com/2010/12/08/550786-la-educacion-argentina-marco-uno-los-mayoresretrocesos-nivel-mundial 
figuran entre los que más progresaron, según el informe PISA de la OCDE publicado hoy.

La clasificación del Programa para la Evaluación Internacional de Alumnos (PISA, por sus siglas en inglés) revela que las naciones latinoamericanas se encuentran, pese al progreso de muchas de ellas, en la segunda parte de la tabla, integrada por 65 países.

El mejor posicionado es actualmente Chile $\left(44^{\circ}\right)$, seguido por Uruguay $\left(47^{\circ}\right)$, México $\left(48^{\circ}\right)$, Colombia $\left(52^{\circ}\right)$, Brasil $\left(53^{\circ}\right)$, Argentina $\left(58^{\circ}\right)$ y Perú $\left(63^{\circ}\right)$. España esté en la mitad de la tabla, en el puesto $33^{\circ}$.

El informe, trienal, analiza la situación tanto de los países de la OCDE (Organización para la Cooperación y el Desarrollo Económicos) un club de una treintena de economías ricas cuyos únicos miembros latinoamericanos son México y Chile como de países asociados.

El promedio de nivel educativo de la OCDE se sitúa en 496 puntos, agrega el informe, que esta vez se focalizó principalmente en la capacidad de lectura de alumnos de 15 años, a punto de concluir su ciclo de escolaridad obligatoria. Los informes de 2003 y 2006 se habían centrado en las competencias matemáticas y en formación científica, respectivamente.

La Argentina, que durante el siglo XX fue un país a la punta de la educación en el continente, tuvo un fuerte retroceso entre 2000 y 2009, cayendo de 418 a 398 puntos (-20 puntos).

El nivel de la Argentina se vio superado en ese período por el de Brasil, que pasó de 396 a 412 puntos (+16 puntos), así como por el de Chile, que subió de 410 a 449 puntos ( +40 puntos).

Brasil fue uno de los escasos países que aumentó sus competencias en las tres materias estudiadas (comprensión de lectura, matemáticas y ciencias). Colombia también experimentó alzas en los tres ámbitos, pero sólo con referencia al informe de 2006, ya que no participó en ningún estudio anterior. 
España cayó 12 puntos con respecto al año 2000, y se situó en 481 puntos, lejos de los 496 puntos de media de la OCDE y de los 497 de Alemania y detrás también de Portugal, que tiene 489 puntos.

Pese a los avances, la directora general de la Organización de las Naciones Unidas para la Educación, la Ciencia y la Cultura (Unesco), Irina Bokova, consideró recientemente que la calidad de la educación sigue siendo deficiente en América Latina y admitió que muchos países recortaron sus presupuestos en esta materia por la crisis.

"Invertir para mejorar la calidad de la educación, al igual que en ciencia, tecnología e innovación, es un camino de salida de la crisis económica, esto ya lo reconocen casi todos", dijo Bokova, que participó el pasado fin de semana en la XX Cumbre Iberoamericana celebrada en Argentina.

Los participantes en esa cumbre se comprometieron a erradicar el analfabetismo en 2015 en América Latina y establecieron un plan educativo hasta 2021 con una inversión de más de 100.000 millones de dólares.

Según la Unesco, en América Latina hay 39 millones de analfabetos y 110 millones de adolescentes no terminaron la escuela primaria.

\section{Nuevo bochazo en el examen para ingresar en Medicina en La Plata ${ }^{11}$}

Sólo 318 estudiantes de los 1149 inscriptos superaron la prueba final que les permite acceder a esa disciplina; hicieron un curso de un año y también tuvieron parciales

Por Sebastián Lalaurette | LA NACION - (27/12/2012)

LA PLATA.- Sólo un quinto de los aspirantes a iniciar el año próximo la carrera de medicina en la Universidad Nacional de La Plata (UNLP) aprobó el examen de ingreso. Un nuevo bochazo volvió a poner de relieve la controversia por el sistema de admisión obligatorio en esa disciplina, una de las pocas en esa casa de estudios que restringen el ingreso mediante una prueba. en-la-plata

11 http://www.lanacion.com.ar/1540568-nuevo-bochazo-en-el-examen-para-ingresar-en-medicina- 
El resultado no fue sorprendente: año tras año, los porcentajes de ingreso en la carrera de medicina son similares. Sólo que, desde hace tres años, los aspirantes deben completar un curso anual con ocho materias y aprobar exámenes parciales antes de la prueba final que determina si pueden cursar la especialidad. Antes, se requería dar el examen de ingreso, y muchos jóvenes recurrían a cursos particulares durante el verano.

De los 1449 jóvenes que se inscribieron este año en el curso de admisión, sólo 543 llegaron a la instancia final y apenas 318 (un $21,9 \%$ de los aspirantes originales) lograron superarla. En agosto pasado, un parcial de historia de la medicina había "filtrado" a la mayoría: dos tercios de los inscriptos quedaron afuera.

Las autoridades de la Facultad consideran que el sistema es "exitoso" y argumentan que la menor cantidad de ingresantes es beneficiosa para la calidad de la cursada. Aunque la proporción de quienes entran en la carrera es casi la misma que en los años previos, el decano de la casa de estudios cree que el curso anual logra que los ingresantes estén "más maduros" y reduce la deserción.

Así lo explicó Jorge Martínez, titular de la Facultad, a LA NACION, como ocurre cada año. "Una vez que los alumnos ingresaron, la deserción es muy poquita. Los profesores nos dicen que ya en primer año, con este sistema, los estudiantes están más maduros. $\mathrm{Y}$ en un plazo de siete años se recibe de médico el 92\%", argumentó Martínez.

Si bien muchas facultades de la UNLP cuentan con cursos introductorios a las carreras, sólo Ciencias Médicas y Lenguas Modernas (para los traductorados de inglés y francés) tienen exámenes de ingreso obligatorio. En el de admisión a medicina, los aspirantes que no llegan al mínimo exigido de 40 respuestas correctas (sobre 60) pueden aspirar a "premios consuelo": con 30 o más respuestas optan por obstetricia o nutrición, y con menos de 30, a tecnicaturas.

"Por la infraestructura y las posibilidades que tenemos, no podemos aceptar a todos", dijo Martínez. "En los primeros años de la cursada necesitamos suficientes cadáveres para las prácticas de los estudiantes, y después, trabajar 
con pacientes vivos. Tenemos un límite para poder garantizar una cursada de calidad", explicó.

Victoria Morelli (19 años) pasó el duro examen de ingreso y ya está "adentro". No fue fácil: además del curso de ingreso, estudió un año y medio en un instituto privado para reforzar sus conocimientos. "Si no lo hubiera hecho, habría sido más difícil aprobar", contó Victoria a LA NACION. "De la secundaria salí con una base de conocimientos, pero con lo que vi en el instituto me sentí más segura", añadió.

Victoria aprobó los parciales y 41 de las 60 preguntas de la prueba decisiva. Muchos de sus compañeros no tuvieron la misma suerte. "Creo que hay algunos exámenes que tendrían que aflojar un poco, porque hay mucha gente que tiene toda la vocación y la capacidad para hacer la carrera y termina fallando en exámenes que no son fundamentales. La mayoría cayó en historia de la medicina", afirmó la joven. Aclaró que no está en contra de que haya un examen de admisión, pero consideró que el nivel de exigencia "no debería ser tan estricto".

Ahora, Victoria espera poder recibirse a los 25 y convertirse en médica nutricionista. Su proyecto es tener su consultorio en esta ciudad, donde vive. "Muchos chicos del interior que no pasaron, para no perder un año, decidieron entrar a obstetricia u otra carrera. Pero muchos otros no lo hicieron y van a volver a intentarlo el año que viene", concluyó.

\section{$>$ Ingreso a la UNLP: Agronomía es noticia por los desaprobados $^{12}$}

Los inscriptos en esa carrera realizaron evaluaciones para evitar el curso de ingreso, pero ninguno logró aprobar todas las asignaturas. Ayer arrancaron en Exactas, Observatorio y Periodismo. En la nota, los resultados.(04/02/2013)

Un minúsculo grupo de ingresantes a la facultad de Agronomía de la Universidad Nacional de La Plata (UNLP) logró evitar el curso de ingreso a esa

\footnotetext{
${ }^{12}$ http://diagonales.infonews.com/Content.aspx?Id=193612
} 
casa de altos estudios, pero no en su totalidad, sino sólo en alguna de las materias. La razón es que fue masivo el número de desaprobados en los exámenes que les fueron tomados a finales de enero para eludir esa instancia.

Las pruebas de nivelación se llevaron a cabo el 29 y 30 de enero y consistieron en un examen de Química en la primera jornada, y evaluaciones de Matemática y Física al día siguiente.

En Química resultaron aprobados sólo 4 de los 39 aspirantes que se presentaron a rendir. En Matemática aprobaron 2 de los 40 alumnos que realizaron la prueba, en tanto en Física salieron airosos 11 entre 36 examinados.

Curiosamente, ninguno de los aspirantes logró aprobar las tres materias, por lo que de igual modo deberán asistir a cursar alguna de las asignaturas.

\section{Otras carreras.}

Este lunes también se pusieron en marcha los cursos de ingreso en las facultades de Ciencias Exactas, Observatorio y Periodismo.

Respecto del ingreso al Observatorio, este se realiza mediante un curso no obligatorio que finaliza el 9 de marzo y consta de clases teórico-prácticas de Matemática y charlas-taller de participación en la vida universitaria.

Cabe destacar que en esta sede universitaria continúa abierta la inscripción hasta el $1^{\circ}$ de marzo, y el número de interesados ya supera ampliamente los guarismos históricos, con 219 ingresantes. Según fuentes de la facultad, este interés se debe a la importante aceptación que tiene la nueva carrera de Meteorología.

\section{$>$ Cómo mejorar la calidad de la educación ${ }^{13}$}

Que los padres se involucren, que no sólo se mida lengua y matemática, que el colegio sea más abierto son algunas de las claves que proponen docentes y especialistas.

Por Alfredo Dillon. (13/06/2013)

${ }^{13} \mathrm{http} / / /$ www.clarin.com/sociedad/mejorar-calidad-educacion_0_937106387.html 
Es la palabra vedette de los debates actuales sobre educación: todos quieren mejorar la calidad educativa. Pero ¿de qué hablamos cuando hablamos de calidad?

Para la Organización para la Cooperación y el Desarrollo Económicos (OCDE), por ejemplo, la calidad de un sistema educativo se mide a través de los aprendizajes de los estudiantes. El instrumento por excelencia es la prueba PISA, que mide el desempeño de los alumnos en matemática, ciencias y lectura. En el último informe PISA disponible, de 2009, Argentina ocupaba el puesto 58 entre las 65 naciones que participaron. La cifra contrasta con el aumento del presupuesto educativo en la última década, que llegó al $6 \%$ del PBI.

La cuestión de la evaluación suele asociarse con los debates sobre calidad. Para Manuel Álvarez Trongé, presidente de la ONG Educar 2050, "la calidad educativa requiere de medición continua. Se necesitan parámetros ciertos y constantes para poder hacer un seguimiento en el corto, mediano y largo plazo. En este sentido, los mejores indicadores para evaluar cómo estamos en calidad son las evaluaciones a los alumnos".

En este punto, Cecilia Veleda, codirectora del programa de Educación de CIPPEC, advierte que no todo es medible en educación, pero a la vez resalta que "hay que generar más y mejores mediciones. Por ejemplo, mejorar los indicadores que ya existen -como los Operativos Nacionales de Evaluación, que deberían ser censales- para avanzar hacia un Sistema Integral de Información Educativa que incluya indicadores sobre infraestructura, equipamiento, diversidad social de los alumnos, etc.". Para ella no alcanza con medir los resultados en Lengua y Matemática: hay que observar "la integralidad del sistema, con miras a instalar en el país una cultura de la evaluación".

Los entrevistados coinciden: la calidad educativa abarca mucho más que la medición de los resultados de los alumnos. Nancy Montes, investigadora de FLACSO, puntualiza que el concepto "engloba también la condición salarial de los docentes, su perfil profesional, los niveles de inversión de una sociedad en su 
sector educativo, las condiciones de infraestructura y equipamiento, los logros de aprendizaje en otras habilidades (artísticas, deportivas, científicas, culturales en sentido amplio)".

Veleda propone mirar no solo los saberes que la escuela enseña, sino las capacidades que brinda a los chicos: "Una de las finalidades del sistema educativo es dar habilidades para la vida, ayudar a los chicos a construir un proyecto de vida. Esto implica transmitirles capacidades para la acción comunitaria, la inserción en el mercado laboral, el trabajo en equipo". En esta línea, toda evaluación de la calidad debería tener en cuenta la capacidad de acción que el sistema brinda a los jóvenes, y no limitarse a los resultados de un multiple choice.

Alicia Cancilieri, directora de la Escuela Primaria $N^{\circ} 8$ Bernardo de Monteagudo, de Vicente López, coincide: "La escuela de calidad es la que prepara a los chicos para que puedan transformar la realidad".

Desde el Colegio Manuel Belgrano, de Belgrano, el rector Eutimio Rubio Sáez sintetiza: "Un colegio de calidad es un colegio abierto, donde se concibe al alumno como un líder capaz de transformar el barrio. Donde importa no solo lo académico, sino también lo deportivo, lo solidario, lo artístico, lo espiritual. En esos terrenos se van creando lazos entre los chicos, y se genera una pertenencia del estudiante, alineada con los valores institucionales". Una escuela abierta es también aquella en la que "se trabaja con la diversidad", "hay un diálogo fluido entre el profesor y el alumno" y "se incorporan las innovaciones tecnológicas al servicio del aprendizaje", dice Eutimio.

Los directores consultados coinciden en que el trabajo en red es clave. Eduardo Toscano, de la Escuela Media N 6 Padre Carlos Mugica, de Retiro, subraya la necesidad de redes internas (el trabajo en equipo entre docentes, junto con los tutores y un equipo de apoyo externo al aula) y externas (el vínculo con otras escuelas de la zona, con los centros de salud del barrio, los terciarios y universidades, y empresas y fundaciones). Desde la Escuela $\mathrm{N}^{\circ} 8$, Alicia Cancilieri hace hincapié en el trabajo interinstitucional. Su escuela trabaja a 
la par del Jardín $\mathrm{N}^{\circ}$ 901, que está en la misma cuadra, para articular los dos niveles. "Queremos crear un polo educativo en el barrio, para que nuestros alumnos se queden en la escuela pública", cuenta Graciela Muñoz, directora del jardín.

De los diversos testimonios se desprende que la calidad no es tanto un resultado, sino un camino de búsqueda: "La calidad es un proceso de mejora continua, no tiene techo", asegura Eutimio. Y remata con una definición que pone en el centro los vínculos que se tejen en la escuela: "No hay calidad sin calidez, sin la ternura del buen trato, la escucha, el diálogo y el estar disponible para el otro".

\section{$>$ Conclusiones de la semana de la Educación: "Argentina hoy está en emergencia educativa" 14}

Por: Daniela Blanco (12/09/2013)

Es una opinión que logró consenso entre los principales protagonistas de la educación del país. La calidad educativa de mal en peor: el $52 \%$ de los adolescentes argentinos no comprenden lo que leen y sólo el $44 \%$ termina el secundario en tiempo y forma. Argentina ocupa el puesto número 7 respecto de su calidad educativa en la región y más del $15 \%$ de los jóvenes integran el grupo "ni, ni": ni estudian, ni trabajan. ¿Por qué la sociedad y la política aún no despiertan?

Si repasamos las últimas "calificaciones" que obtuvo la Argentina en el grupo de exámenes internacionales que luego permiten construir los índices e indicadores de calidad educativa de todos los países del mundo, los números nos atraviesan como dagas a toda la sociedad.

${ }^{14}$ www.infobae.com/2013/09/12/1508404-conclusiones-la-semana-la-educacion-argentina-hoy-estaemergencia-educativa 
Porque las cifras demuestran que la cuestión acerca de la calidad educativa es un desafío urgente e involucra a todos los argentinos y aleja la imagen de la Argentina calificada, que supo ser el país modelo y con la mejor educación de América Latina.

Hoy Argentina, a 125 años de la muerte de Domingo Faustino Sarmiento, ocupa el séptimo lugar en el ranking de países según su calidad educativa, detrás de Brasil, Chile, Colombia, México y Uruguay.

"La calidad educativa está en situación de emergencia", fue una de las conclusiones consensuadas entre los principales referentes del sector entre autoridades nacionales, de la ciudad y del mundo que participaron del $\mathrm{V}$ Foro de Calidad Educativa que organiza anualmente la asociación civil Proyecto Educar 2050, en el marco de la Semana de la Educación.

Según el último Informe del Programa Internacional para la Evaluación de Estudiantes o Informe PISA (por su sigla en inglés: Program for International Student Assessment), el $52 \%$ de los adolescentes argentinos de 15 años no comprenden lo que leen, y este es un dato que se sostiene en el caso argentino desde al año 2000. EI PISA se realiza cada tres años en varios países con el fin de determinar la valoración internacional de los alumnos y es llevado a cabo por la Organización para la Cooperación y el Desarrollo Económico (OCDE).

"El primer gran déficit que tiene nuestro país en materia de calidad educativa es la gran desigualdad, que establece diferencias importantes entre regiones y ciudades. En las zonas de mayor pobreza estamos dando la peor educación, cuando la Ley de Educación Nacional exige lo contrario. Las mejores escuelas deberían estar en las zonas más necesitadas", explica Manuel Álvarez Trongé, presidente de la ONG Proyecto Educar 2050.

Según Álvarez Trongé, otro de los grandes desafíos pendientes en la Argentina para lograr calidad educativa es el colegio secundario: "Según las últimas cifras del Ministerio de Educación de la Nación, el 56\% de los chicos no lo terminan y sólo lo completan en tiempo y forma el 44 por ciento". 
Bajo el lema "Educar mejor es urgente", los principales referentes del sector se sentaron a debatir durante el Foro y las conclusiones fueron unánimes al señalar el resquebrajamiento de la calidad de la educación hoy en la Argentina y hasta hicieron un mea culpa.

La apertura fue del ministro de Educación de la Ciudad de Buenos Aires, Esteban Bullrich, quien comenzó con un panorama preocupante: "El 25\% de los alumnos que cursan la enseñanza obligatoria en el país (primario y secundario) alcanza buen nivel educativo y el restante $75 \%$ no tiene los niveles mínimos necesarios y suficientes para considerar que el menor esté educado". El ministro hizo un fuerte llamado a terminar con el "fraude educativo" y convocó a los políticos a encarar el tema con visión estratégica de país.

La última mesa de Política Educativa comenzó con un video de una entrevista al ex ministro de Educación de la Nación, Juan Carlos Tedesco, quien señaló que debería declararse de manera urgente la "Emergencia Educativa" en determinadas jurisdicciones del país. También hizo referencia a la necesidad de fijar metas a 10 años y que se apruebe su financiamiento por ley.

La jefa de Educación del BID, Emiliana Vegas, expuso un análisis profundo de la realidad en la región con datos y cuadros estadísticos muy detallados, y remarcó la situación argentina como una de las más graves en la región, especialmente en lectura. También señaló la necesidad de que los países que están entre los de menor desempeño (como la Argentina) tengan el objetivo de alcanzar los niveles de calidad mínimos fijados para todas las escuelas del país.

\section{La ley que no alcanzó}

¿Cuáles son las causas principales de esta situación de emergencia educativa? "Tenemos que despabilarnos como sociedad y entender en profundidad el concepto y el desafío de educar. No es sólo una responsabilidad del Estado; el desafío es de la sociedad argentina en su conjunto. La política tiene que tomar a la educación como desafío electoral, y la sociedad se lo tiene que pedir. Está faltando liderazgo educativo en nuestro país", refuerza Álvarez Trongé". 
En el año 2006, en la Argentina se sancionó la nueva Ley de Educación Nacional, que reemplazó el marco jurídico que regía en nuestro país desde 1993, logrando consenso mayoritario de la comunidad educativa y política. Si bien la letra de la ley basó sus principios básicos sobre la equidad, la justicia, la solidaridad y el bien común, no alcanzó para revertir la profunda desigualdad y la situación de escolarización degradada en la que se encuentran muchísimos argentinos.

"La Ley de Educación Nacional es muy buena, y eso también hay que decirlo; el gran problema es que no se aplica, no se cumple", advierte Álvarez Trongé. La ley tiene una serie de artículos muy precisos sobre cómo deben destinarse los recursos educativos para evitar la desigualdad; establece que el secundario es obligatorio y esto debe exigirse".

\section{La generación "ni, ni"}

Tristemente, ya tienen nombre de pila: son los chicos "ni, ni" (ni estudian, ni trabajan) y representan en la Argentina entre el $10 \%$ y el $15 \%$ de la población juvenil, según los últimos informes realizados en base a datos del INDEC. Es la franja joven que aún no ha podido vencer el cerco de la ignorancia.

Alieto Guadagni, en una de las mesas del Foro, se refirió al fenómeno objetando la falta de cifras para encararlo: "Es muy importante contar con datos fidedignos, como ocurre en países vecinos que están mejorando su nivel educativo como Brasil, Uruguay y Chile". Y resaltó como contraste la prohibición del Art. 97 de nuestra Ley Nacional de Educación, que no permite la utilización de esta información por estigmatización, lo cual no ayuda al desarrollo de la calidad.

\section{Las conclusiones}

Pasados 125 años de la muerte de Domingo Faustino Sarmiento y en la semana donde se celebró el Día del Maestro en su honor, fueron más de 40 organizaciones las que se reunieron para convertir a la educación en una pasión argentina, entre el domingo 8 y el sábado 14 de septiembre.

Para Guillermina Tiramonti, de FLACSO, las falencias educativas afectan a todas las clases sociales en un sistema absolutamente fragmentado. Las 
escuelas públicas se enfocaron en las clases medias bajas y bajas; en cambio, el sector privado puso su ojo en los sectores con recursos medios y altos.

Por su parte, el senador nacional Ernesto Sanz hizo una recorrida histórica por la educación en nuestro país desde la Ley 1420 y explicó la importancia del compromiso político en la cuestión con un enfoque detallado en "tener información sobre cómo se piensa manejar el dinero invertido en educación". Y aseguró que en el país se desperdició dinero y tiempo, y que se perdieron los objetivos planteados. "Hoy la escuela tiene dinero, pero carece de rumbo y estrategias". Su propuesta es lograr un nuevo pacto educativo entre escuelas, docentes, alumnos, Estado, sindicato, familias y sociedad que permita un cambio de enfoque para mirar a la educación como prioridad y mejorar la calidad", expresó Sanz.

\section{América Latina: alumnos más felices pero con malos resultados $^{15}$}

Así lo determinó el informe PISA sobre Evaluación Internacional de Alumnos. Colombia y México lideran el ranking de felicidad. Argentina está en último lugar. (3/12/13)

El informe del Programa para la Evaluación Internacional de Alumnos (PISA, por sus siglas en inglés), realizado por la Organización para la Cooperación y el Desarrollo Económicos (OCDE), mide los conocimientos en matemáticas, ciencias y lectura de más de medio millón de alumnos en 64 países o territorios.

Los estudiantes tienen entre 15 años y tres meses y 16 años y dos meses cuando realizan la evaluación, que es complementada con un cuestionario sobre ellos.

En el informe, basándose en las pruebas de 2012, los estudiantes latinoamericanos muestran un alto grado de felicidad con su escuela.

\footnotetext{
$15 \quad$ www.infobae.com/2013/12/03/1528057-america-latina-alumnos-mas-felices-pero-malos$\underline{\text { resultados }}$
} 


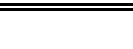

Perú aparece en tercer lugar en esa estadística, seguido de Colombia (5), México (7), Costa Rica (8), Uruguay (13), Chile (25) y Brasil (27), todos ellos por encima de la media de la OCDE y por encima de Shanghai (28), el lugar con mejores resultados académicos. La Argentina

Cinco países/territorios asiáticos copan la parte alta del ranking estrictamente académico: Shanghai (613 puntos), Singapur, Hong Kong, Taiwán y Corea del Sur.

El primero de los países latinoamericanos evaluados es Chile $\left(51^{\circ}\right.$, con 423 puntos), seguido de México $\left(53^{\circ}, 413\right)$, Uruguay $\left(54^{\circ}, 409\right)$, Costa Rica $\left(55^{\circ}, 407\right)$, Brasil $\left(56^{\circ}, 391\right)$, la Argentina $\left(57^{\circ}, 388\right.$ puntos), Colombia $\left(58^{\circ}, 376\right)$ y Perú $\left(59^{\circ}\right.$, 368). Todos ellos están por debajo de la media académica de la OCDE, que es de 494 puntos.

Todos los países latinoamericanos progresaron en alguno de los tres capítulos examinados por PISA, salvo Uruguay y Costa Rica, cuyos alumnos ofrecieron peores resultados tanto en matemáticas como en ciencia y lectura.

El informe revela una correlación entre los resultados académicos y la puntualidad de los alumnos (quienes admitieron llegar tarde logran 10 puntos menos en las pruebas de matemáticas).

Uruguay, Costa Rica, Chile y Perú están en la franja más alta de impuntualidad, con el 50-60\% de los estudiantes que llegan tarde al menos una vez en las dos semanas anteriores a las evaluaciones PISA. Una cifra que en el caso de los de Hong Kong, Shanghai, Vietnam y Liechtenstein iba del 15\% al $19 \%$, y en Japón, de 9 por ciento. 


\section{Mala nota}

Los paises latinoamericanos siguen rezagados en ciertos aspectos en comparación a otros

Inversión en educación como \% del PIB

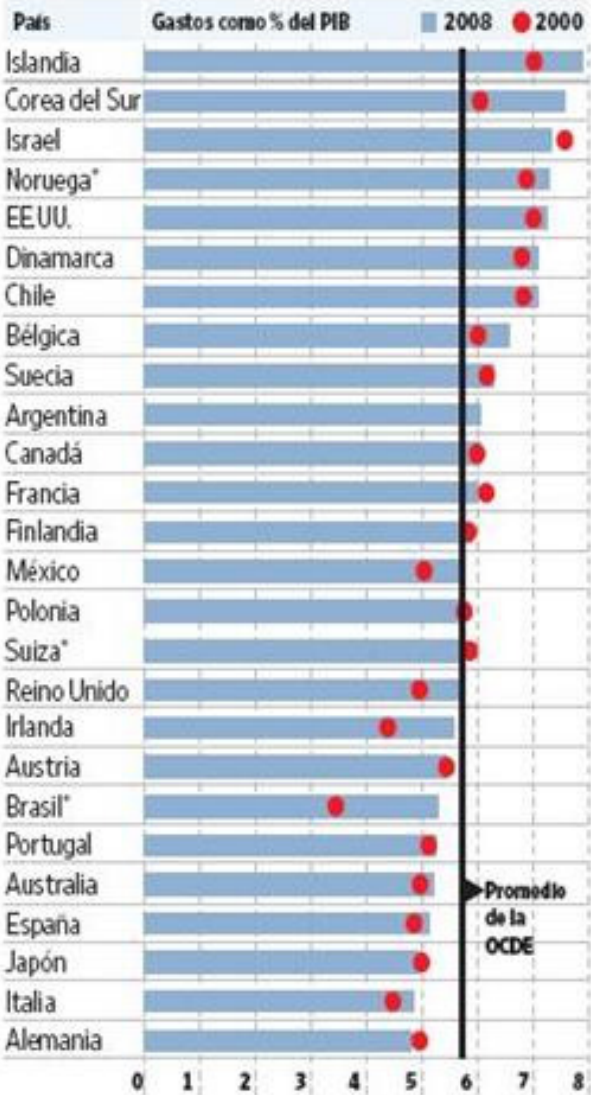

Nota: Para todes los niveles educativos $(2000$ y 2008$)$ y camblo

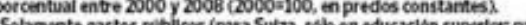

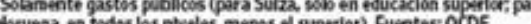

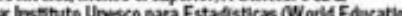
incicators Progranime).

Inversión en educación en Brasil,

2000-09 en miles de mill. de reales

Prueba Pisa, matematica

Algunos palses, 2000-2009

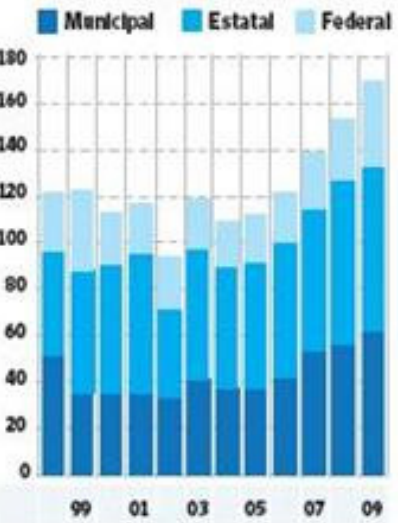

Fuentes: Tesow Naxionat; OCDE (PAsal, via el Banco Munda:

Años de escolaridad en Brasil por renta familiar

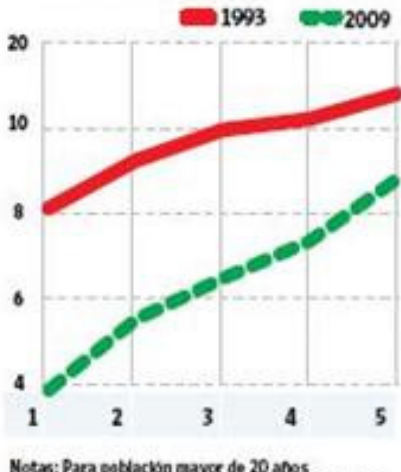

Funte PNAD 1993 y 2002 PIs dates $2000-2009$

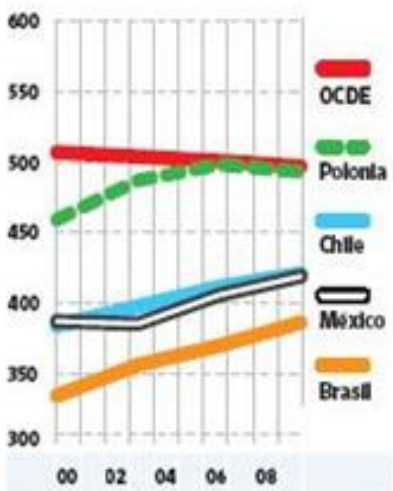

Prueba Pisa, matemática Por quintil de renta en Brasil

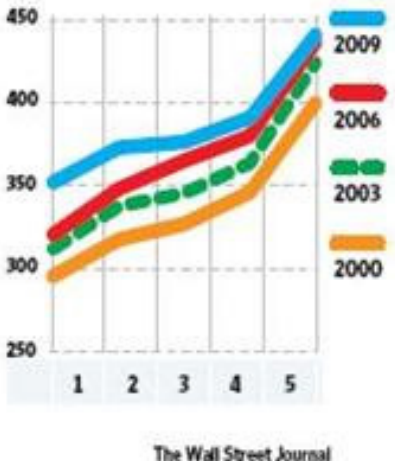

